\title{
La Marge de Solvabilité et l'Egalité des Chances pour Accéder aux Marchés de l'Assurance Non-vie
}

\author{
par André Gabus et Susanne Hagemann
}

\begin{abstract}
AVANT-PROPOS
Ce rapport final est l'aboutissement d'une étude entreprise par Battelle, centre de recherches de Genève, à partir de l'examen des textes réglementaires et de commentaires publiés dans la presse professionnelle. Elle se réfère à de nombreux entretiens avec des personnes qui, dans les compagnies d'assurance, les fédérations nationales, les autorités de contrôle ou la direction des assurances de la Communauté Européenne, traitent à des titres divers de l'application de la marge de solvabilité communautaire. Dès le départ, les membres-correspondants de $l$ "Association de Genève » ont été associés aux travaux et, par la suite, furent consultés à plusieurs reprises. Dans une dernière étape et sur la base d'un rapport préliminaire, ils ont bien voulu, en s'appuyant sur les avis d'experts de leur pays, procéder à un certain nombre de vérifications et apporter des compléments indispensables. Ce rapport, qui n'aurait pas pu être rédigé sans leur concours, n'en est pas moins de la seule responsabilité des auteurs.

L'étude se limite aux pays suivants: la République Fédérale d'Allemagne, la Belgique, la France, l'Italie, les Pays-Bas et le Royaume-Uni; les problèmes qui se posent pour les pays tiers sont examinés en référence plus particulière à la Suisse. Par ailleurs, elle ne prétend pas être exhaustive: certains problèmes posés par la marge n'ont pas été traités ou l'ont été seulement superficiellement; d'autres recherches sont en cours qui ont précisément pour thème ces problèmes (par exemple: les aspects fiscaux). Dans la pluralité des études entreprises, nous nous sommes efforcés d'apporter une contribution à l'examen des problèmes que l'introduction d'une réglementation nouvelle peut ou semble pouvoir poser en matière de concurrence entre compagnies d'assurance non-vie.
\end{abstract}


- Avant-propos

1. LA MARGE DE SOLVABILITE COMMUNAUTAIRE * NON-VIE * : INSTRUMENT DE COMPETITION LOYALE OU SOURCE DE DISPARITES ENTRE ENTREPRISES?

\section{7}

1.1. Objet de l'étude

1.2. Concurrence et disparités entre entreprises

1.3. Caractéristiques types des disparités

1.4. Etendue de l'étude

2. ACCENTUATION DE DIFFERENCES ENTRE ENTREPRISES PAR UN CALCUL UNIFORME DE LA MARGE ET EN VERTU D'ALLEGEMENTS REGLEMENTAIRES POUR LA REASSURANCE

2.1. Mode de calcul de la marge : de certaines conséquences économiques 11

2.1.1. Règles applicables pour le calcul $\quad 11$

2.1.2. Quasi-non-proportionnalité par rapport aux risques assurés 12

2.2. Prise en compte de la réassurance: d'allègements pouvant créer des disparités

2.2.1. Cas particulier de l'effet neutre et sources de disparités 15

$\begin{array}{ll}\text { 2.2.2. Contenu et portée } & 17\end{array}$

3. PRINCIPE DU CONTRÓLE ET PRATIQUE DU CERTIFICAT DE SOLVABILITE

3.1. Sources de disparités $\quad 18$

3.1.1. Au plan réglementaire $\quad 18$

3.1.2. Au plan de l'application $\quad 20$

3.2. Etendue potentielle 22

3.3. Contenu et portée $\quad 22$

$\begin{array}{ll}\text { 3.3.1. Entreprises nationales et succursales communautaires } & 22\end{array}$

3.3.1.1. Insuffisance de l'harmonisation des réglementations nationales 22

3.3.1.2. Inconséquences dans la pratique des certificats de solvabilité
globale

3.3.2. Entreprises communautaires et entreprises des pays tiers 27

$\begin{array}{ll}\text { 3.3.2.1. Accentuation de disparités antérieures } & 27\end{array}$

3.3.2.2. Transformation de succursales en filiales ou accords de réci-
procité

$\begin{array}{ll}\text { 3.3.2.3. Accord entre la Suisse et la CE } & 30\end{array}$ 
4. Plus-VAlues Resultant de la SOUS-ESTIMATION D'ACTIFs 31

4.1. Rôle central de la plus-value 31

4.2. Les vraies sources de disparités $\quad 32$

4.2.1. Non-admissibilité d'actifs 34

4.2.2. Valeur de marché retenue $\quad 35$

4.2.2.1. Pratiqunes nationales 35

$\begin{array}{ll}\text { 4.2.2.2. Cas des participations non cotées } & 37\end{array}$

$\begin{array}{ll}\text { 4.2.3. Déductions pour moins-values } & 38\end{array}$

$\begin{array}{ll}\text { 4.2.4. Conditions de prise en compte } & 40\end{array}$

5. PLUS-VAlues Resultant de la SURESTIMATION DE PASSIFS

5.1. Provisions pour sinistres $\quad 41$

5.2. Provisions pour primes $\quad 41$

$\begin{array}{ll}\text { 5.2.1. Source de disparités } & 41\end{array}$

5.2.2. Contenu et portée des disparités $\quad 42$

5.3. «chwankungsrückstellungen 》 et réserves latentes 44

6. FINANCEMENT DE LA MARGE 44

6.1. Différences de conditions d'opérations 45

6.1.1. Contrôle des taux de prime $\quad 45$

$\begin{array}{ll}\text { 6.1.2. Taxes sur polices émises } & 47\end{array}$

6.2. Différences de conditions de financement 47

6.2.1. Réglementations en matière de placements 47

6.2.1.1. Pour les actifs en représentation des provisions techniques 47

$\begin{array}{ll}\text { 6.2.1.2. Pour le patrimoine libre } & 49\end{array}$

6.2.2. Pratiques nationales en matière de dépôts par les réassureurs 50

6.2.3. Financements autres que ceux provenant de l'activité de l'assurance
non-vie

6.3. Différences de conditions économiques générales 54

6.3.1. Rémunération des placements $\quad 54$

6.3.2. Conséquences des taux d'inflation 55

$\begin{array}{ll}\text { 6.3.3. Incidence des taux de change } & 58\end{array}$

$\begin{array}{ll}\text { 6.3.4. Aspects fiscaux } & 59\end{array}$

$\begin{array}{ll}\text { 6.3.4.1. Imposition du revenu d'exploitation } & 59\end{array}$

6.3.4.2. Taxes se répercutant sur les résultats de la gestion des pla-
cements

$\begin{array}{ll}\text { 6.3.4.3. Traitement fiscal des profits destinés à alimenter la marge } & 61\end{array}$ 
7. EVALUATION COMPAREE DES DISPARITES ET CONCLUSIONS 62

7.1. Problèmes de l'évaluation de l'importance des disparités 62

7.2. Essai de comparaison et d'appréciation 63

7.2.1. Tableau récapitulatif des disparités $\quad 63$

7.2.2. Tableau évaluant les principales disparités identifiées 63

7.3. Conclusion: Appréciation des disparités entre entreprises résultant de l'introduction de la marge de solvabilité

ANNEXE II A - REFERENCES CITEES

B - AUTRES REFERENCES BIBLIOGRAPHIQUES

\section{LISTE DES FIGURES ET TABLEAUX}

- Figure 1: Evolution du montant de la marge de solvabilité en fonction des sinistres payés et des primes encaissées

— Figure 2: Contrôle de l'assurance et contrôle de solvabilité 21

- Figure 3: Schémas de bilan 33

- Tableau 1: Aperçu sur l'importance des succursales dans les pays étudiés sur le marché de l'assurance vie et non-vie (1976-78)

- Tableau 2: Aperçu sur l'importance des succursales dans les pays étudiés sur le marché de l'assurance dommages (1976-78)

- Tableau 3: Branches et pays les plus assujettis à un contrôle du taux de prime 46

- Tableau 4: Rentabilité des fonds propres de sociétés privées 54

- Tableau 5: Performance intégrée moyenne (ou « return $»$ ) en termes réels entre 1961 et 1976

- Tableau 6: Taux de change effectifs en termes réels 58

- Tableau 7: Récapitulatif des disparités entre entreprises d'assurance non-vie (résultant de ou renforcées par l'introduction de la marge de solvabilité de la CE)

- Tableau 8: Essai d'évaluation des disparités entre entreprises d'assurance résultant de l'introduction de la marge de solvabilité de la $\mathrm{CE}$ 


\section{La marge de solvabilité communautaire "non-vie ": instrument de compétition loyale ou source de disparités entre entreprises?}

\subsection{Objet de l'étude}

L'assurance est une industrie internationale avec des caractéristiques propres à chaque nation. L'introduction d'une marge de solvabilité minimale sur la base d'une réglementation générale commune au sein de la Communauté Européenne (CE) constitue un élément d'égalité dans la concurrence ${ }^{1}$. Il s'agit tout au moins d'une égalité de traitement formelle qu'il convient d'apprécier quant à ses conséquences sur l'égalité des chances entre entreprises, et cela tant au plan de leurs activités nationales qu'internationales.

La question est d'autant plus importante que les textes réglementaires donnent des possibilités d'interprétation aux contrôles nationaux et reconnaissent à ces derniers une certaine marge de manœuvre. Des disparités subsisteront, de ce point de vue, aussi longtemps que l'harmonisation dans l'application entre pays ne sera pas achevée.

L'étude des incidences de la marge de solvabilité sur l'égalité des chances entre entreprises pour accéder aux marchés de l'assurance non-vie ou s'y maintenir implique ainsi de partir des différences réglementaires ou d'application pour déboucher ensuite sur leurs conséquences économiques.

Le problème général ainsi posé, il convient dès lors de préciser que notre propos ne sera pas de remettre en question des dispositions légales et réglementaires, mais bien d'étudier les répercussions possibles au plan de la concurrence entre entreprises. Quelles que soient les critiques éventuellement négatives que nous soyons amenés à formuler, le bien-fondé du contrôle financier en général et de la marge de solvabilité réglementaire en particulier ne sera pas mis en question. Cette dernière est la première pierre de l'établissement d'un ordre nouveau qui, après deux décennies de réflexion et de négociation, commande le respect. Par ailleurs, les conditions économiques générales ont bien pu se transformer et les différences entre pays s'accentuer à cet égard. On allègue parfois ces transformations et ces accentuations pour remettre en cause le principe de la réglementation commune ; pour notre part, nous les apprécierons quant aux seules conséquences qu'elles peuvent avoir sur le sujet délibérément choisi comme thème d'étude, à savoir la modifications des conditions de concurrence entre entreprises imputables à lintroduction de la marge de solvabilité communautaire "non-vie».

\subsection{Concurrence et disparités entre entreprises}

La concurrence n'a pas toujours le même sens pour le chef d'entreprise et l'économiste. Face à de nouvelles dispositions législatives, l'entreprise d'assurance est intéressée à ce que les règles du jeu pour accéder aux marchés ou s'y maintenir ne se modifient pas en sa défaveur.

Toutes modifications réglementaires allant dans ce sens sont ressenties par l'entrepreneur comme des distorsions des conditions de concurrence. L'économiste en pensera

1 PLESCOFF, Georges : «Allocution à l'occasion du 25e anniversaire du Comité Européen des Assurances », octobre 1978. 
éventuellement autrement si la sélection des entreprises qui doit s'ensuivre est de nature à améliorer l'alimentation optimale du marché de façon durable et de contribuer ainsi à la croissance globale (conception moderne de la concurrence, notamment en référence à la théorie nouvelle de John M. Clark ${ }^{2}$ ). Ce sera en particulier le cas si cette amélioration porte sur la transparence de l'offre et la protection du consommateur.

L'obligation (i) de faire désormais état de bénéfices accumulés et (ii) de réaliser et retenir années après années des profits à des niveaux prescrits par la loi (toutes choses qui constituent l'essence de la marge) représente, pour plusieurs des pays étudiés, une modification importante du cadre réglementaire. Cette double contrainte ou celle - qui l'implique - de recourir éventuellement plus souvent au marché des capitaux, va constituer pour certaines entreprises d'assurance une restriction à l'exercice de leurs activités et être perçue comme une limitation à l'accès aux marchés. L'économiste - qui se range à l'avis que, en tendant à abolir les tarifs de dumping et en éliminant les entreprises à coûts d'acquisition et d'administration trop élevés, la marge peut contribuer à une alimentation optimale de ces marchés - ne qualifiera pas nécessairement ces entraves comme des distorsions des conditions de concurrence. Les concentrations d'entreprises qui pourraient résulter de l'introduction de la marge ne sont pas nécessairement incompatibles avec les intérêts de l'assuré et sa protection.

On admettra néanmoins que les dispositions nouvelles en matière de solvabilité peuvent bien a priori modifier les conditions de concurrence entre offrants et qu'en conséquence les entreprises puissent être touchées à des degrés divers selon leurs caractéristiques (taille, statut juridique, localisation du siège central, etc.). On parlera alors de disparités entre entreprises résultant de l'introduction de la marge (ci-après dénommée simplement « disparités »).

La présente étude vise précisément à identifier ces disparités et leurs conséquences possibles, leurs effets positifs ou négatifs sur la concurrence en termes réels devant s'apprécier ultérieurement par l'observation des faits économiques (plutôt que par une anticipation difficilement compatible avec la rigueur d'analyse en usage en recherche économique).

\subsection{Caractéristiques types des disparités}

Les entraves que l'entreprise d'assurance peut rencontrer suite à l'entrée en vigueur de la marge non-vie - pratiquement depuis 1979 sur la base des comptes annuels au 31 décembre 1978 - résultent des difficultés qu'elle peut avoir :

(i) pour justifier un niveau suffisant de fonds propres (aspect statique de la marge) ;

(ii) pour financer la marge nécessaire au développement de ses affaires (aspect dynamique).

2 Sur ce sujet, se référer à SCHMIDT, Reimer : « L'importance de la puissance financière des entreprises d'assurance en ce qui concerne la concurrence, compte tenu plus particulierement du marché européen », dans Compte Rendu du Rendez-vous de Monte-Carlo, Septembre 1978. On notera que cette conception de la concurrence se distance de la théorie traditionnelle (Augustin Cournot, Jean Marchal, etc.) qui implique la réponse instantanée à la demande dans des quantités aussi grandes que possible et au prix le plus faible possible. 
Sur le plan statique, le niveau des fonds propres dont l'entreprise d'assurance doit faire état dépend - à part des règles de calcul unifiées ${ }^{3}$ - d'une base de référence différente selon la localisation du siège central (sur le territoire de la $C E$ ou dans un pays tiers) ; par ailleurs, pour des entreprises opérant sur un même territoire national, les autorités de surveillance qui sont habilitées à se prononcer sur l'adéquation des fonds propres relèvent d'Etats membres différents selon le statut juridique et le domicile (sièges d'entreprises nationales et succursales de pays tiers/succursales d'entreprises communautaires). Quant au niveau des avoirs nets dont l'entreprise peut faire état, il dépend de l'évaluation des actifs et des passifs. Cette évaluation fait problème parce que les règles d'estimation ne sont pas harmonisées entre les Etats membres, laissant ainsi une liberté d'interprétation aux autorités de surveillance du pays dont l'entreprise relève pour le contrôle de solvabilité. Des disparités entre entreprises peuvent ainsi exister a priori au niveau statique de la justification de la marge.

Sur le plan dynamique, le financement de la marge dépend des conditions d'opération de l'entreprise et des conditions économiques générales constitutives de son environnement. L'introduction de la marge ne modifie pas - directement tout au moins - ces conditions, mais ces dernières influencent à des titres divers la capacité bénéficiaire (selon les branches d'activité exercées), l'autofinancement (par la fiscalité, la politique générale en matière de distribution de dividendes), le financement extérieur (au travers du marché des capitaux nationaux) et le maintien de la substance des bénéfices nets accumulés (selon le taux d'inflation, les possibilités de placements en valeurs réelles). Les disparités existantes entre assureurs sur ces différents plans deviennent plus contraignantes à partir du moment où les entreprises sont soumises à une obligation uniforme d'accumuler des profits minimums élevés et d'en préserver la substance, toutes choses qu'implique la marge.

Qu'il s'agisse de disparités résultant des aspects statiques ou dynamiques de la marge, il y aura lieu de distinguer :

(i) les disparités qui peuvent modifier les conditions de concurrence entre offrants sur un même marché national ;

(ii) les disparités qui peuvent entraver l'accès au marché commun de l'assurance en Europe et le développement d'activités dans les pays tiers.

On distinguera par ailleurs les disparités durables des disparités passagères. Les disparités durables résultent de défauts d'harmonisation dans l'interprétation de la réglementation commune ou de défaut d'harmonisation des conditions économiques générales. Les disparités passagères ne peuvent être au contraire imputables qu'au temps d'adaptation nécessaire à la mise en place du contrôle financier de l'entreprise d'assurance par les différentes autorités nationales concernées. On relèvera, par exemple, que le Parlement des Pays-Bas n'a été saisi qu'en 1979 d'une nouvelle législation en matière d'assurance tenant compte de la directive communautaire ; dans d'autres pays, telle l'Italie, les modifications législatives devaient être complétées encore au début 1980 par des dispositions réglementaires pour que la nouvelle loi puisse être appliquée dans toute son étendue.

3 Voir infra, section 2. 
Les disparités durables identifiées indiqueront les domaines où l'harmonisation est souhaitable pour éviter qu'elles ne deviennent permanentes. Quant aux disparités passagères, elles seront relevées essentiellement pour éviter une confusion avec les premières ; elles serviront aussi de références pour pouvoir suivre ultérieurement les progrès de l'application du nouveau régime.

On distinguera enfin les disparités objectives de disparités subjectives. Les disparités objectives résultent d'une situation de fait, tant au plan de la réglementation que des conditions économiques générales. Des disparités peuvent être qualifiées de subjectives lorsqu'elles résultent de la prise de conscience d'une situation antérieure à la marge mais éveillée par son introduction ou encore de comportements de l'entreprise qui, bien que pouvant être fondés, ne sont pas commandés par le nouveau régime ; on citera à titre d'exemple de ce second aspect la réserve que l'entreprise d'assurance peut avoir dans certains pays, et non dans d'autres, à faire état de plus-values latentes alors que, pour justifier sa solvabilité, elle y est autorisée.

En résumé, on s'est efforcé dans cette étude d'identifier des disparités entre entreprises qui peuvent être classées a priori selon les caractéristiques suivantes :

- disparités pour faire état de la marge actuelle / pour financer la marge à venir ;

- disparités en matière de développement sur un même marché national/sur les marchés étrangers (de la $\mathrm{CE}$ ou des pays tiers) ;

- disparités durables / passagères ;

- disparités objectives / subjectives.

Dans la pratique, ces différentes caractéristiques types se combinent selon les sources spécifiques de disparité. Les sections suivantes étudient les disparités entre entreprises d'assurance selon leurs origines, sans préjuger de leur importance. Avant de les examiner on fera une remarque préalable quant à l'étendue de l'étude.

\subsection{Etendue de l'étude}

Sans vouloir ignorer les problèmes de concurrence entre entreprises qui découlent de la composition du portefeuille de primes, de la taille de la société ou de la fiscalité, la présente étude met l'accent plus particulièrement sur l'analyse de disparités qui sont plus étroitement liées à l'introduction de la marge ou qui, à notre connaissance, sont moins fréquemment évoquées.

Les disparités ici étudiées sont en relation avec :

- les conséquences économiques du calcul uniforme de la marge (section 2) ;

- le principe du contrôle et la pratique du certificat de solvabilité (section 3);

- la prise en compte de plus-values résultant de la sous-estimation d'actifs (section 4) ou de la surestimation de passifs (section 5);

- le financement de la marge (section 6) que les disparités proviennent de différences de conditions d'opération, de conditions de financement ou de conditions économiques générales.

Par ailleurs, l'étude est limitée aux pays suivants de la $\mathrm{CE}$ : République fédérale d'Allemagne, Belgique, France, Italie, Pays-Bas et Royaume-Uni. Les problèmes qui 
se posent pour les entreprises de pays tiers ont été examinés en référence plus particulière à la Suisse.

\section{Accentuation de différences entre entreprises par un calcul uniforme de la marge et en vertu d'allègements réglementaires pour la réassurance}

Le but principal de la première directive de coordination du 23 juillet 1973 a été de créer des conditions conduisant à l'harmonisation des garanties financières entre entreprises établies sur le territoire de la CE. Ses auteurs ont été conscients de l'importance d'établir un régime non discriminatoire entre entreprises; ils n'ont pas moins saisi les limitations pratiques d'un tel objectif. Le neuvième «considérant » du Conseil des Communautés européennes introduisant la directive, en mentionnant que "les obligations imposées sont déterminées en fonction de critères objectifs », souligne aussi que les dispositions arrêtées visent à placer «sur un pied d'égalité de concurrence les entreprises de même importance ». Il aurait peut-être été prudent d'ajouter « et comparables par ailleurs ».

Le but de cette étude n'étant pas de démontrer que le calcul de la marge, tel qu'il existe aujourd'hui, est la cote la moins mal taillée possible ou la meilleure parmi des cotes nécessairement mal taillées, on examinera dans cette section certaines conséquences inévitables d'obligations s'y rapportant. En privilégiant un point de vue ou un autre, on montrera que ce mode de calcul et la nature même de dispositions s'appliquant identiquement à des exploitations diverses par leur structure ou leurs activités peuvent conduire à une accentuation des différences entre entreprises. Certaines d'entre elles pourront dès lors s'estimer désavantagées face à une même obligation. La disparité peut n'être que subjective en ce sens que la marge n'est qu'un révélateur d'une situation antérieure; parfois aussi la disparité est objective du point de vue qui sera considéré. On analysera ces disparités tant du point de vue des disposition impératives de la directive pour le calcul de la marge que des allègements réglementaires pour prendre en compte les affaires cédées en réassurances. D'une façon plus générale, on examinera les allègements pouvant résulter de la structure organique de l'entreprise (cas des multibranches) en traitant de certains aspects du financement de la marge (voir section 6.23).

\subsection{Mode de calcul de la marge : de certaines conséquences économiques}

\subsubsection{Règles applicables pour le calcul}

La marge est établie en rapport avec le volume global des affaires de l'entreprise ; elle est déterminée en fonction de deux indices de sécurité fondés, l'un sur les primes, l'autre sur les sinistres.

Le mode de calcul est simple ${ }^{4}$ :

« Représentent les éléments constitutifs de la marge :

- le capital social versé et la moitié de la fraction non versée dans le cas où celui-ci n'est pas entièrement libéré ;

4 Nous reprenons ici un texte de M. Legrand, présenté au Congrès de Monte-Carlo en septembre 1978: LEGRAND, G.: "Réflexions sur la marge de solvabilité et son application dans le marché français » dans l'Argus, Paris, 15 septembre 1978. 
- les réserves ne correspondant pas à des engagements ;

- le report à nouveau et, pour les sociétés mutuelles, la moitié du rappel possible au titre de l'exercice des cotisations variables.

Quant à la marge à constituer, le calcul par rapport aux primes s'effectue sur deux tranches :

- la première sur la tranche inférieure à 10 millions d'unités de compte à laquelle est appliqué le coefficient 0,18 ;

- la deuxième sur la tranche supérieure à laquelle est appliqué le coefficient 0,16 .

Le chiffre ainsi obtenu est réduit dans la proportion existant entre le montant net de sinistres (réassurance déduite) et le montant des sinistres bruts, cette proportion ne pouvant néanmoins être inférieure à $50 \%$.

Par rapport aux sinistres, le calcul prend, comme période de référence, les trois derniers exercices en ajoutant aux sinistres payés dans cette période la provision pour sinistres à la fin de la période de référence et en déduisant la provision au début de la même période. Il en est déduit une moyenne annuelle en divisant le chiffre ainsi obtenu par trois.

Est effectué ensuite un calcul en deux tranches :

- l'une inférieure à 7 millions d'unités de compte à laquelle est appliqué le coefficient 0,26 ;

- l'autre supérieure, le coefficient étant de 0,23.

Le chiffre total ainsi obtenu est réduit comme le précédent, en appliquant le même pourcentage résultant de la proportion entre sinistres restant à la charge de l'assureur et sinistres bruts.

Les deux chiffres obtenus, rapportés aux primes d'une part, aux sinistres de l'autre, sont comparés, le plus élevé des deux étant le chiffre retenu.»

\subsubsection{Quasi-non-proportionnalité par rapport aux risques assurés}

En raison des coefficients respectifs choisis pour les indices de sécurité sur la base des primes $(0,16)$ et des sinistres $(0,23)$ ainsi que des taux de frais d'exploitation se situant en moyenne entre $29 \%$ (moyenne inférieure pour la France et la R.F. d'Allemagne) et $40-45 \%$ (Belgique) ${ }^{5}$, le calcul s'opère dans la pratique sur la base des primes, le montant ainsi obtenu étant le plus fréquemment supérieur à celui calculé sur la base des sinistres ${ }^{6}$. L'équivalence théorique entre le mode de calcul sur encaissement et le mode de calcul sur sinistres se situe à un niveau de taux de chargement relativement bas, à savoir $30,4 \%$. On a en effet :

$$
100-30,4=69,6 \times 0,23=100 \times 0,16
$$

ou $16 \%$ de 100 francs de primes $=23 \%$ de 69,90 francs de sinistres payés.

5 Compagnie Suisse de Réassurances : chiffres pour l'année 1975, cité par BARBIER, J. : « Aspects économiques de la marge de solvabilité » dans le Petit Moniteur des Assurances, Bruxelles, 12 janvier 1978.

6 Sauf lors d'exercices exceptionnels supportant des sinistres particulièrement élevés. 
Si l'on admet en simplifiant que les sinistres payés correspondent aux risques assurés et les frais d'exploitation et autres charges (y compris la rémunération du capital) à la marge commerciale brute, l'éventail des situations les plus fréquentes en Europe est donné par le graphique suivant :

Fig. 1 : Evolution du montant de la marge de solvabilité en fonction des sinistres payés et des primes encaissées

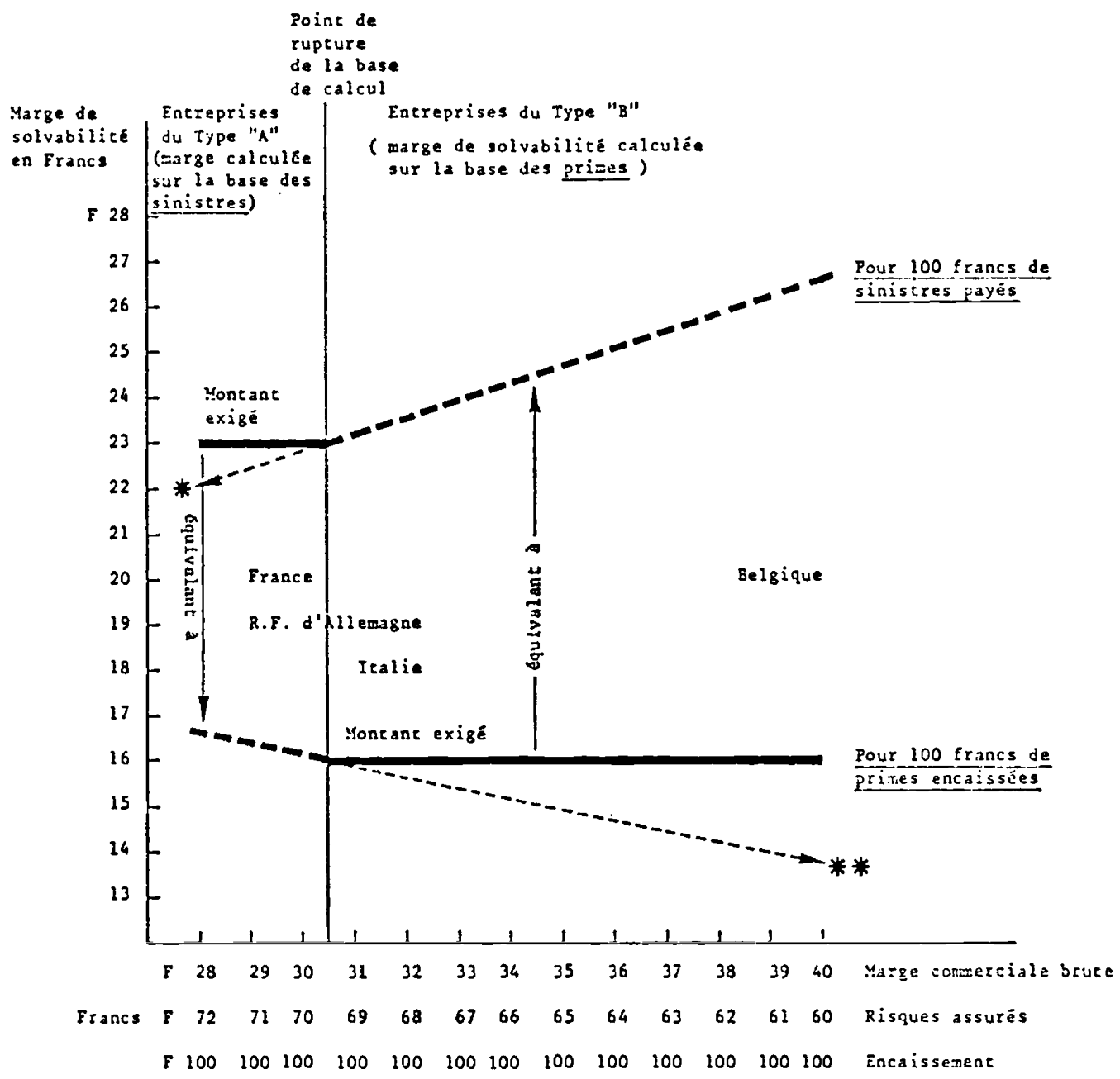

* Marge théorique si la marge était uniformément de $16 \%$ des primes encaissées (elle baisserait par rapport aux sinistres en fonction de la diminution des charges).

** Marge théorique si la marge était uniformément de $23 \%$ des sinistres payés (elle baisserait par rapport aux primes en fonction de l'accroissement des charges). 
Du point de vue des différences entre entreprises qui nous intéressent ici, ce graphique fait ressortir deux classes d'entreprises selon que la marge s'établit sur la base des sinistres (Entreprises du Type * $\mathrm{A} »)$ ou sur la base des primes (Entreprises du Type «B»).

Pour les entreprises « A \la marge est uniformément proportionnelle aux sinistres, mais décroît par rapport aux primes (passant de 16,5\% à $16 \%$ ). Inversément, pour les entreprises \& B », la marge est uniformément proportionnelle aux primes mais, exprimée en \% des sinistres payés, elle croît de $23 \%$ à 26,67\%.

Pour un même montant de risques assuré, le preneur d'assurance doit payer non seulement des frais d'exploitation croissants mais aussi une quote-part à la constitution de la marge toujours plus élevée. Il y a en effet aussi prélèvement de la marge sur la part de la prime qui n'est pas affectée au paiement des sinistres. Si la situation de concurrence ne permet pas à l'entreprise d'obtenir de l'assuré le supplément de prime nécessaire, elle devra affecter tout ou partie de ses revenus financiers à l'alimentation de la marge pour continuer d'exercer son activité.

A l'intérieur de la classe des entreprises du Type «B » (marge de solvabilité sur la base des primes), les conséquences de l'introduction de la marge sont ainsi loin d'être uniformes, et ce d'autant plus que les montants à dégager des revenus d'exploitation pour alimenter la marge sont assujettis à l'impôt sur les bénéfices (environ $50 \%$ dans les pays étudiés ${ }^{7}$ ).

Si l'on fait l'hypothèse que les frais d'exploitation ( $\mathrm{y}$ compris les commissions payées aux producteurs) sont approximativement proportionnels à la marge commerciale brute (le bénéfice net après impôts étant alors comparable d'une compagnie à l'autre), l'introduction de la marge de solvabilité communautaire agit dans le sens d'un renforcement de la tendance à l'élimination des entreprises aux frais d'exploitation les plus élevés, et ce au profit des assureurs plus dynamiques sur le marché. La marge, telle qu'elle est actuellement calculée, n'est donc pas neutre d'un point de vue concurrentiel. Du point de vue statique, elle ne pourrait l'être qui si elle était uniquement déterminée en relation avec les risques assurés. Sa fonction unique de couvrir les aléas de gestion technique ne pourrait alors être discutée.

D'un point de vue dynamique, on peut toutefois arguer que, en prévision de l'augmentation cu montant des sinistres futurs (occasionnés par le développement des affaires ou par la hausse des prix), il est raisonnnable d'accroître la couverture qui est calculée en fonction des sinistres déjà payés et à payer. A défaut d'indicateurs plus précis, les primes encaissées offrent une base de calcul qui est loin d'être dépourvue de sens pour déterminer le besoin de cet accroissement de couverture.

Cet argument n'est toutefois pas entièrement satisfaisant pour être opposé à ceux qui, comme J. Barbier, après avoir relevé les différences nationales des taux moyens de frais d'exploitation (voir graphique), relèvent que :

« toutes autres choses restant égales, les compagnies belges par rapport aux compagnies allemandes ou françaises sont obligées de constituer une marge sur une partie de la prime destinée à couvrir les frais d'exploitation plus élevés qu'elles connaissent... Le calcul de la marge sur la prime commerciale va donc à l'encontre

7 Pour les différences de taux, voir infra, p. 60. 
de l'esprit de la directive puisqu'elle place sur un pied d'inégalité de concurrence les entreprises des différents pays de la Communauté 8 ... »

Toutes choses égales par ailleurs, on relèvera aussi que les entreprises qui pratiquent des activités d'assurance occasionnant des frais d'exploitation particulièrement élevés sont désavantagées pour des raisons similaires. On relèvera, à titre d'exemple, les branches «Individuelles Accidents 》 et « R.C. Particuliers 》 (Belgique), « Incendie » (Pays-Bas) ou «Assurances Crédit et Risques Pécunaires 》 (Royaume-Uni) dont les frais de gestion et autres charges dépassent couramment $40 \%$ des primes ; certaines de ces branches (exemple : «Incendie » en France) ont un total des charges approchant ce pourcentage $(37,6 \%$ en 1977$)$.

A propos de telles disparités liées aux différences des charges - nationales ou sectorielles - on remarquera à ce stade - ainsi qu'on l'a fait à la section 1 - que le chef d'entreprise envisage sous un autre angle la concurrence que l'économiste (et, dans le cas d'espèce, on peut ajouter le preneur d'assurance dont un des intérêts présumés est l'abaissement des primes, donc indirectement aussi celui des coûts de l'assureur). On se gardera toutefois d'anticiper sur les effets positifs que la marge sous sa forme actuelle pourrait avoir à long terme du point de vue de l'efficacité économique.

\subsection{Prise en compte de la réassurance: d'allègements pouvant créer des disparités}

\subsubsection{Cas particulier de l'effet neutre et sources de disparités}

Il est dans la logique du contrôle de solvabilité de ne pas exiger de l'entreprise cédante de constituer une marge pour des risques qui ne lui incombent pas. Contrairement au principe du contrôle financier anglo-saxon, ce ne sont pas les primes cédées qui sont déterminantes dans la marge communautaire pour l'allègement de la solvabilité brute, mais la part que le réassureur assume dans le montant brut des sinistres survenus 9 . Ainsi qu'il a été indiqué plus haut, le montant obtenu pour la marge est réduit en le multipliant par un coefficient réducteur égal à la proportion existant entre le montant net de sinistres (réassurance déduite) et le montant des sinistres bruts. Cette proportion ne peut néanmoins être inférieure à $50 \%$.

De ce principe et mode de calcul, il s'ensuit que la marge de solvabilité n'est de 18-16\% des primes que pour autant qu'il existe une corrélation rigoureuse entre la prime cédée et les sinistres à la charge du réassureur ${ }^{10}$. Dans ce seul cas, le coefficient réducteur a un effet neutre. Dans les autres cas, et supposant que le calcul de la marge sur la base des primes donne un résultat supérieur à celui effectué sur la base des sinistres "11, le taux effectif de marge n'est plus uniforme suivant la situation des entreprises cédantes considérées.

8 BARBIER, J.: op. cit., p. 12.

9 Ce principe a été adopté en considération du fait que la réassurance comprend des affaires proportionnelles et des affaires non proportionnelles aux primes.

10 Voir HARVEY, Michael : "When is a $16 \%$ Solvency Margin not a $16 \%$ Solvency Margin ? " in Reinsurance, February 1978, p. 460.

11 Cas de loin le plus fréquent, voir supra, p. 12. 
Pour l'illustrer, quelques exemples tirés de la presse professionnelle 12 sont reproduits ici :

(1) Exemple d'une compagnie moyenne

Primes

Sinistres

Marge de solvabilité - à $18 \%$ - à $16 \%$

$\times 11 / 14=$

\begin{tabular}{|c|c|c|}
\hline Brut & Net & Net en $\%$ du brut \\
\hline$£ 20 \mathrm{~m}$. & $£ 14 \mathrm{~m}$. & $70 \%$ \\
\hline$£ 14 \mathrm{~m}$. & $£ 11 \mathrm{~m}$ & $78,6 \%$ \\
\hline$£ \quad 6,4 \mathrm{~m}$. & $£ 1152000$ & \\
\hline f $13,6 \mathrm{~m}$. & $£ 2176000$ & \\
\hline$\overline{f 20,0 \mathrm{~m}}$. & $\overline{£ 3328000}$ & \\
\hline & $£ 2614850$ & \\
\hline
\end{tabular}

soit en $\%$ des primes nettes

(2) Exemple de la même compagnie réassurant de nouveaux contrats à $95 \%$

Primes courantes

Primes additionnelles

Sinistres

Sinistres additionnels

Marge de solvabilité - à $18 \%$

$$
\text { - à } 16 \%
$$$$
\times 11,15 / 17=
$$

soit en $\%$ des primes nettes

\begin{tabular}{|c|c|c|}
\hline Brut & Net & Net en $\%$ du brut \\
\hline$£ 20 \mathrm{~m}$. & $£ 14 \mathrm{~m}$. & $70 \%$ \\
\hline$£ \quad 4 \mathrm{~m}$. & $£ \quad 0,2 \mathrm{~m}$. & $5 \%$ \\
\hline$\overline{£ 24 \mathrm{~m}}$ & $\overline{£ 14,2 \mathrm{~m} .}$ & $59 \%$ \\
\hline$£ 14 \mathrm{~m}$. & f $11 \mathrm{~m}$. & $78,6 \%$ \\
\hline f $3 \mathrm{~m}$. & f $\quad 0,15 \mathrm{~m}$. & $5 \%$ \\
\hline$\overline{f 17 \mathrm{~m}}$. & $\overline{£ 11,15 \mathrm{~m} .}$ & $65 \%$ \\
\hline$£ \quad 6,4 \mathrm{~m}$. & $£ 1152000$ & \\
\hline$£ 17,6 \mathrm{~m}$. & $£ 2816000$ & \\
\hline & $\overline{£ 3968000}$ & \\
\hline & $\overline{£ 2602540}$ & \\
\hline & $18,33 \%$ & \\
\hline
\end{tabular}

ou une réduction de la marge de $£ 12310$ en

valeur absolue et en $\%$ des primes nettes de

(3) Exemple d'une compagnie captive

Primes

Sinistres

Marge de solvabilité - à $18 \%$ $50 \mathrm{Min}$

$$
\times \frac{50 \text { Min. }}{100}=
$$

\begin{tabular}{|c|c|c|}
\hline Brut & Net & Net en \% du brut \\
\hline$£ 5 \mathrm{~m}$. & $£ 3,8 \mathrm{~m}$. & 76 \\
\hline$£ 2 \mathrm{~m}$. & $£ 0,8 \mathrm{~m}$. & $40 \%$ \\
\hline$£ 5 \mathrm{~m}$. & $£ 0,9 \mathrm{~m}$. & \\
\hline
\end{tabular}

soit en $\%$ des primes nettes$$
\text { £ } 0,45 \mathrm{~m} \text {. }
$$

$$
11,8 \%
$$

L'exemple (2) montre que des affaires sur certains marchés (par exemple : marine, aviation, ...), permettant à l'entreprise cédante de modifier rapidement sa politique de réassurance, lui donnent la possibilité de réduire la marge requise. D'autres marchés,

12 HARVEY, M. : op. cit. 
se prêtant moins bien à la réassurance ou étant peu rémunérateurs, voire déficitaires (exemple : la responsabilité civile automobile en Italie), ont un effet opposé en ce sens que les autres branches ont la charge de financer la part de marge imputable aux affaires qui y sont traitées.

D’une façon générale, les entreprises dépendantes des réassureurs pour leur solidité financière vont chercher à alléger le poids des nouvelles dispositions en matière de solvabilité en recourant davantage à la réassurance. Il sera intéressant d'observer d'ici un ou deux ans la modification des taux de rétention.

Bien que les chiffres ne soient pas disponibles, une évolution dans ce sens se serait déjà produite en Italie. La situation de beaucoup d'entreprises d'assurance l'exigeait en effet. Sur la base des bilans pour l'exercice 1975, 41 entreprises sur 142 analysées pratiquant les branches dommages montraient, à moins d'éventuelles plus-values, un défaut d'actifs nets pour couvrir leur marge de solvabilité. La situation s'était pourtant améliorée, le pourcentage du nombre d'entreprises présentant des garanties financières insuffisantes sur la base du bilan étant passé de 37,4\% à 28,9\% de 1973 à 1975 13,

Des compagnies auraient aussi créé leur propre entreprise de réassurance pour bénéficier des allègements des dispositions en matière de réassurance et éviter de céder des commissions aux réassureurs professionnels.

\subsubsection{Contenu et portée}

Qu'il s'agisse d'un recours accru à la réassurance professionnelle ou de la création de compagnies de réassurance dépendantes, toutes les entreprises ne jouissent pas d'une même position de départ pour tirer avantage des allègements de marge ainsi obtenus. On l'a déjà relevé en matière de marchés. Par ailleurs, le coût de ces allègements diffère selon les entreprises et aussi suivant les pays (exemple : coût de la création d'une compagnie de réassurance).

On examinera plus particulièrement la situation des entreprises de taille petite ou moyenne.

Le coefficient réducteur se calculant sur la base du dernier exercice - et non pas par rapport à une moyenne de sinistres - il peut varier considérablement d'année en année pour les entreprises petites et moyennes (qui sont précisément celles qui recourent le plus à la réassurance). En effet, la survenance de quelques gros sinistres auxquels les réassureurs participent peut faire varier le coefficient réducteur dans des proportions importantes (dans la limite réglementaire se situant néanmoins entre 1,0 et 0,5$)^{14}$.

Certains types de traités (« catastrophe » ou «stop-loss») peuvent contribuer à accentuer ces fluctuations, puisque le réassureur n'intervient en principe qu'exceptionnellement en raison même de la nature de ces traités. En dépit du coût de ces derniers

13 ZIMOLO, A.: « L'amornizzazione del settore assicurativo nelle directive della communita economica europea 》 dans Pratica, mai 1978.

14 Pour l'ensemble des entreprises en activité sur le marché français, le rapport sinistres à charge des réassureurs sur sinistres bruts a varié entre $16,4 \%$ et $17,7 \%$ au cours des cinq années 1973-77; en Italie, ce même rapport a fluctué entre $24,4 \%$ et $27,6 \%$ avec une nette tendance à la hausse durant cette période. 
et de la sécurité qu'ils offrent, la marge de solvabilité n'est pas réduite pour autant dans des circonstances normales. De plus, les années exceptionnelles (où le coefficient réducteur pourrait être théoriquement abaissé en dessous de 0,5 en raison de la part très importante prise par les réassureurs) ne sont pas prises en considération pour diminuer un taux qui serait moins élevé s'il était calculé sur plusieurs années.

Si l'on ajoute à ces inconvénients le fait que pour l'entreprise petite ou moyenne le taux de $18 \%$ sur la première tranche de primes équivalant à 10 millions d'unités de compte pèse beaucoup plus que pour la grande entreprise, on comprend que la première puisse s'estimer désavantagée par rapport à la seconde pour maintenir sa part de marché.

L'argument peut être toutefois retourné. Selon la théorie collective du risque, les entreprises petites devraient allouer une plus grande part de leur encaissement à une réserve de sécurité que les grandes compagnies n'ont besoin de le faire. C'est d'ailleur ce qui va vraisemblablement se produire en R.F. d'Allemagne suite aux dispositions récentes en matière de réserves de rééquilibrage ("Schwankungsrückstellungen ») 15 .

La vraie question est finalement de savoir si à l'avenir le coefficient réducteur, calculé sur une base annuelle, ne va pas obliger les entreprises petites et moyennes à constituer une marge de solvabilité plus importante que ne l'exigerait leur situation moyenne, compte tenu de la nature des traités de réassurance qu'elles peuvent avoir passés. La question est particulièrement importante pour celles d'entre elles qui, avec l'appui des réassureurs, entendent aller vers une plus grande dimension par autofinancement (l'accès au marché financier leur étant de surcroît plus fermé ou plus onéreux que pour la grande entreprise). Ces entreprises cumulent à la fois les difficultés ici évoquées et celles, beaucoup moins discutables, qui s'appliquent à tout assureur — petit ou grand - qui cherche à accroître rapidement sa part de marché (voir infra, p. 55 et ss.).

\section{Principe du contrôle et pratique du certificat de solvabilité}

\subsection{Sources de disparités}

\subsubsection{Au plan réglementaire}

Le contrôle de solvabilité, institué par la première directive de coordination $73 / 239 / \mathrm{CE}$, distingue deux principales catégories d'entreprises d'assurance : les entreprises de droit national (ou « entreprises nationales ») et les entreprises étrangères. En

15 A risques égaux, les «Schwankungsrückstellungen » devaient permettre à toute entreprise allemande, en référence à une période d'observation, d'absorber à raison de $95 \%$ les sinistres au-dessus de la moyenne. La fonction d'égalisation de ces provisions supplémentaires tend à diminuer les différences entre entreprises de tailles différentes. Dès lors que ces provisions constituent une charge plus élevée pour les entreprises de taille modeste les taux de $18 \%$ et $16 \%$ de la marge de sécurité paraissent moins justifiés. Par ailleurs, le mode de calcul et d'application du coefficient réducteur, qui a pour effet de fixer le montant de la marge à son niveau le plus élevé en période moyenne, devient plus discutable si les prélèvements effectués pour constituer les «Schwankungsrückstellungen » ne sont pas considérés comme un élément constitutif de la marge. (Sur cette question, voir infra, p. 56). 
raison des différences de principe qui s'appliquent à ces dernières, il convient de les subdiviser en deux sous-catégories :

- les agences et succursales ou sièges secondaires d'entreprises ayant leur siège social dans d'autres pays membres de la $\mathrm{CE}$ (dénommés ci-après les succursales communautaires) ;

- les agences et succursales ou sièges secondaires d'entreprises ayant leur siège social dans les pays tiers (succursales des pays tiers) ${ }^{16}$.

Du point de vue du contrôle de solvabilité, les autorités de surveillance nationales ont ainsi affaire à trois types d'entreprises :

- les entreprises de droit national (les plus nombreuses, représentant en moyenne $69 \%$ du total dans les pays étudiés) ;

- les succursales communautaires $(18 \%)$;

- les succursales des pays tiers $(13 \%)$.

L'«entreprise nationale» doit calculer et justifier sa solvabilité minimum en prenant en considération l'ensemble de ses activités non-vie (affaires directes et acceptations en réassurance sur le marché national et à l'étranger). L'autorité de surveillance du pays membre sur le territoire duquel l'entreprise a son siège est chargée du contrôle ; elle délivre un certificat de solvabilité globale qui est reconnu par les autorités de surveillance des autres Etats membres.

La «succursale communautaire » est tenue en tout temps de satisfaire aux conditions d'accès sur le marché national et, entre autres, à produire le certificat de solvabilité globale délivré au siège par les autorités compétentes. La succursale communautaire n'échappe pas entièrement au contrôle financier de l'autorité de surveillance du pays où elle exerce son activité ${ }^{17}$, même si sa solvabilité est attestée par l'autorité de surveillance du pays sur le territoire où l'entreprise a son siège. En effet, si l'autorité de surveillance de la succursale est tenue de fournir les informations nécessaires à l'autorité de surveillance du siège, la première est aussi habilitée à demander des informations à la seconde. Au cas où l'autorité de surveillance de la succursale communautaire ne se satisferait pas de la marge de solvabilité globale existante, en référence notamment à l'application de critères d'évaluation par elle appliqués, il ne faut pas exclure a priori la possibilité d'un réexamen qui résulterait alors d'un accord entre les deux autorités de surveillance concernées, «les Etats membres vérifiant en étroite collaboration la situation des entreprises agréées »(art. 13) ${ }^{18}$.

La «succursale de pays tiers» est tenue, quant à elle, de posséder une marge de solvabilité qui lui soit propre. Cette marge est calculée selon les mêmes règles que celles applicables à l'entreprise nationale, seules les opérations réalisées par la succur-

16 Selon le pays membre, l'entreprise étrangère peut être agréée sous des formes juridiques différentes définies par le droit national; par simplification, on retiendra ici le terme de «succursale » pour recouvrir aussi bien les statuts d'agences, sièges secondaires, représentations générales, etc., que de succursales proprement dites, nous conformant en cela à la pratique communautaire.

$17 \mathrm{Ne}$ serait-ce en premier lieu que pour la couverture des provisions techniques.

18 Nous reproduisons ici un point de vue d'expert sans pour autant vouloir nous prononcer sur les aspects juridiques de cette interprétation de la directive. 
sale étant toutefois prises en considération. De plus, les actifs représentatifs de la marge de solvabilité doivent être localisés à l'intérieur du pays d'exploitation jusqu'à concurrence du fonds de garantie (le tiers de la marge, ou plus si le montant minimum absolu n'est pas atteint), et, pour le surplus, à l'intérieur de la $\mathrm{CE}$.

Des avantages sont prévus pour l'entreprise de pays tiers opérant avec des succursales établies dans deux ou plusieurs pays membres en accord avec les Etats concernés. L'essentiel de ces avantages consiste en la globalisation de la marge pour toutes les activités exercées à l'intérieur de la $\mathrm{CE}$, la désignation d'une seule autorité de surveillance pour la vérification de la marge et la localisation sans restriction à l'intérieur de la $\mathrm{CE}$ pour les actifs représentatifs de la marge (art. 26 et 27 de la directive de coordination). Faute de textes législatifs dans tous les pays étudiés, ces avantages prévus n'ont, à notre connaissance, pas encore été concédés. Pour cette raison, on se contentera d'en faire simplement mention sans les considérer à ce stade comme une source de disparité additionnelle.

La Figure 2 schématise la différence du contrôle de solvabilité selon le statut juridique de l'entreprise d'assurance. En résumé, on retiendra que, sur le territoire d'un Etat membre déterminé opèrent :

- des entreprises soumises à un contrôle de solvabilité global et relevant des autorités de surveillance de cet Etat déterminé (entreprises nationales) ;

- des succursales communautaires relevant d'un contrôle de solvabilité global exercé par d'autres autorités de surveillance nationales ;

- des succursales de pays tiers soumises à un contrôle de solvabilité partiel et relevant des autorités de surveillance de cet Etat déterminé.

L'harmonisation des garanties financières entre ces différents types d'entreprises est incomplète du fait :

(i) que les autorités de surveillance nationales impliquées conservent leur liberté d'interprétation et d'appréciation sur des facteurs essentiels telles l'estimation des actifs et des passifs, la prise en compte des plus-values, etc.

(D'où des conditions a priori différentes à cet égard selon qu'il s'agit d'entreprises nationales ou succursales communautaires.)

(ii) que la base retenue pour le calcul de la solvabilité n'est pas uniforme (contrôle global ou partiel).

(D'où des conditions à cet égard différentes selon qu'il s'agit d'entreprises communautaires - sièges ou succursales - ou d'entreprises de pays tiers).

\subsubsection{Au plan de l'application}

A part les disparités résultant d'un traitement différencié selon le type d'entreprise considéré, l'application même de la directive eu égard à la délivrance des certificats de solvabilité n'est pas encore complètement uniformisée. Il s'agit, d'une part, de délais dans la délivrance de ces certificats et, d'autre part, d'un problème posé par la fréquence de leur établissement (annuel ou à intervalles plus rapprochés). Par ailleurs, on relève que le maintien d'une législation antérieure peut avoir pour conséquence, du moins pour les entreprises de pays tiers, un double contrôle de solvabilité. D'une 
Fig. 2 : Contrôle de l'assurance et contrôle de solvabilité

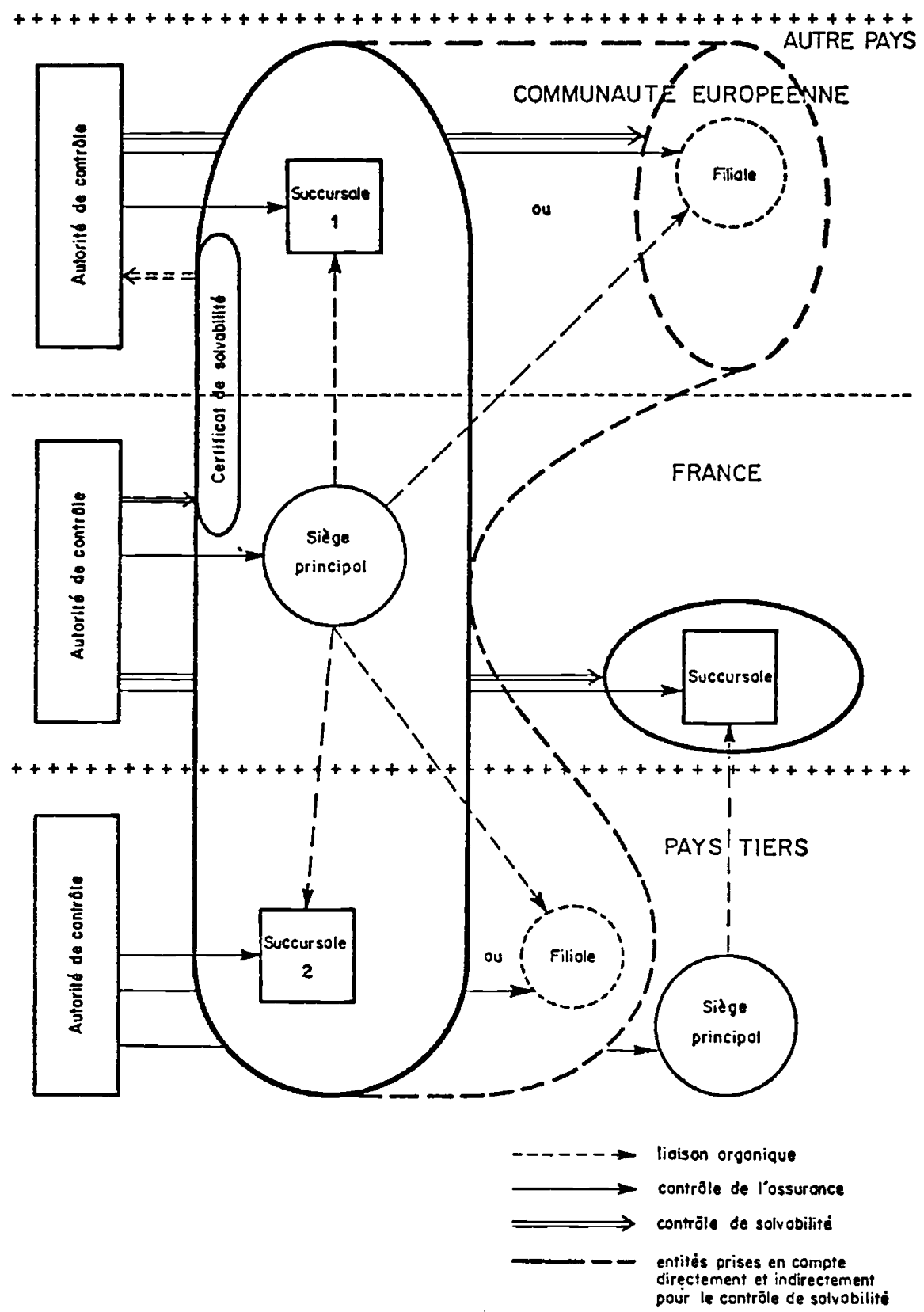


manière plus générale, la question des pays tiers évolue et méritera à ce titre qu'elle soit examinée sous l'angle de la concurrence entre entreprises.

Qu'il s'agisse de disparités ayant leurs sources dans la réglementation même ou dans son application, on essayera d'en apprécier le champ potentiel avant d'en discuter le contenu.

\subsection{Etendue potentielle}

Le champ potentiel des disparités entre les catégories d'entreprises considérées peut s'apprécier par le nombre et l'importance des succursales (communautaires ou des pays tiers) sur les marchés nationaux.

Le Tableau 1 indique que le nombre des succursales est relativement plus important que leur part de marché. Ce tableau ne montre pas que dans certains pays, telles la Belgique et la France, quelques entreprises étrangères peuvent à elles seules occuper une place relativement importante (cas notamment des compagnies suisses).

Sur la base de ces chiffres, on ne peut non plus se prononcer sur une évolution. Du fait même de certaines sources de disparités mentionnées à la section 2.1., les structures mises en évidence ne vont-elles pas se modifier fondamentalement ? La discussion sur le contenu même des disparités va fournir quelques éléments qui devraient au moins permettre de préciser la question.

\subsection{Contenu et portée}

\subsubsection{Entreprises nationales et succursales communautaires}

\subsubsection{Insuffisance de l'harmonisation des réglementations nationales}

Des entreprises concurrentes sur un même marché national sont déclarées solvables ou non par les autorités de surveillance des pays où elles ont leur siège. A la limite, il y aurait autant d'interprétations possibles de la directive de coordination et des dispositions législatives qui en découlent qu'il y a d'Etats membres dans la $C E$.

Au moins tout aussi important que le nombre des autorités compétentes sont sans doute les différents domaines donnant lieu à d'éventuelles divergences d'appréciation. Les autorités de surveillance se consultent toutefois et elles se sont déjà entendues sur un certain nombre d'aspects.

Du point de vue de la constitution de la marge, les principaux domaines qui méritent un examen approfondi concernent la prise en compte des plus-values et l'estimation d'actifs particuliers, telles les participations dans d'autres compagnies d'assurance. Vu l'importance ou le degré de complexité de ces domaines, les disparités qui s'y rapportent seront analysées dans le cadre des sections 4 et 5 .

3.3.1.2. Inconséquences dans la pratique des certificats de solvabilité globale

a) usage du certificat pour bénéficier des dispositions nouvelles en faveur des succursales communautaires

Les sièges sociaux ont été intéressés dès l'entrée en vigueur de la directive au 31 juillet 1978 à faire état de leur solvabilité globale pour se libérer du cautionnement dans les pays membres où ils ont des succursales. 


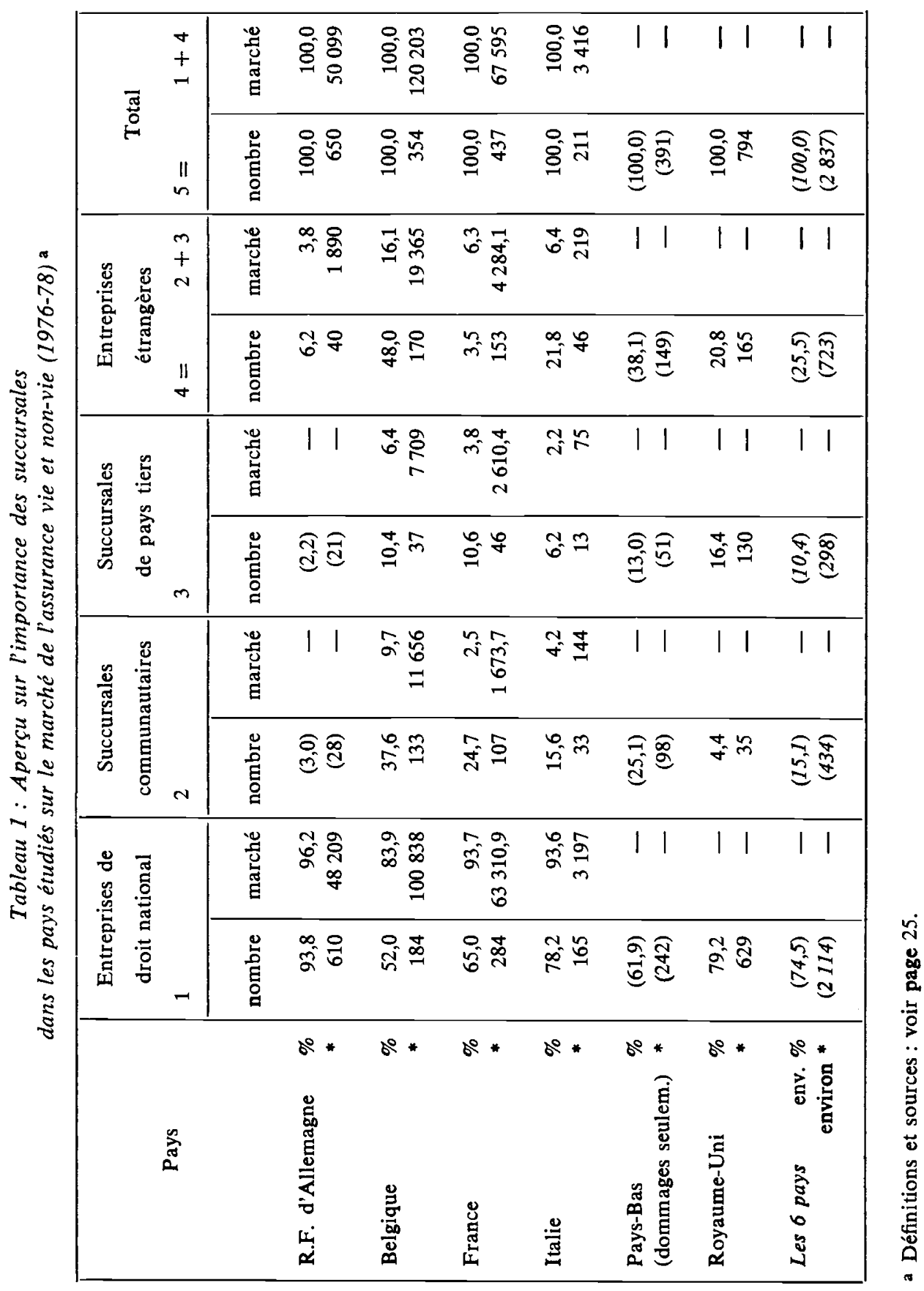




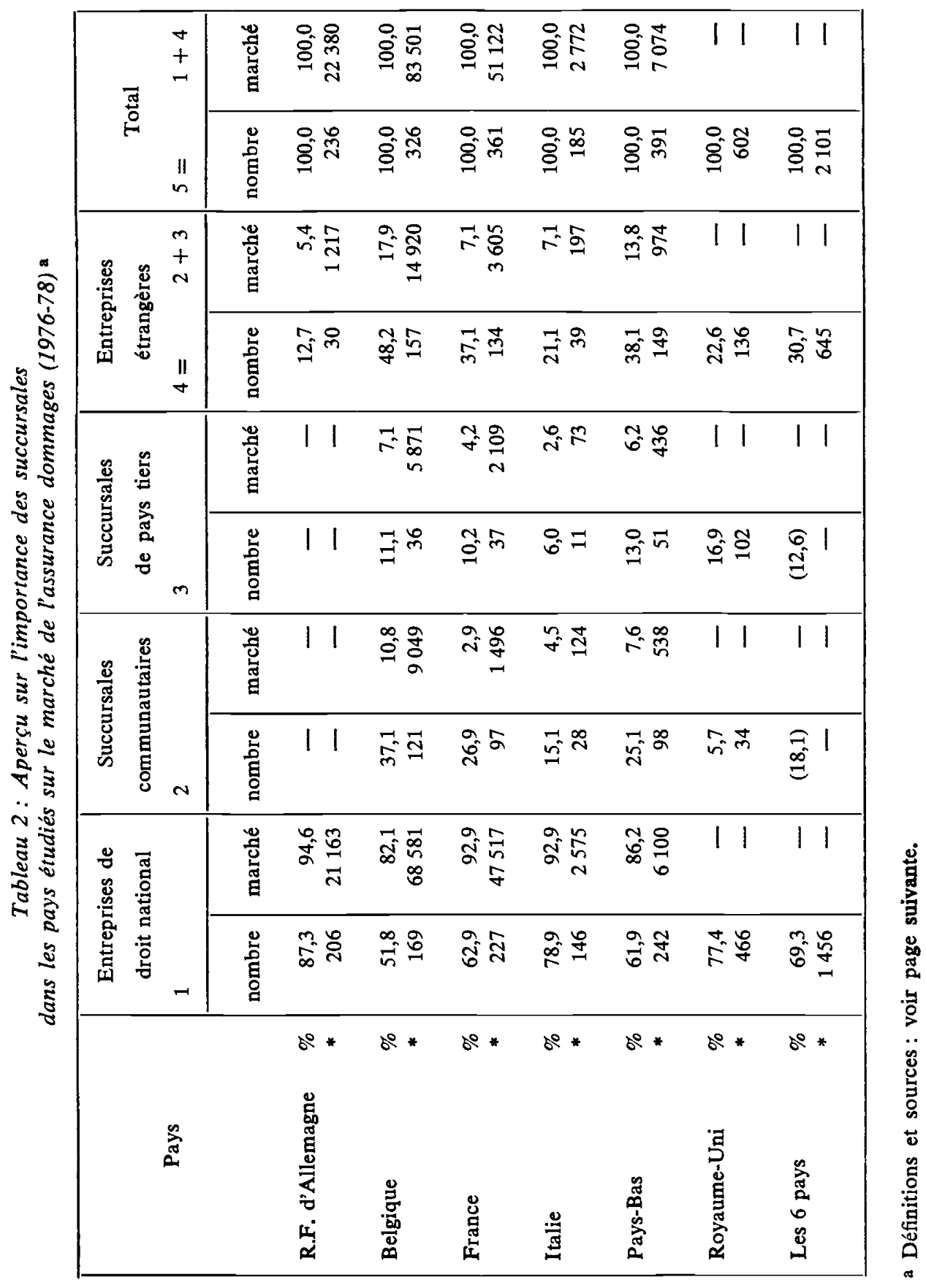




\section{TABLEAUX 1 ET 2 : DEFINITIONS ET SOURCES}

\section{R.F. D'ALLEMAGNE}

Définitions :

- Marché vie et dommages : Brutto-Beiträge für das selbst abgeschlossene Versicherungsgeschäft der unter Bundesaufsicht stehenden Versicherungsunternehmen (en millions de DM).

- Dommages : Schaden- und Unfallversicherungsunternehmen.

- Nombre entre parenthèses: Anzahl der unter Bundesaufsicht stehenden Unternehmen (Tableau 1).

Source:

«Bundesaufsichtsamt für das Versicherungswesen », Geschäftsbericht 1976, Berlin 1977.

\section{BELGIQUE}

Définitions :

- Vie et dommages : assurance-vie, RC, auto-obligatoire et risques divers (hormis l'encaissement de l'institution publique).

- Marché correspondant : primes relatives aux affaires directes, brutes de cessions et nettes d'acceptations en réassurances (en millions de FB).

\section{Source:}

«L'Europe des Assurances», Annuaire international, Tome 2, L'Argus 1979.

FRANCE

Définitions :

- Marché dommages et vie: encaissements totaux de l'assurance française (en millions de francs).

Source:

- Rapport du Ministre de l'Economie et des Finances au Président de la République sur l'activité des organismes d'assurance et de capitalisation en 1976.

- Fédération Française des Sociétés d'Assurance.

\section{ITALIE}

Définitions :

— Marché vie et dommages : Incassi Lavoro diretto Italiano (en milliards de Lires).

Sources:

- ANIA et ISTAT.

$P A Y S-B A S$

Définitions :

- Marché dommages (seulement): primes brutes affaires indirectes incluses (en millions de Florins).

Source :

Verslag van de Verzekeringskameringevolge de wet op het schadeverzekeringsbedrijf over het jaar 1977.

\section{ROYAUME-UNI}

Définitions :

- Marché : non disponible.

- Nombre : vie et dommage

(Tableau 1), dommages (Tableau 2).

Source :

Department of Trade : «Insurance Business - Annual Report 1977 », Londres 1978. 
Cependant les entreprises italiennes ont rencontré à cet égard des difficultés en France et en Belgique.

Or, depuis l'entrée en vigueur de la loi belge du 23 mars 1976, les entreprises italiennes - au même titre d'ailleurs que les autres entreprises étrangères dont le siège social est situé dans la Communauté - sont dispensées (art. 14, §2) de disposer en Belgique d'une marge de solvabilité et de déposer la moitié du fonds minimum de garantie à titre de cautionnement (art. 15, § de la loi du 29 juillet 1975).

Ces entreprises italiennes n'ont pu toutefois se libérer de leurs obligations antérieures, faute d'avoir été en mesure de produire un certificat de solvabilité aux autorités de surveillance belges. Les assureurs italiens auraient ainsi subi un préjudice par rapport à leurs concurrents établis dans d'autres pays membres et qui opèrent, comme eux, sur le marché belge par des agences ou des succursales. Selon des sources belges, la situation se serait toutefois régularisée en 1980.

Pour les mêmes raisons, à savoir le défaut de pouvoir produire matériellement un certificat, ces entreprises auraient rencontré des difficultés similaires en France. Le problème a eu toutefois plus d'importance qu'en Belgique en raison du montant plus élevé des actifs nets qui y étaient immobilisés en couverture de la réserve de garantie, une obligation à laquelle les entreprises étrangères étaient assujetties dans le cadre de la marge de sécurité (une réglementation française qui a précédé la marge de solvabilité communautaire) 19 .

On relèvera que ces disparités, tout au plus passagères, sont imputables à la carence des autorités de surveillance italiennes qui, faute d'une réglementation adéquate, n'avaient pas pu donner suite aux demandes des entreprises italiennes de certificats de solvabilité globale.

Les entreprises belges et françaises — au même titre d'ailleurs que d'autres entreprises étrangères - pourraient quant à elles ne pas être non plus satisfaites de l'application de la loi italienne du 26 juin 1978. Suite à la reformulation de demandes d'agrément en suspens, les entreprises désireuses d'ouvrir une succursale en Italie ou d'exercer d'autres branches n'avaient pu obtenir en mars 1979 l'autorisation requise des autorités de surveillance italiennes.

Or, en ce qui concerne plus particulièrement les entreprises des autres Etats membres, ces autorités auraient dû se prononcer dans un délai de six mois venant à échéance à fin 1978 pour celles d'entre elles qui avaient reformulé leur demande d'agrément à fin juin de la même année.

Ces retards d'application, non discriminatoires puisqu'ils touchent aussi bien des entreprises italiennes qu'étrangères, expliqueraient pourquoi des pays comme la Belgique et la France auraient tardé à libérer de leurs obligations antérieures les entreprises italiennes opérant sur leur territoire. En d'autres termes, les avantages résultant des nouvelles dispositions en matière d'agrément et de certificat de solvabilité globale paraissaient être concédés sur la base de la réciprocité, et non pas en application pure et simple de la loi.

19 On remarquera toutefois que le dépôt spécial qui était constitutif de la réserve de garantie en sus du cautionnement avait été abrogé en 1976. 
Cette appréciation de la situation existante est confirmée par la constatation que la pratique de l'agrément et du certificat de solvabilité globale semble fonctionner sans heurts entre les autres pays membres 20 .

L'application de la directive sur la base de la réciprocité n'est certainement pas clans la lettre des nouvelles dispositions en matière de solvabilité et de libre établissement. De ce qui précède, on peut toutefois penser que les disparités résultant de cette pratique ne devraient être que passagères ; elles seront sans doute surmontées dès lors que les problèmes d'adaptation administrative auront été résolus dans tous les pays membres.

\section{b) fréquence de délivrance du certificat}

On relèvera ici un autre problème d'application qui pourrait entraîner des disparités. Alors que dans les pays étudiés, le Royaume-Uni mis à part, les certificats de solvabilité globale sont établis sur une base annuelle, les autorités de surveillance britanniques demandent aux entreprises nouvellement établies ou en difficultés de justifier de leur solvabilité à des intervalles plus rapprochés. L'éventualité d'étendre le contrôle sur une base trimestrielle à toutes les entreprises, y compris les succursales communautaires, a été évoquée. S'il en était ainsi, ces dernières ne seraient pas en mesure de répondre aux exigences britanniques, dès lors que les sièges sociaux auxquels elles sont rattachées ne se voient délivrer leur certificat que sur une base annuelle. Les autorités de surveillance des autres pays devraient alors, ou bien s'aligner sur la pratique du pays introduisant des états trimestriels, ou bien étendre ou renouveler la validité du certificat de solvabilité globale délivré annuellement aux entreprises qui ont des succursales dans ce pays.

S'il n'en était pas ainsi, d'aucuns estiment que les succursales communautaires risqueraient en Grande-Bretagne d'être astreintes aux exigences du contrôle financier antérieur à la directive, ce qui constituerait alors une disparité durable au sein de la CE. Cette éventualité paraît néanmoins peu probable et en tout cas peu conforme à l'esprit d'harmonisation qui prévaut à l'heure actuelle au niveau des autorités de surveillance.

\subsubsection{Entreprises communautaires et entreprises des pays tiers}

\subsubsection{Accentuation de disparités antérieures}

En première analyse, les assureurs ayant leur siège dans des pays tiers paraissent avantagés par la directive communautaire puisque ceux-ci n'ont à constituer qu'une marge de solvabilité proportionnelle à leur activité dans la $\mathrm{CE}$ et limitée à cette activité ${ }^{21}$. En fait, les principaux concurrents provenant des pays tiers ont été jusqu'ici, d'une part, les assureurs des Etats-Unis (lesquels sont assujettis à une marge plus élevée que celle exigée à l'intérieur de la $\mathrm{CE}$ ) et, d'autre part, les assureurs japonais qui ne

20 On relève néanmoins que les succursales françaises d'entreprises belges ne seraient pas parvenues à se dégager de leurs obligations antérieures en produisant le certificat de solvabilité globale. N'ayant pas eu connaissance de difficultés similaires rencontrées par les succursales belges d'entreprises françaises, on ne peut donc entièrement exclure l'existence de traitements administratifs discriminatoires au moment de la mise en place des nouvelles dispositions légales.

21 HATCH, M. : «Assemblée générale du Comité Européen des Assurances », Paris 1978. 
posent pas de problèmes graves pour le moment ${ }^{22}$. En ce qui concerne les assureurs helvétiques qui disposent en général de marges confortables, un accord entre la $\mathrm{CE}$ et la Suisse va les soumettre aux règles communautaires (voir plus loin section 3.3.2.3.).

Par ailleurs, en comparaison avec la situation antérieure à l'application de la marge, une analyse plus approfondie montre que les succursales des pays tiers sont au contraire désavantagées sur certains points. Leur position peut être résumée comme il suit.

On rappellera tout d'abord que des différences de traitement entre entreprises nationales et entreprises étrangères (tant du point de vue de l'agrément que des garanties financières) sont bien antérieures à l'introduction de la marge communautaire. La première directive de coordination s'y rapportant et instituant la liberté d'établissement assimile désormais les entreprises étrangères qui ont leur siège social dans un autre pays de la $\mathrm{CE}$, soit les succursales communautaires, aux entreprises nationales. Seules les succursales d'entreprises de pays tiers restent ainsi soumises à des différences de traitement.

Dans les pays où le contrôle financier de l'entreprise d'assurance exigeait, en plus du cautionnement, un dépôt d'actifs libres de tout engagement (exemple : pour constituer la réserve de garantie en France), la question a été de savoir si le nouveau régime ne serait pas plus contraignant que l'ancien. Selon les avis recueillis et les textes réglementaires communiqués, il ne fait aucun doute que les conditions antérieures étaient préférables aux nouvelles ${ }^{23}$, tant en ce qui concerne le montant total des actifs nets à disposer dans la $\mathrm{CE}$ en couverture de la marge que le risque monétaire accru découlant de l'obligation de localisation des actifs additionnels. De ce dernier point de vue, les entreprises helvétiques en particulier qui opèrent souvent par l'intermédiaire de succursales sur le territoire de la CE préféreraient sans doute localiser en Suisse le supplément de marge exigé plutôt que de devoir le faire, par exemple, partie en Italie, partie à l'intérieur de la Communauté.

Au Royaume-Uni, où le contrôle de solvabilité de l'entreprise étrangère s'exerçait déjà en vertu de l'« Insurance Act » de 1974, la succursale de pays tiers est désormais soumise à un double contrôle. Elle est tenue de constituer la marge communautaire en couverture de ses affaires au Royaume-Uni et doit en plus continuer à apporter la preuve que le siège social auquel elle est rattachée dispose, pour l'ensemble de ses opérations, d'une marge de solvabilité suffisante aux termes des prescriptions britanniques antérieures à l'introduction de la marge communautaire ${ }^{\mathbf{2 4}}$.

Contrairement à la France qui a renoncé à appliquer ses dispositions antérieures en matière de marge de sécurité, le Royaume-Uni a accru ainsi sa pression pour que l'entreprise étrangère exerce son activité au travers d'une filiale plutôt que d'une succursale. On peut se demander si la pratique britannique ne devra pas disparaître pour s'harmoniser avec les dispositions communes de la CE. Pour cette raison, la disparité qui résulte de cette pratique particulière pourrait bien n'être que de nature passagère.

22 PLESCOFF, G. : loc. cit.

23 Même si des conditions spécifiques pouvaient être requises lors de l'agrément.

24 DEPARTMENT OF TRADE : «Insurance Business Account Report 1977 », p. 2, London 1978. 
Dans les autres pays étudiés (notamment en Italie et aux Pays-Bas ${ }^{25}$ ), la marge est une obligation financière entièrement nouvelle pour les succursales des pays tiers. Elle ne constitue certes pas dans l'immédiat et pour la plupart d'entre elles une charge financière supplémentaire, car les entreprises dont elles dépendent disposent en général de fonds propres en suffisance. La localisation de la marge dans le pays d'exercice et le reste de la $\mathrm{CE}$ implique toutefois des transferts de fonds propres du pays tiers vers la $C E$, ce qui représente un risque monétaire accru.

D'une façon plus générale, des conditions de concurrence entre entreprises étrangères sont modifiées, les succursales communautaires étant libérées de leurs obligations antérieures en matière de garanties financières alors que les succursales des pays tiers voient les leurs s'accroître.

Cette modification des conditions de concurrence entre deux catégories d'entreprises ne devrait toutefois être ressentie que de façon transitoire, car toutes les entreprises opérant sur le territoire de la CE seront astreintes à l'avenir aux mêmes obligations pour alimenter la marge additionnelle requise par le développement de leurs affaires. Par contre, les disparités relatives à la localisation de la marge sont de nature durable et ne devraient pas être sous-estimées dans les conditions monétaires de notre époque.

\subsubsection{Tranformation de succursales en filiales ou accords de réciprocité}

Compte tenu des disparités identifiées, nombre de succursales de pays tiers pourraient être à l'avenir transformées en filiales de la société-mère et venir grossir ainsi les rangs des entreprises de droit national. Les groupes étrangers opérant avec des succursales dans plusieurs pays de la CE depuis l'extérieur ont aussi la faculté de transformer une seule de leurs succursales en filiale et de rattacher les succursales restantes à l'entreprise nouvellement créée pour les mettre au bénéfice du statut de succursales communautaires. Elles peuvent ainsi éviter les inconvénients auxquels l'entreprise étrangère doit faire face.

Dans la mesure où les Etats membres n'y mettraient pas d'entraves, elles choisiront alors, pour l'établissement de leur filiale communautaire, le pays de la $C E$ qui offre le plus d'avantages pour faire état de la marge et surtout pour la financer à l'avenir. Les disparités additionnelles créées par l'introduction de la marge à l'égard des succursales des pays tiers pourraient ainsi se retourner à l'avantage des groupes étrangers.

De tels changements risquent de s'effectuer sans que les Etats membres n'aient obtenu de la part des pays tiers les concessions qu'ils sont en position de faire valoir au travers d'accords de réciprocité. De tels accords peuvent en effet prétendre étendre la liberté d'établissement et la notion de solvabilité globale aux autres pays partenaires de la CE. Ainsi, l'octroi de la liberté d'établissement sur le territoire des Etats-Unis pourrait être particulièrement attrayant pour les entreprises communautaires.

En accroissant les disparités à l'égard des entreprises étrangères, la $\mathrm{CE}$ a en fait créé une dynamique de la libéralisation du marché de l'assurance. Une telle libéralisation s'inscrit dans la ligne des travaux initiés en 1954 par l'OECE. Pour les pays qui en avaient donné l'impulsion, il y a là un heureux retour des choses.

25 En Belgique, les succursales de sociétés étrangères avaient les mêmes obligations que les entreprises beiges. Elles devaient déposer un cautionnement fixe d'un million de francs belges en R.C. Auto qui, avant l'introduction du contrôle généralisé, était la seule branche contrôlée. 


\subsubsection{Accord entre la Suisse et la CE}

Les intérêts entre les assureurs suisses et les assureurs de la $\mathrm{CE}$ sont équilibrés en terme de part de marché, l'interpénétration par des succursales se situant à environ $3 \%$ des primes encaissées pour chacun des partenaires ${ }^{26}$. En valeur absolue, les encaissements sont bien entendu nettement en faveur de la Suisse, vu la différence de volume entre le marché helvétique et celui des Neuf. A l'exclusion des affaires traitées par des filiales ou des holdings, l'encaissement des primes «non-vie » par les succursales suisses dans la CE se montait à fr.s. 2363 millions et représentait environ $33 \%$ de l'ensemble des recettes réalisées par les entreprises suisses sur le marché intérieur et à l'étranger (1972) ${ }^{27}$.

Pour les raisons précédemment citées, les assureurs suisses pourraient être amenés à transformer tout ou partie de leurs succursales en filiales selon les schémas indiqués. Ils préféreraient toutefois parvenir à un arrangement avec la CE et continuer à opérer dans les mêmes conditions qu'avant l'introduction de la marge de solvabilité communautaire, et ce pour trois catégories de raisons.

Tout d'abord, les entreprises suisses opèrent depuis de longue date au travers de succursales; les structures organiques créées ont fait leur preuve. Toute modification conduirait à la longue à une déconcentration qui n'est pas souhaitée à l'heure actuelle.

Ensuite, la transformation de succursales en filiales conduirait à des liquidations d'actifs ou à des apports en nature qui, en raison de l'ancienneté des succursales, ferait apparaître des plus-values non négligeables. Ces plus-values étant taxables dès lors qu'elles changent de propriétaire, les entreprises suisses devraient s'acquitter d'impôts additionnels.

Enfin, certaines compagnies opèrent au travers de filiales et de succursales. Elles préféreraient pouvoir maintenir cette souplesse stratégique.

Du côté de la $\mathrm{CE}$, un accord de réciprocité avec la Suisse aurait aussi des avantages. En échange des prérogatives attachées au statut de succursale communautaire qui seraient concédées aux succursales suisses, les assureurs de la $C E$ se verraient accorder la liberté d'établissement en Suisse, laquelle est souvent envisagée comme un premier pas vers la liberté de prestations de services. Par ailleurs, la Suisse devrait trouver un aménagement pour au moins limiter les effets des monopoles cantonaux existant en matière d'assurance incendie.

Plus déterminant pour les assureurs des pays à monnaie faible de la $\mathrm{CE}$ pourrait être l'avantage de pouvoir créer librement en Suisse une succursale à laquelle les autorités helvétiques pourraient difficilement appliquer les mesures qu'elles sont fréquemment amenées à prendre pour décourager ou interdire l'afflux de fonds de l'étranger. Or, dans le cadre d'une stratégie financière visant à préserver la substance de la marge, il est évident que l'entreprise communautaire a intérêt à placer une partie de ses fonds propres en francs suisses et à disposer d'une antenne en Suisse à cette fin au moins.

26 BLANKART, Franz : "Das Versicherungsabkommen Schweiz / EWG aus Integrationspolitischer Sicht », Assemblée générale de l'Association suisse des compagnies d'assurance, Winterthur, 17 mai 1977.

27 GMEINER, P.: "The EEC Interest of the Swiss Insurance Industry », dans International Insurance Monitor, janvier 1975. 
Tenant compte des intérêts des deux parties, un accord a été élaboré entre la Commission de la $\mathrm{CE}$ et les autorités gouvernementales helvétiques. Il a été soumis à l'approbation des Etats membres en 1979 et, si le Conseil des Ministres de la CE en tombe d'accord, le document et ses annexes prêts à être paraphés pourraient être signés prochainement.

Cet accord ne recueille toutefois pas l'unanimité des assureurs des Etats membres. D'aucuns redoutent que la Suisse ne renforce encore sa position sur le marché européen de l'assurance. D'autres préféreraient attendre que les directives vie ${ }^{28}$ et libre prestation de services soient sous toit pour passer des accords bilatéraux globaux. Enfin, dans certains pays, l'argument de l'avantage du libre placement en francs suisses est retourné pour justifier au contraire une réticence à un accord de réciprocité avec la Suisse. Dans la situation actuelle, des entreprises qui opèrent en Suisse au travers de succursales et qui y sont établies depuis un certain temps ont pu en effet alléguer jusqu'ici l'existence de ces dernières et de leurs besoins de financement locaux pour ne pas rapatrier la totalité des bénéfices réalisés sur le marché helvétique (ce que le contrôle des changes auquel elles sont soumises pourrait les obliger à faire à partir du moment où les autorités suisses de surveillance devraient se contenter du certificat de solvabilité globale).

Quoi qu'il advienne du projet d'accord entre la Suisse et la $\mathrm{CE}^{*}$, il paraît évident que les problèmes de concurrence avec les entreprises des pays tiers se posent avec plus d'acuité dès lors que les Etats membres libéralisent entre eux leurs marchés. La marge de solvabilité poussant par ailleurs à une plus grande efficacité dans la gestion des fonds propres immobilisés, la libéralisation des mouvements de capitaux est une question qui gagne en actualité et qui dépasse le cadre strict des pays membres.

\section{Plus-values résultant de la sous-estimation d'actifs}

\subsection{Rôle central de la plus-value}

Ainsi qu'on l'a relevé précédemment (voir section 3.3.1.1.), le maintien des règles nationales en matière d'estimation des actifs et des passifs constitue a priori une source de disparités. S'il s'agit là d'une condition nécessaire, elle n'est toutefois pas suffisante pour qu'il $y$ ait distorsion du point de vue de la justification de la marge. En effet, les autorités de surveillance sont habilitées à considérer comme élément de l'actif net la différence entre la valeur portée au bilan et la valeur dont il est fait par ailleurs mention dans les comptes annuels à titre indicatif ou en vertu de dispositions particulières aux compagnies d'assurance.

28 Adoptée par le Conseil des Ministres le 5 mars 1979, applicable par les entreprises dans les 30 mois, soit à partir de juillet 1981 (les Etats membres ont 18 mois pour adapter leur législation et 30 mois pour la mettre en vigueur; les entreprises disposent d'un délai supplémentaire de 30 mois pour se conformer aux exigences financières posées par la directive, soit d'ici à novembre 1983).

* L'accord a été soumis à l'approbation des Etats membres en 1979 et, si le Conseil des Ministres en tombe d'accord, le document et ses annexes - pratiquement prêts à être paraphés - pourraient être signés prochainement, soit probablement en 1981, la ratification restant toutefois soumise aux procédures usuelles. 
Ainsi, si les valeurs du marché des différents postes d'actifs sont indiquées dans une annexe publiée du bilan commercial, elles peuvent faire apparaître par différence avec les valeurs comptables une "plus-value explicite ". Cette dernière ne constitue pas une plus-value au sens de l'article 16 , paragraphe 1 , alinéa 2 , tiret 6 , de la première directive de coordination. Les autorités de surveillance des Etats membres se sont mises d'accord pour que cet élément «explicite » figure dans l'état de la marge de solvabilité, et ce sous la rubrique « Autres éléments » du modèle de formulaire de déclaration. Quant aux plus-values au sens de l'article 16, elles sont cachées ou latentes, résultant de la différence entre l'estimation publiée des actifs et leur valeur réelle ou valeur du marché (voir infra, p. 33).

Dès lors que dans tous les Etats membres l'entreprise d'assurance - en exception à la quatrième directive sur la présentation des comptes de l'entreprise - peut faire état de cette valeur du marché de différentes manières, à savoir :

- soit par son admission au bilan commercial;

- soit par sa mention dans les comptes publiés ;

- soit par une déclaration ad hoc aux autorités de contrôle,

les différences nationales entre les règles d'estimation des actifs perdent beaucoup de leur importance du point de vue de la justification de la marge. Il est indifférent, par exemple, qu'en France le principe du prix d'achat soit appliqué à l'évaluation des actifs alors qu'au Royaume-Uni le prix du marché prévaut.

Soit le cas de deux compagnies identiques ayant l'une (A) son siège social à Paris, l'autre (B) à Londres (voir Fig. 3 : schémas de bilan, p. 33). L'une et l'autre compagnie ayant les mêmes actifs et les mêmes engagements sont ainsi sur pied d'égalité pour faire état de la marge, bien que les règles d'estimation leur étant applicables soient différentes en raison du droit national dont elles relèvent.

Si au lieu d'être «explicites», les plus-values sur actifs sont «cachées », l'évaluation des éléments qui la composent aurait pu faire problème si les autorités de surveillance des Etats membres ne s'étaient pas mises d'accord pour définir la plusvalue sur actifs comme la différence entre la valeur inscrite au bilan et une valeur plus élevée, la valeur du marché. Or, elles ont précisément signé un protocole d'accord à ce sujet en 1977. La plus-value "cachée », ou plus-value au sens strict de la directive, ne pose pas moins dans la pratique un certain nombre de problèmes qui peuvent constituer des sources de disparités entre entreprises.

\subsection{Les vraies sources de disparités}

Les plus-values au sens strict de la directive sont prises en compte, dans la mesure où elles n'ont pas un caractère exceptionnel, sur demande et justification de l'entreprise et en accord avec l'autorités de surveillance où l'entreprise exerce son activité (art. 16, paragraphe 1 , alinéa 2 , tiret 6 ). Ces autorités se sont mises d'accord pour que les plusvalues au sens strict ne soient prises en considération que dans le cas où, sans leur prise en compte, les entreprises ne rempliraient pas les exigences de solvabilité (Protocole de 1977).

Il y a inégalité face aux plus-values d'une façon générale si les entreprises concurrentes sont soumises à des règles de placement nationales qui interdisent ou limitent 

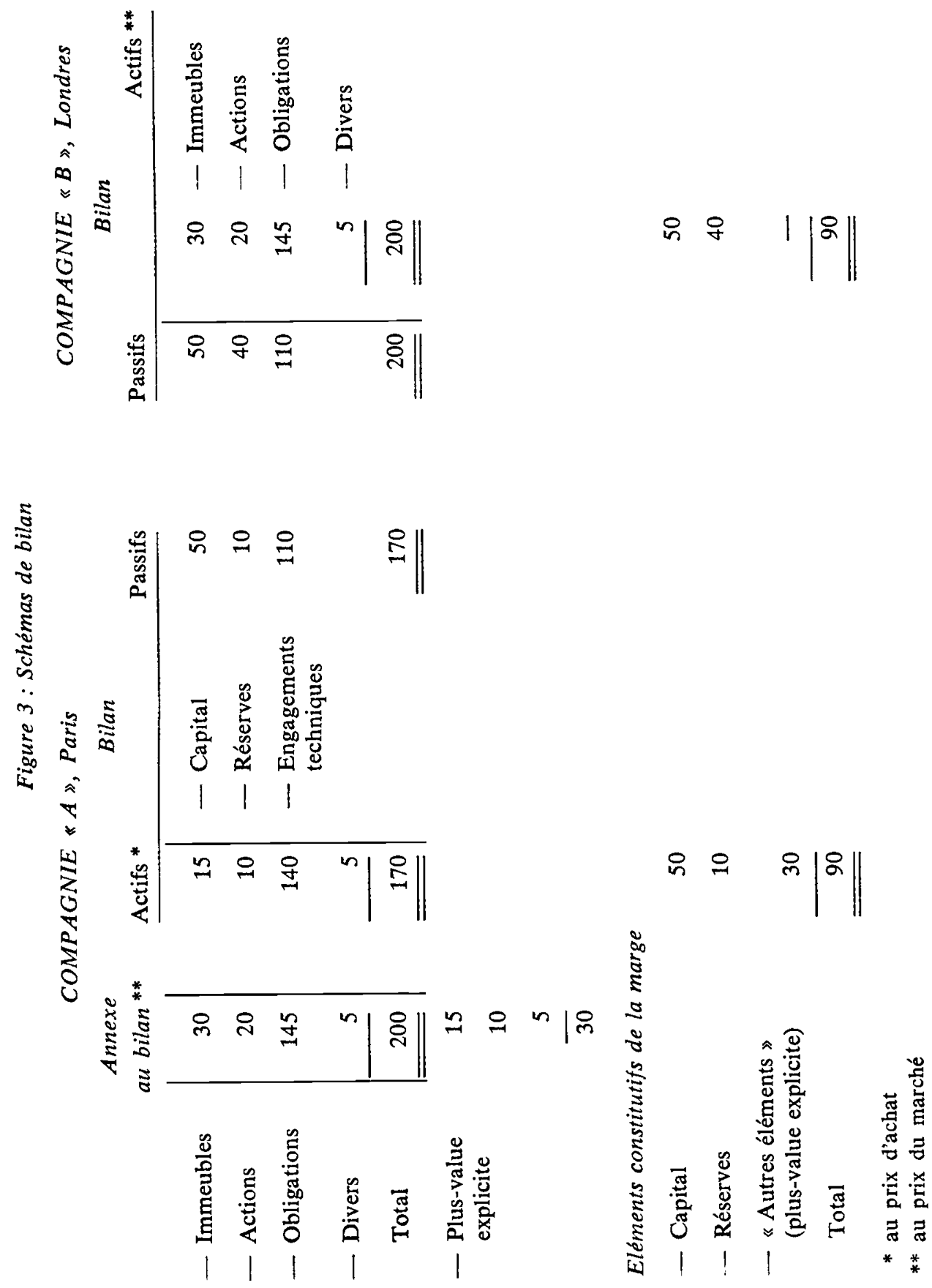
la possession de certains actifs de nature à s'apprécier (valeurs réelles). De plus, toutes choses étant égales par ailleurs, les conditions pour acquérir ces valeurs sur les marchés internationaux comme d'ailleurs leur possibilité d'appréciation nette dépendent de conditions économiques également différentes selon les pays (contrôle des changes, fiscalités, etc.). Ces inégalités ont trait au financement de la marge ; à ce titre, elles seront traitées dans le cadre de la section 6 .

Du point de vue de la justification de la marge, on considérera ici les différences qui peuvent exister entre pays selon qu'il s'agit :

-.- de la non-admissibilité de certains actifs comme éléments du patrimoine ;

- de la valeur de marché effectivement retenue ;

- des montants à déduire pour des moins-values sur d'autres postes ;

- des conditions de prise en compte.

\subsubsection{Non-admissibilité d'actifs}

Alors que certains actifs peuvent être détenus sans enfreindre des dispositions légales, ils n’en sont pas moins exclus des éléments constitutifs du patrimoine en couverture de la marge.

Au Royaume-Uni, il s'agit de postes tels les fonds de placement non cotés, les collections d'œuvres d'art, ... ou de la part d'actifs dépassant les quotas admissibles (exemple : pour une entreprise de petite taille, partie de l'immeuble où elle a son siège social). On cite aussi la non-admissibilité de biens-fonds sis à l'étranger qui n'ont pu être évalués par des experts agréés par le Department of Trade, en raison notamment de difficultés rencontrées dans certains pays d'outre-mer.

Ces différents types d'actifs non admis peuvent être conservés pour des motifs divers, tel un rendement intéressant ou l'espérance de prises de bénéfice extraordinaires. Il paraît toutefois vraisemblable que ces postes de l'actif seraient réalisés avant que l’entreprise ne soit amenée à faire état de plus-values pour couvrir sa marge.

On relèvera néanmoins leur importance ; pour une grande compagnie britannique, ce type d'actifs représentait quelque $15 \%$ de sa marge en 1978.

En Italie, une situation similaire pourrait naître de nouvelles dispositions en matière de placement. La branche de la responsabilité civile automobile devra réduire à $35 \%$ de ses provisions techniques la part des fonds placés en biens immobiliers. Au cas où cette disposition serait étendue aux autres branches, certaines compagnies qui possèdent jusqu'à $80 \%$ de leurs actifs en immeubles pourraient ne pas pouvoir modifier suffisamment rapidement la structure de leurs investissements et, de ce fait, se voir retrancher, des placements en couverture de leur patrimoine net, les montants non admis en couverture des provisions techniques. Il ne devrait toutefois s'agir que de difficultés transitoires, la proportion des placements autorisés en immeubles tendant par ailleurs à s'uniformiser au sein de la $\mathrm{CE}$.

En France, on notera que les valeurs non cotées ne sont pas admises en couverture des provisions techniques, mais elles le sont pour la couverture de la marge.

Sur le plan plus général, on relèvera que les Pays-Bas, le Royaume-Uni et, sans doute à titre transitoire, l'Italie sont les pays qui offrent la plus large base pour la 
constitution de plus-values en raison des facilités en matière de placements en valeurs réelles (biens-fonds et actions).

La non-admissibilité des créances sur réassureur dans certains pays peut aussi avoir une incidence sur la base prise en considération pour la couverture de la marge.

L'article 15 , paragraphe 3 , de la première directive prévoit expressément qu'un Etat membre peut admettre ou ne pas admettre les créances sur les réassureurs en représentation des réserves techniques. Le cas échéant le pourcentage admis est fixé pai la loi.

Parmi les pays étudiés, seules la Belgique, la France et l'Italie exigent la représentation au brut des provisions pour sinistres en suspens et risques en cours ${ }^{29}$. La question de l'admission du réassureur comme débiteur ne se pose donc que dans ces pays. La loi italienne admet $90 \%$ du montant des créances direct de l'assureur sur le réassureur. A concurrence de $10 \%$ en Italie et de $100 \%$ en Belgique et en France ${ }^{30}$, l'assureur est ainsi devant le choix, soit de demander au réassureur un dépôt, soit de constituer la provision technique exigée avec des moyens propres. Dans ce dernier cas, une partie des actifs libres sont soustraits à la représentation de la marge de solvabilité. Pour cette raison, ce cas est le moins fréquent, l'assureur préférant demander au réassureur de fournir un dépôt.

On remarquera ainsi que le dépôt du réassureur ne relève pas nécessairement d'une disposition réglementaire qui lui serait directement applicable, mais peut constituer une pratique contractuelle résultant du système de calcul et de représentation des provisions techniques imposée à l'assurance directe. Les conséquences au plan de la gestion financière seront analysées dans le contexte du financement de la marge (voir section 6.2.2).

\subsubsection{Valeur de marché retenue}

\subsubsection{Pratiques nationales}

La valeur du marché des titres cotés n'offre guère le champ à des interprétations nationales du fait de la publication des cours de bourse. On notera toutefois qu'au Royaume-Uni, le cours retenu est la moyenne entre celui de l'offre et de la demande, et non le prix de la dernière transaction faite à la date la plus rapprochée de l'établissement du bilan.

Les immeubleus offrent une plus grande flexibilité d'appréciation qui suit les pratiques nationales.

Pour éviter toute confusion, il n'y a pas lieu de considérer parmi ces dernières les estimations résultant de la réévaluation de bilan qui, en France et en Italie, visent précisément à faire apparaître régulièrement les réserves latentes contenues dans les

29 En R.F. d'Allemagne, ces provisions sont calculées au brut et portées au net au bilan, le montant brut figurant en marge.

30 Avec cette réserve que, par arrêté ministériel, les créances nettes sur les réassureurs peuvent être représentées à l'actif pour ce qui est des provisions afférentes aux assureurs maritimes et aériens. 
éléments de l'actif. On notera seulement que ces réévaluations peuvent servir de référence à des estimations annuelles intermédiaires des immeubles.

En R.F. d'Allemagne, la valeur du marché des biens immobiliers ne peut pas être inscrite au bilan; l'autorité de surveillance peut néanmoins accepter en constitution de la marge la différence entre la valeur du marché, diminuée de l'amortissement, et la valeur d'achat ${ }^{31}$. La valeur du marché est fixée par expertise.

Dans les autres pays étudiés, où la valeur du marché peut être publiée, l'entreprise a la possibilité de constituer une plus-value cachée et pouvant être prise en compte pour la couverture de la marge en inscrivant librement - jusqu'à une certaine limite une valeur plus faible (en Belgique pour les immeubles compris dans le patrimoine libre, aux Pays-Bas, en Italie et en France pour tous les immeubles en couverture des provisions techniques ou des fonds propres). La valeur d'expertise est celle :

- d'une vente de gré à gré en Belgique, aux Pays-Bas et en France (par exemple) ; ou

- d'une vente de liquidation au Royaume-Uni (pour les filiales).

Cette dernière estimation, plus basse, défavorise les pays où elle est pratiquée ${ }^{32}$.

Par ailleurs, il en est de même lorsque, comme en France et aux Pays-Bas, il est d'usage de procéder à un abattement sur la valeur retenue en vue des impôts et frais qui pourraient être dus lors de la réalisation des actifs ou lors de l'incorporation des plus-values aux réserves libres déclarées ${ }^{33}$.

En France, on notera qu'il peut y avoir en plus, lors de réévaluation des bilans, interférence entre valeur d'expertise et valeur de réévaluation des immeubles. Si la valeur d'expertise antérieure est supérieure à la valeur de réévaluation, la première est retenue comme valeur de réalisation et la seconde comme valeur d'inventaire portée au bilan. Il en résulte une plus-value «explicite», puisque ressortant des comptes annuels publiés. Si au contraire la valeur d'expertise antérieure est inférieure à la valeur de réévaluation, la seconde est retenue à la fois comme valeur de réalisation et comme valeur d'inventaire; aucune plus-value explicite ne peut plus alors apparaître ${ }^{34}$.

Du point de vue de la marge de solvabilité, cette pratique n'a pas d'influence directe, car de toute manière la valeur du marché ou de réalisation est retenue comme valeur plafond. On relèvera toutefois que, faute de plus-values explicites sur immeubles, le compte d'exploitation devra supporter d'éventuelles moins-values comptables sur d'autres catégories d'actifs. Le report des bénéfices, qui est un élément constitutif de

31 A titre exceptionnel seulement, selon la circulaire du 6 juillet 1978 de l'autorité de surveillance allemande.

32 En Italie, sauf en cas de réévaluation d'actifs, les immeubles ne peuvent figurer au bilan à une valeur supérieure au prix d'acquisition. Il y a dérogation à la rigueur du principe, lorsqu'une évaluation au prix du marché est requise pour répondre aux exigences de la constitution de la marge. Il s'agit alors de la valeur qui peut être réalisée lors d'une vente normale, en dehors de toute procédure de liquidation forcée.

33 On notera aussi que dans certains cas les frais d'expertise peuvent absorber tout ou partie de la plus-value de sorte que l'entreprise préfère ne pas en faire état.

34 Une plus-value cachée peut cependant exister si la valeur de réévaluation est inférieure à une valeur d'expertise plus élevée et dont il n'est pas fait mention dans les comptes annuels publiés. 
la marge, sera ainsi amputé à due concurrence. La conséquence serait toutefois la même pour une entreprise ayant son siège social dans un autre pays étudié, bien que ne suivant pas la pratique française en matière de compensation des moins-values par les plus-values.

Le traitement des moins-values en relation avec les plus-values sera pris en compte plus particulièrement à la section 4.2.3.

\subsubsection{Cas des participations non cotées}

Aux termes du protocole d'accord de 1977 entre les autorités de surveillance des Etats membres, des plus-values, au sens de la directive, peuvent être prises en considération de la même manière pour les participations que pour les titres, même si ces participations ne sont pas cotées en bourse. Dans ce cas, la procédure pour fixer la valeur du marché des participations est celle prévue par le droit national.

Les filiales non cotées appartenant à une entreprise d'assurance qui se trouve dans l'obligation de faire état de plus-values posent un problème nouveau d'évaluation. A l'exclusion de la valeur de cession qui comprend les actifs incorporels (goodwill, valeur commerciale du portefeuille de primes, etc.) ${ }^{35}$, il existe désormais deux valeurs du marché qui paraissent devoir retenir l'attention du point de vue du contrôle de solvabilité : la valeur qui résulte de l'application du droit national en matière d'estimation de participations non cotées et la valeur qui s'obtient en référence au calcul des actifs nets de la filiale (valeur qui fait l'objet d'une communication à l'autorité de surveillance à laquelle cette dernière est assujettie en vertu du contrôle de solvabilité).

Dans le cas où la valeur de la filiale communautaire résultant de ce dernier calcul serait supérieure à la valeur résultant de l'application du droit national, il semble difficile que cette seconde estimation puisse être opposée à la première, sans que l'autorité de surveillance de la société-mère déjuge les autorités d'un autre pays de la $\mathrm{CE}$ où la filiale a son siège.

En Belgique et en R.F. d'Allemagne, l'application des dispositions nationales l'emporte toutefois. Les filiales sont évaluées sur la base du prix d'acquisition. La circulaire belge D.8 précise que l'O.C.A. se montrera très réticente pour accepter une plus-value éventuelle sur les filiales non cotées alors que la circulaire allemande du 6 juillet 1978 indique d'une façon générale que les plus-values latentes (« stille Reserven ») ne peuvent être prises en considération comme élément constitutif de la marge qu'à titre exceptionnel.

$\mathrm{Au}$ Royaume-Uni, la valeur de la filiale ou plus précisément la société dite dépendante ${ }^{36}$ est égale à la différence entre ses actifs, évalués à leur valeur de liquidation, et ses passifs, ses engagements étant estimés en conformité avec les dispositions générales applicables à toute compagnie d'assurance. Les règles généralement acceptées en matière de provisions techniques doivent être suivies. Les règles d'admissibilité des

35 On rappellera que les actifs incorporels ne peuvent être pris en considération pour faire état de la marge.

36 Une société $\mathrm{x}$ est dite dépendante si au moins $1 / 3$ des voix est sous le contrôle d'une société $\mathrm{m}$. 
actifs doivent être aussi respectées, ce qui peut avoir pour conséquence de réduire le montant de l'actif net ( Statutory Instruments 1976, No. 87, Regulation 4 »).

Des ajustements sont toutefois concédés dans le cas de conglomérats complexes ( Regulation $5 »)$. Ces conglomérats peuvent comprendre des sociétés dépendantes qui n'exercent pas une activité d'assurance.

A notre connaissance, le Royaume-Uni est, parmi les pays étudiés, celui qui a poussé le plus loin l'évaluation des filiales avec pour effet de pouvoir les inscrire au bilan à un montant approchant la valeur intrinsèque (encore que la valeur des actifs incorporels - souvent très importants - ne soit pas prise en considération). Les sociétés-mères britanniques ont ainsi la possibilité de faire état des actifs nets de leurs filiales sur la base d'un ajustement annuel.

En France, les titres de participation non cotés (de filiales ou d'autres sociétés) sont évalués au prix d'achat, conformément à l'article R-332-20 du Code des Assurances. Ce régime dérogatoire au droit commun ne s'applique toutefois que pour les participations affectées en représentation des provisions techniques. Les participations faisant partie des fonds propres sont évalués à leur valeur d'utilité ${ }^{37}$, c'est-à-dire " ce qu'un chef d'entreprise prudent et avisé accepterait de décaisser pour les obtenir, s'il avait à les acquérir, cette valeur d'usage étant fonction de l'utilité que la participation représente pour l'entreprise (Avis du Conseil National de la Comptabilité du 23 octobre 1973) ». Il s'ensuit que, pour justifier de sa solvabilité, l'entreprise française a tout intérêt à inscrire ses participations non cotées dans d'autres entreprises d'assurance en couverture de ces fonds propres ${ }^{38}$. A l'instar de leurs consœurs britanniques, elles peuvent dans ce cas aussi les porter au bilan pour un montant approchant la valeur intrinsèque (encore que la valeur d'utilité puisse lui être sensiblement inférieure).

En Italie, les filiales non cotées peuvent être évaluées sur la base du montant de leur actif net tel qu'il ressort du bilan, compte tenu de la valeur des actifs incorporels qu'il est possible d'estimer de façon certaine. Les réévaluations de bilan fournissent régulièrement l'occasion de procéder à de telles estimations.

Aux Pays-Bas, la grande latitude existant en matière d'évaluation des actifs permet aussi d'évaluer les filiales non cotées sur la base du montant de leur actif net.

En résumé, les entreprises d'assurance domiciliées en Belgique et en R.F. d'Allemagne sont celles qui, dans les pays étudiés, sont nettement désavantagées par rapport à leurs concurrentes lorsqu'on considère le mode d'évaluation des filiales non cotées.

\subsubsection{Déductions pour moins-values}

Les plus-values au sens strict de la directive constituant des correctifs aux comptes annuels publiés, il importe également d'examiner si tous les pays étudiés appliquent les même règles en matière de moins-values. En matière de solvabilité, c'est en effet le montant net des plus-values qui est déterminant.

37 Et non pas leur valeur vénale.

38 Sur le plan fiscal, il résulte toutefois que les titres correspondants ne peuvent faire l'objet d'une provision pour dépréciation que dans l'hypothèse d'une dépréciation réelle par rapport au prix de revient (art. 2 de la Loi finances rectificatives pour 1973). 
Il est de règle que les plus-values « explicites », apparaissant comme la différence entre valeurs du marché et prix d'achat publiés, sont réduites à due concurrence des moins-values ressortant de la même différence lorsque la valeur du marché est inférieure au prix d'achat.

Dans ce dernier cas, des exceptions sont acceptées dans certains pays pour certains postes. Par ailleurs, le principe de la compensation entre plus-values et moins-values explicites est parfois appliqué avec des nuances qui ont des conséquences pour la justification de plus-values au sens strict de la directive.

Tout d'abord, en ce qui concerne les actions, les entreprises françaises ont été autorisées à ne pas prendre en compte la moins-value ressortant d'un cours de bourse inférieur au prix d'achat si la valeur du marché est contenue à l'intérieur d'une marge de fluctuation dont le plancher est fixé à $75 \%$ du prix d'achat, ce qui peut paraître considérable.

En ce qui concerne les titres à revenu fixe, les entreprises françaises sont aussi autosirées à retenir comme valeur d'inventaire inscrite au bilan la valeur nette de remboursement, au lieu de la valeur du marché, à condition que la valeur de remboursement soit à la fois supérieure au cours de bourse et inférieure au prix d'achat. En Italie, une valeur au remboursement supérieure au cours de bourse peut être retenue dans ce même cas au lieu du prix d'achat même si la valeur de remboursement est supérieure au prix d'achat.

En France et dans une certaine mesure en Italie aussi, les assureurs sont ainsi en position de masquer des moins-values qui, dans les autres pays étudiés, viendraient en déduction des actifs nets admis en couverture de la marge.

Au Royaume-Uni, l'ancienne disposition qui permettait d'amortir la différence entre une valeur du marché, plus basse, et la valeur de remboursement, en tenant compte du nombre d'années restant à courir avant l'échéance, a été abrogée.

Par ailleurs, en ce qui concerne la compensation de moins-values par des plusvalues explicites, les assureurs belges et allemands sont pour leur part désavantagés par rapport à ceux des autres pays étudiés. En Belgique, la compensation n'est pas autorisée. En R.F. d'Allemagne, la différence entre plus-values et moins-values se fait poste par poste, ligne par ligne, de sorte que des plus-values sur actions, par exemple, ne peuvent servir à couvrir des moins-values sur immeubles. De telles moins-values doivent être supportées par les résultats d'exploitation ${ }^{39}$, alors que les plus-values nettes sur actions ne sont pas prises en considération par le bilan commercial (ceci en conformité avec le principe d'estimation au plus bas des deux valeurs prix d'achat / valeur du marché et le principe de la compensation ligne par ligne).

On remarquera néanmoins qu'au cas où les actifs nets, tels qu'ils ressortent des comptes annuels publiés, seraient insuffisants pour couvrir la marge de solvabilité, l'entreprise allemande ou belge - comme toute autre entreprise communautaire peut, à sa demande et avec l'autorisation des autorités de surveillance, faire valoir l'ensemble des plus-values nettes qui ne ressortiraient pas des comptes annuels (celles

39 Une provision pour dépréciation étant alors alimentée par le débit du compte de Profits et Pertes. 
sur actions dans notre exemple) pour justifier de sa solvabilité. Le principe de la compensation ligne par ligne n'annihile pas ainsi des plus-values dans le cas où ces dernières sont nécessaires pour faire état de la marge réglementaire. Dans la pratique, la circulaire du 6 juillet 1978 des autorités de surveillance allemandes indique néanmoins que les réserves latentes - les plus-values en question en étant un exemple typique - ne peuvent être admises comme élément constitutif de la marge qu'à titre exceptionnel.

$\mathrm{Si}$, fondamentalement, les assureurs allemands et belges ne devraient pas être moins bien traités sur ce point que leurs autres concurrents de la $\mathrm{CE}$, les dispositions réglementaires nationales leur sont toutefois défavorables pour le moment. Il convient par ailleurs de relever la position privilégiée des assureurs français et, dans une moindre mesure, italiens pour masquer des moins-values par rapport à la valeur du marché. Les assureurs hollandais bénéficient aussi de certains avantages puisque les moins-values sur actifs ne viennent pas en déduction des résultats de l'exercice aussi longtemps qu'elles ne sont pas réalisées et qu'elles peuvent être absorbées par une réserve pour risques en matière de placements.

\subsubsection{Conditions de prise en compte}

Les plus-values au sens strict de la directive et qui correspondent à des réserves cachées sont soumises à des conditions diverses selon les pays pour leur prise en compte par les autorités de surveillance.

Au Royaume-Uni, par exemple, les correctifs au bilan sont établis sur simple déclaration avec des justificatifs à l'appui, tels rapports d'expertise, indice des prix à la construction, etc. Il n'est pas nécessaire de montrer que la marge de solvabilité ne serait pas couverte s'il n'était pas fait état des réserves cachées.

En France et en Italie, au contraire, une demande spéciale - motivée par de telles circonstances - doit être faite par l'assureur auprès de l'autorité de surveillance pour que soient prises en compte des plus-values résultant de la sous-estimation délibérée des valeurs publiées.

En R.F. d'Allemagne, ainsi qu'on vient de le voir, même par demande spéciale, les plus-values au sens strict de la directive ne sont considérées que dans des cas particuliers et à titre exceptionnel.

Indépendamment des différences administratives, les conséquences fiscales de la déclaration de réserves cachées peuvent amener l'assureur à renoncer à en faire état suivant le pays où les contrôles sont exercés.

Dans les pays où, comme au Royaume-Uni, il y a une séparation stricte entre le contrôle financier et le contrôle fiscal, l'assureur se sent libre de faire état de ses réserves cachées. Il en est de même de l'assureur hollandais pour qui le bilan commercial est distinct du bilan fiscal.

Les conditions sont différentes dans d'autres pays, comme la France et l'Italie, où les déclarations faites à l'autorité de surveillance peuvent être communiquées aussi à l'autorité fiscale. Cette communication n'entraîne pas en principe d'imposition puisque, dans les pays étudiés, les plus-values comptables sont traitées en général en suspension fiscale. Elle peut toutefois entraîner un réexamen des déclarations fiscales antérieures. Sans vouloir entrer dans ce domaine, qui devrait être traité à notre connaissance dans 
une étude du CEA, on se contentera de relever ici qu'en raison de conditions à la fois administratives et fiscales, les assureurs français et italiens peuvent être enclins à s'abstenir de faire état de plus-values, bien que ces dernières puissent leur être nécessaires pour justifier l'existence de la marge réglementaire. Il n'y a pas de disparités objectives à proprement parler, mais seulement des conditions qui commandent un comportement différent de l'assureur; on peut parler de disparités en quelque sorte subjectives à son encontre.

\section{Plus-values résultant de la surestimation de passifs}

Les plus-values résultant de la surestimation de passifs se définissent comme la différence positive entre le montant inscrit au bilan et le montant résultant d'une évaluation sur des bases commerciales raisonnables, ce dernier montant étant moins élevé que celui inscrit au bilan.

En l'absence le plus souvent de règles aussi précises que pour l'estimation des actifs, il est difficile d'apprécier les différences de régime et d'usage pouvant exister entre Etats membres pour évaluer les provisions techniques.

\subsection{Provisions pour sinistres}

Cette remarque vaut en particulier pour les provisions pour sinistres (qu'il s'agisse des sinistres déclarés à payer, des sinistres en cours de règlement ou des sinistres survenus mais non déclarés). Il paraît difficile, même si des aménagements existent, de faire état de plus-values sur provisions pour sinistres en comparant des évaluations qui, notamment après liquidation de la provision, peuvent montrer que dans le passé cette dernière a été supérieure à ce qui a été nécessaire (boni) ${ }^{40}$. Les provisions pour sinistres non déclarés mais survenus étant estimées statistiquement, des plus-values latentes existent lorsque, par exemple, d'anciennes statistiques sont utilisées alors que de plus récentes tendent à montrer que l'importance de ces sinistres a diminué. Cette situation assez particulière ne paraît toutefois pas donner lieu à des traitements différents selon les pays étudiés. D'ailleurs, même si des autorités de surveillance prenaient en considération ces réserves latentes alors que d'autres ne le feraient pas, il est plus que probable que les plus-values correspondantes - au cas où elles existeraient disparaîtraient à partir du moment où l'entreprise rencontrerait des difficultés pour couvrir sa marge.

\subsection{Provisions pour primes}

\subsubsection{Source de disparités}

Les provisions de primes pour risques en cours ne peuvent donner lieu à des plusvalues que pour autant que ces risques, au lieu d'être évalués selon la méthode " contrat par contrat », sont calculés par un pourcentage déterminé par rapport aux primes.

$40 \mathrm{Par}$ contre, une succession de mali sur les provisions pour sinistres peuvent bien indiquer une sous-estimation des passifs commandant un examen plus approfondi des éléments de la marge. 
Aux termes de la directive (article 16, paragraphe 1, dernier alinéa), seulement les $75 \%$ de la différence entre la provision pour risque en cours calculés forfaitairement par application d'un pourcentage minimum et le montant de celle qui aurait été obtenue par un calcul contrat par contrat peuvent être admis comme plus-values, et ce pour autant que ces dernières ne dépassent pas $20 \%$ de la marge de solvabilité réglementaire.

Des disparités peuvent provenir du fait que certains pays n'admettraient pas des plus-values de ce type (France, Royaume-Uni). Par ailleurs, l'admission de ces plusvalues dans d'autres poserait des problèmes par rapport à une situation antérieure (Italie, Royaume-Uni).

\subsubsection{Contenu et portée des disparités}

En France, le minimum fixé par le Code des Assurances pour le montant forfaitaire est de $36 \%$ des primes. Quant à elles, les autorités fiscales acceptent $42 \%$ au maximum. Il est d'usage que les entreprises saines inscrivent au bilan le montant correspondant au maximum fiscal. Les autorités de surveillance françaises ne permettraient pas de prendre en compte, pour le calcul de la marge, les plus-values latentes qui résultent de la différence entre l'évaluation forfaitaire fiscalement acceptable et l'évaluation qui serait obtenue par la méthode contrat par contrat. Notre interprétation de cette situation est la suivante : les autorités françaises n'acceptent les plus-values sur provisions pour primes dans la mesure indiquée par la directive que pour autant que ces plus-values sont nécessaires pour atteindre la marge réglementaire (et ce en conformité avec le protocole d'accord passé entre les services de contrôle des pays de la $C E$ en 1977). La disparité qui est parfois relevée en la matière resterait ainsi sans conséquences pratiques.

En Italie, la nouvelle loi admet l'estimation forfaitaire des provisions pour risques en cours pour autant qu'elle corresponde aux résultats qui seraient obtenus en appliquant la méthode analytique (Loi No. 295, art. 30, paragraphe 3). Le montant de la provision calculée forfaitairement ne peut être inférieur à $35 \%$ des primes $(40 \%$ pour la responsabilité civile automobile). Or, pour l'ensemble du marché, on estime généralement à $30 \%$ les résultats qu'on obtiendrait avec la méthode analytique ${ }^{41}$. En vertu de la nouvelle loi, nombre d'entreprises italiennes seraient ainsi amenées à augmenter malgré elles leurs provisions pour risques en cours, pour ne pas abandonner la méthode forfaitaire.

Pour l'entreprise, cette augmentation des provisions pour s'adapter à de nouvelles dispositions légales est une charge supplémentaire sans contre-partie. Il n'y aurait de plus-values pour elle que le jour où elle renoncerait à la méthode forfaitaire pour la méthode analytique ou en cas de liquidation.

L'entreprise à solvabilité insuffisante serait amenée quant à elle à devoir renoncer à la méthode forfaitaire et devrait procéder à une estimation contrat par contrat pour

41 BECCHIO, L., et al. : "La nuova legge sulle assicurazioni private contro $i$ danni» in * Capire l'assicurazione, una pubblicazione della Società Assicurazione Industriale », No. 4-5, octobre 1978. 
éviter une surestimation de passifs que les autorités de surveillance se refuseraient à reconnaître comme telle avec la méthode forfaitaire. Il y aurait ainsi différence de traitement entre entreprises solvables et moins solvables.

Pour le fisc, il est difficile de considérer la charge supplémentaire résultant de l'adaptation au taux forfaitaire minimum comme une réduction du bénéfice imposable. Une exemption fiscale au titre d'une réévaluation de bilan n'est d'ailleurs pas applicable, une telle exemption ne pouvant porter que sur des éléments de l'actif.

La solution adoptée par les autorités fiscales italiennes a été la suspension d'impôt, la condition étant toutefois que le bénéfice comptable imposable soit réinvesti dans l'entreprise.

Quant aux autorités de surveillance italiennes, il semble qu'elles attendront l'aboutissement d'un projet de révision de l'article 30, paragraphe 3, avant d'obliger les entreprises concernées à augmenter leurs provisions pour risques en cours.

Ainsi, en Italie, comme en France, les disparités provenant du traitement des provisions pour risques en cours seraient pour le moment sans conséquences pratiques. Une exception doit être toutefois signalée en Italie en matière de contrats pluriannuels. Suivant les branches (par exemple : incendie, vol, grêle, nucléaire) et en période d'inflation rapide, les dispositions restrictives introduites par la nouvelle loi pourraient avoir des implications négatives pour les entreprises italiennes.

$\mathrm{Au}$ Royaume-Uni, on relèvera que le pourcentage maximum de $40 \%$ admis précédemment par les autorités fiscales pour l'estimation forfaitaire des risques en cours a été supprimé. Ces provisions ne devraient plus pouvoir constituer à l'avenir une source de plus-values, la méthode analytique devant être appliquée impérativement. Ces dispositions nouvelles n'affectent pas la justification de la marge ; par contre, elles privent l'entreprise britannique d'une source de financement de la marge en franchise d'impôts.

En Belgique, le calcul forfaitaire de la provision de primes pour risques en cours est admis en prenant comme base les primes diminuées des commissions ; l'administration fiscale est particulièrement libérale : elle admet cette provision pour autant qu'elle n'excède pas $50 \%$ du montant des primes. Par contre, l'autorité de surveillance belge a indiqué sa réticence à prendre en considération des surestimations de passifs - dont notamment les excédents de provisions pour risques en cours - comme éléments constitutifs de la marge.

Aux Pays-Bas, il n'existe pas de règles particulières en matière de provisions de primes pour risques en cours; elles sont calculées pro rata temporis.

D'une façon plus générale, il semble se dessiner dans la $\mathrm{CE}$ une tendance pour supprimer la poche éventuelle de plus-values que peuvent constituer les provisions pour risques en cours ou de ne considérer celles qui sont possibles qu'en cas de besoin.

Par ailleurs, il est important d'avoir à l'esprit que, vu l'importance de l'estimation des provisions techniques pour déterminer les résultats d'exploitation et juger de la solidité d'une entreprise d'assurance, la Commission de la $\mathrm{CE}$ envisage depuis plusieurs années de mettre au point une directive communautaire en la matière. L'harmonisation en matière de provisions techniques devrait singulièrement renforcer l'uniformisation des conditions de la constitution de la marge de solvabilité au sein de la $\mathrm{CE}$. 


\section{3. «Schwankungsrückstellungen » et réserves latentes}

En référence à une période d'observation, les entreprises allemandes sont assujetties à la constitution de provisions additionnelles par branche qui sont proportionnelles aux sinistres payés et aux primes acquises ("Schwankungsrückstellungen»). Une formule de calcul complexe, définie par la directive du 21 septembre 1978, apparente ces provisions à des réserves d'équilibrage. Juridiquement, on peut leur attribuer le caractère de provisions techniques et la part des actifs qui les représente ne devrait pas alors pouvoir être considérée comme un élément constitutif de la marge de solvabilité. D'un point de vue économique, D. Farny ${ }^{42}$ et P. Braess ${ }^{43}$ estiment qu'il s'agit toutefois d'une surestimation de passifs qui commande d'inclure cette part d'actifs dans la marge. $\mathrm{N}$. Konrath ${ }^{44}$ les rejoint en se référant à l'esprit d'harmonisation institué par la directive communautaire et au protocole que les autorités de surveillance sont convenues en 1977 pour y donner suite. Si les actifs en représentation des « Schwankungsrückstellungen » ne pouvaient pas être pris en considération dans la marge comme toute autre réserve légale ou statutaire, les assureurs allemands seraient sur ce point désavantagés par rapport à leurs concurrents des autres pays membres.

Bien que la question reste ouverte, elle est pratiquement résolue par la prise de position de l'autorité de surveillance allemande en matière de réserves latentes.

Dans la circulaire déjà citée du 6 juillet 1978, cette autorité a en effet précisé que «les réserves latentes ne seront considérées comme un élément de la marge de solvabilité que dans des cas particuliers et à titre exceptionnel ». Ceci va à l'encontre de l'esprit de la directive et de l'attitude des autorités de surveillance des autres pays membres. Les entreprises d'assurance non-vie domiciliées en R.F. d'Allemagne seraient ainsi l'objet d'une disparité notoire par rapport à leurs concurrentes européennes.

Cette disparité est toutefois moins tranchée dans la pratique qu'il y paraît au premier abord. Car si toutes les autres autorités de surveillance s'entendent à reconnaître le principe de l'admissibilité des réserves latentes, toutes n'ont pas défini comment l'entreprise peut en faire état (section 4.2.4.). Par ailleurs, on a déjà relevé les différences de traitement entre pays qui existent suivant l'origine des plus-values.

\section{Financement de la marge}

Certains aspects de l'alimentation de la marge ont été traités dans les sections précédentes, notamment :

- les impacts négatifs, pour les entreprises à frais d'exploitation élevés, d'un prélèvement sur la part de l'encaissement qui ne correspond pas à des risques assurés ;

- les à-coups dans l'augmentation de la marge résultant pour les entreprises petites et moyennes de la fluctuation du coefficient réducteur pour tenir compte des affaires cédées en réassurance ;

42 FARNY, D. : "Versicherungsbilanzen », Francfort s/Main 1975, p. 48.

43 BRAESS, P. : «Betriebswirtschaftliche Aspekte der Solvabilitätsvorschriften », dans VW 1969, p. 153.

44 KONRATH, N. : «Solvabilitätsregeln auf dem Prüfstand », dans VW 1979, p. 1509. 
- l'immobilisation de capitaux peu rentables et les risques monétaires y étant attachés qui résultent de dispositions applicables aux succursales étrangères ;

- le supplément de couverture induit par la non-admissibilité de certains actifs en représentation de la marge ;

- la crainte d'être imposé sur des plus-values cachées et ses conséquences pour le maintien de la substance de la marge.

Ces aspects sont toutefois secondaires par rapport aux questions examinées jusqu'ici et qui traitaient plus particulièrement de différences entre entreprises pour faire état d'un niveau satisfaisant de garanties financières.

L'alimentation de la marge pour faire face à l'augmentation requise par le développement des affaires (réel ou seulement nominal suite à l'inflation) est soumise à :

- des conditions d'opérations ;

- des conditions de financement ;

- des conditions économiques générales,

qui peuvent varier suivant les entreprises et les pays. Des disparités peuvent ainsi s'ensuivre, notamment si l'on se place du point de vue du partage du marché européen de l'assurance non-vie. Elles affectent toutes le financement de la marge.

\subsection{Différences de conditions d'opérations}

En plaçant de plus grandes exigences en matière de formation des bénéfices, la marge réglementaire est une incitation supplémentaire à améliorer la gestion technique. Celle-ci est en partie dépendante de conditions extérieures à l'entreprise qui sont différentes selon les pays et les branches. Cela s'applique en particulier aux interventions de l'Etat, qu'il s'agisse de la fixation des taux de prime ou de prélèvements fiscaux sur polices émises.

\subsubsection{Contrôle des taux de prime}

La source de financement la plus évidente de la marge est la prime. Or, la détermination de son montant se fait dans des conditions différentes selon les pays et les branches.

Le Tableau 3 ci-après donne un aperçu général des pays et des branches pour lesquelles des contrôles existent et tendent de ce fait à comprimer les marges bénéficiaires.

$\mathrm{Vu}$ l'importance relative de la branche automobile, les entreprises opérant au Royaume-Uni sont incontestablement dans une situation privilégiée pour reporter sur l'assuré le financement de la marge. Ce pays étant aussi celui, avec la Belgique et les Pays-Bas, où la concurrence est particulièrement vive, cela ne se fera cependant pas sans une certaine tension entre entreprises. Aux Pays-Bas, on relève toutefois depuis récemment une régression de la pratique de dumping qui était pratiqué par certaines compagnies sur ce marché ouvert. 
蹇

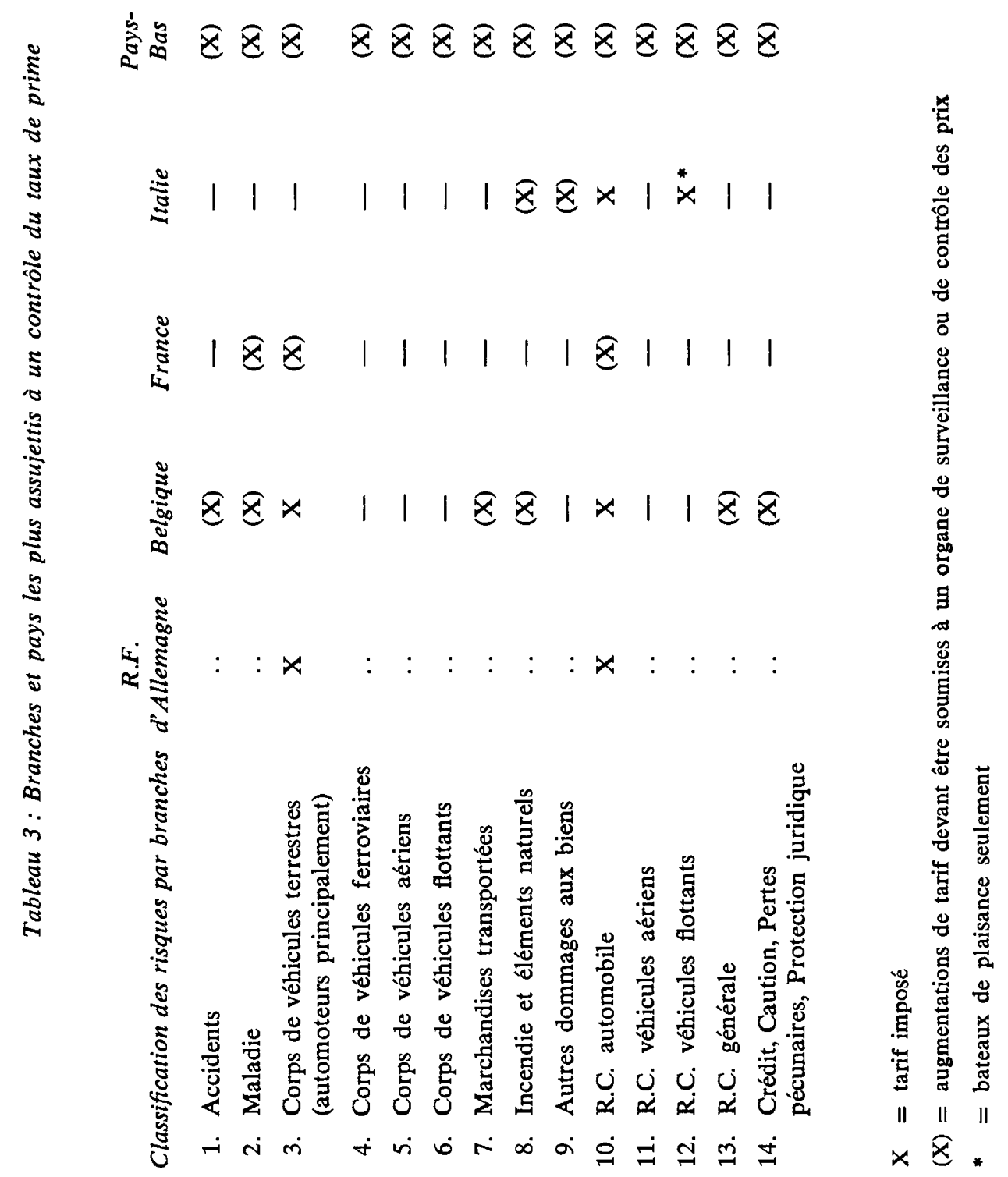




\subsubsection{Taxes sur polices émises}

Les charges fiscales et autres redevances sont déduites des primes brutes pour effectuer le calcul de la marge de la solvabilité. Elles n'en sont pas moins un élément de coût qui limite l'encaissement net. En l'absence d'impôts et de redevances, ou bien le bénéfice avant impôts des entreprises serait plus élevé dans les pays où elles sont les plus importantes, ou bien par un abaissement correspondant des primes la pénétration de l'assurance non-vie serait plus forte, ce qui devrait aussi contribuer à augmenter les profits.

On trouvera en annexe un tableau qui, sur la base d'une publication de la Compagnie de Réassurance Suisse, donne un aperçu des prélèvements sur les polices émises dans les pays étudiés.

On relèvera une fois encore la position privilégiée du Royaume-Uni et dans une moindre mesure des Pays-Bas. La France et l'Italie se situent à l'autre extrémité.

Qu'il s'agisse d'un contrôle exercé par les pouvoirs publics sur les taux de prime ou de prélèvements sur les polices émises, on relèvera que ces conditions sont antérieures à l'introduction de la marge de solvabilité. Les différences qui en résultent entre entreprises pour la formation des profits, donc pour le financement de cette dernière, ne sont pas imputables au nouveau régime. On ne peut toutefois les ignorer quand on sait que l'harmonisation des conditions d'opération sur le territoire de la CE constitue un des éléments permettant d'atténuer les inégalités dans les répercussions économiques d'une disposition réglementaire uniforme, telle la marge.

\subsection{Différences de conditions de financement}

En plaçant une plus grande exigence sur la formation des bénéfices, la marge incite à améliorer la gestion financière au même titre que la gestion technique. Les réglementations en matière de placements, les pratiques touchant les dépôt de réassureurs, l'éventuelle possibilité d'avoir recours à des financements autres que ceux provenant de l'exercice de l'assurance non-vie sont autant de conditions qui peuvent contrarier ou au contraire valoriser les efforts de la compagnie d'assurance pour améliorer ses performances financières, et ce dans une mesure variant suivant les dispositions nationales ou la structure d'organisation de l'entreprise. On considérera séparément (voir section 6.3.) l'incidence des conditions économiques générales sur la constitution des garanties financières désormais exigées.

\subsubsection{Réglementations en matière de placements}

Dans tous les pays étudiés, les autorités de surveillance imposent aux entreprises un certain nombre de règles de placement. Dans les pays où ils existent, les contrôles des changes ajoutent des contraintes supplémentaires.

\subsubsection{Pour les actifs en représentation des provisions techniques}

Ces règles et contraintes visent essentiellement le placement des actifs en représentation des provisions techniques. Elles n'en ont pas moins une signification pour le financement de la marge. Suivant les pays, elles affectent à des degrés divers le rende- 
ment sur le capital immobilisé, notamment lorsque des taux minimums en fonds d'Etat peu rémunérés sont exigés (exemple : en Italie). Par ailleurs, les limitations des placements en valeurs réelles (actions et surtout biens immobiliers) réduisent à des degrés divers aussi le potentiel de plus-values, lesquelles sont particulièrement importantes pour maintenir la substance de la marge en période d'inflation. Au contraire, les assouplissements aux règles de la congruence et de la localisation des actifs en représentation des provisions techniques (exemple : au Royaume-Uni pour les affaires traitées dans des pays tiers) donnent des avantages pour se protéger des risques monétaires encourus par des placements dans des pays à monnaie faible (par un meilleur rendement ou des gains de change sur les actifs transférés).

Dans les pays les plus libéraux en matière de placement, à savoir le Royaume-Uni et les Pays-Bas, des dispositions récentes ou prévues tendent à indiquer que l'on va vers une certaine harmonisation au sein de la $C E{ }^{45}$.

Dans le cas de l'Italie ${ }^{46}$, qui a bénéficié jusqu'ici d'une grande liberté en matière de placements en biens immobiliers (certaines compagnies détiennent jusqu'à 50-80\% de leurs actifs sous cette forme), la situation évolue aussi. Les actifs immobiliers en représentation des provisions techniques constituées au titre de la responsabilité civile automobile devraient être réduits à $35 \%$ du total d'ici à 1985 . Une règle similaire pourrait être introduite pour les autres branches. Dans une recommandation ministérielle de 1977 les entreprises d'assurance étaient instruites de ne pas dépasser un taux de $60 \%$.

En devant réduire leur assiette sur laquelle les compagnies italiennes pouvaient réaliser des gains en capital ou enregistrer des plus-values, le maintien de la substance de la marge va se poser avec une acuité particulière en raison de l'inflation élevée que connaît le pays. D'aucuns estiment toutefois que le cumul des intérêts composés sur les valeurs à revenu fixe devraient pouvoir compenser la diminution des plus-values, beaucoup moins appréciables d'ailleurs depuis quelques années, et surtout le manque à gagner qui a fait suite au déclin du rendement sur immeubles. La démonstration de cette thèse reste toutefois à faire.

En Belgique, les prescriptions en matière de placement ne se rapportent qu'aux provisions techniques. La valeur de l'ensemble des immeubles et des prêts hypothécaires ne peut dépasser $65 \%$ du montant de ces provisions. Le quota maximum pour les actions belges de sociétés existant depuis au moins cinq ans est de $25 \%$ (avec un maximum de $5 \%$ par valeur). Celui pour les valeurs mobilières étrangères cotées auprès d'une bourse agréée est de $25 \%$ également. La valeur des fonds communs de placements ne peut excéder $5 \%$ du montant des provisions techniques.

En France, les provisions techniques ne peuvent pas être couvertes par des biens immobiliers et des actions à raison de plus de $2 / 3$ des engagements. Les immeubles

45 Exemples : au Royaume-Uni, un terrain d'un seul tenant ne peut dépasser $5 \%$ du total des engagements de l'entreprise; pour les actions, un maximum de $21 / 2 \%$ par valeur cotée et de $1 \%$ par valeur non cotée est applicable depuis le 1er mai 1976.

46 L'Italie ne peut être classée dans la catégorie des pays les plus libéraux en raison des entraves constituées par l'obligation de l'inscription des actifs et des difficultés administratives qui en découlent pour opérer des arbitrages entre actifs enregistrés auprès de l'autorité de surveillance. 
proprement dits et les valeurs assimilées (parts et actions de SICOMI, droits immobiliers) ne peuvent pas représenter plus de $40 \%$ des placements réglementés. En matière d'actions, une même valeur ne peut pas représenter plus de $5 \%$ de ces placements.

D'une façon plus générale, l'influence des règles nationales en matière de placement sur la gestion financière de l'entreprise d'assurance devrait être analysée quantitativement en fonction de cas types pour pouvoir mieux apprécier les disparités existantes dans les pays étudiés. Une telle analyse sort du cadre de la présente étude, quoique ses résultats soient importants pour juger objectivement des différences de conditions de financement entre entreprises et identifier celles d'entre elles qui sont en moins bonne position pour alimenter la marge avec tout ou partie de leurs revenus financiers.

\subsubsection{Pour le patrimoine libre}

En conformité avec l'article 18 de la première directive de coordination, les pays membres retenus pour l'étude ne fixent aucune règle concernant le choix des actifs qui dépassent ceux représentant les provisions techniques. Ils ne restreignent pas non plus la libre disposition de ces actifs, à moins d'insuffisance de provisions techniques ou du fonds de garantie. Les remarques précédentes ne s'appliquent donc pas à la gestion du patrimoine libre.

On notera toutefois que tous les pays étudiés ne jouissent pas de fait de la même liberté de placement de leurs fonds propres. Ainsi, en Italie, tout placement à l'étranger est autorisé à la condition qu'un montant égal à $50 \%$ des fonds transférés soit déposé auprès de la Banque d'Italie, et ce à des conditions peu intéressantes qui prohibent pratiquement les investissements hors d'Italie.

En France, il n'y a pas de restrictions figurant au Code des Assurances. Toutefois, le contrôle des changes oblige les compagnies d'assurance à rapatrier chaque année le total de leurs excédents d'actifs à l'étranger, diminué d'une quote-part de $5 \%$ correspondant aux fonds de roulement des comptes en devises ${ }^{47}$. Sur autorisation préalable de la Direction du Trésor, les assureurs français peuvent toutefois effectuer des investissements directs à l'étranger (exemple : création de filiales, augmentation du capital action de ces dernières, etc.).

Au Royaume-Uni, des limites à l'admissibilité de certains actifs en représentation de la marge de solvabilité peuvent théoriquement résulter des pourcentages maximaux admis par rapport au total des affaires traitées par la compagnie.

Paradoxalement, les compagnies suisses qui bénéficient par ailleurs de conditions très libérales pourraient être astreintes à des règles en matière de placement de leurs fonds propres.

En considérant l'ensemble des différentes règles et contraintes en matière de placement auquel sont astreintes les entreprises dans les pays étudiés, il apparaît que les compagnies établies aux Pays-Bas et au Royaume-Uni sont dans une position favorable pour optimiser leur gestion financière, et partant pour alimenter tout ou partie de

47 Comptes pouvant être ouverts par les entreprises d'assurance sur autorisation de la Direction des Assurances en dérogation à la réglementation générale des changes. 
l'augmentation de la marge par leurs revenus financiers. Au contraire, les compagnies établies en France et dans une certaine mesure en Italie sont défavorisées. Seule une étude quantitative sur la base d'hypothèses bien définies permettrait toutefois de préciser ces disparités.

\subsubsection{Pratiques nationales en matière de dépôts par les réassureurs 48}

On a déjà relevé les conséquences indirectes de la représentation au brut des provisions techniques pour sinistres en suspens en Belgique et en France, à savoir la pratique du dépôt par les réassureurs auprès de la société cédante (voir derniers paragraphes de la section 4.2.1., p. 35). En Italie, cette pratique subsiste dans une certaine mesure, mais les dispositions de la nouvelle loi ne la justifient pratiquement plus puisque $90 \%$ des créances sur réassureur sont désormais admises en représentation des provisions techniques calculées au brut.

La pratique du dépôt par le réassureur peut concerner l'alimentation de la marge de la cédante, car ce que le premier perd sur le plan du rendement des placements la seconde peut en tirer parti pour améliorer ses performances financières. Dans la mesure où le réassureur fournit un dépôt pour couvrir sa part dans les provisions techniques de la cédante, cette dernière peut en effet dégager ses propres actifs et alimenter ainsi sa marge de solvabilité. D'un autre côté, les entreprises mixtes, notamment britanniques, pratiquant à la fois des activités non-vie et la réassurance dans les pays mentionnés ne peuvent pas toujours compenser par le prix des traités les conséquences de la diminution du volume de placements qui est attribuable à la pratique du dépôt auprès des cédantes.

En analysant les conséquences financières de la pratique du dépôt, il convient toutefois de faire une distinction entre la France et la Belgique.

En France, le réassureur a le choix des papiers-valeurs déposés; ceux-ci ne sont en effet déposés qu'à titre de gage auprès de l'assureur. L'immatriculation des titres au nom de ce dernier ne lui en confère pas pour autant la propriété économique qui reste celle du réassureur ${ }^{49}$. Le revenu et les plus-values reviennent ainsi au réassureur, à moins d'une convention contraire stipulée dans le traité de réassurance. Les papiersvaleurs déposés par le réassureur étranger peuvent même être libellés dans une autre monnaie que le franc français sous certaines conditions (il peut penser éviter ainsi un risque de change); en pratique le réassureur ne pourra toutefois déposer de telles valeurs qu'avec l'accord de la cédante qui l'obligera le plus souvent à dépendre de son plan de placements en francs français.

A défaut de dépôt de papiers-valeurs, le réassureur peut aussi en France remettre des espèces à la cédante pour l'acquisition par celle-ci de titres pour son propre compte. Bien que ces derniers puissent être immatriculés au nom de la cédante, le réassureur en demeure le propriétaire économique comme dans le cas du transfert direct de titres à la cédante. Dans la pratique, il reste cependant dépendant du plan de placements de la cédante.

48 L'information de base pour traiter de cette question nous a aimablement été communiquée par la Compagnie Suisse de Réassurance. Les déductions qui en sont tirées n'engagent toutefois que les auteurs.

49 PICCARD, M., et BESSON, A. : "Les Assurances terrestres », Tome II, Paris 1977. 
En Belgique, la pratique du dépôt a des répercussions financières plus importantes.

En effet, le réassureur a indirectement l'obligation de faire des dépôts en espèces auprès de la cédante. Cette situation est le résultat de l'interprétation restrictive qui a été donnée à la notion de la «pleine propriété » des actifs représentatifs des provisions au brut ${ }^{50}$; elle a amené les assureurs directs en Belgique à exiger des dépôts en espèces des réassureurs pour leur part à ces provisions.

Une évolution s'est toutefois dessinée quant à la représentativité des créances sur réassureurs. L'article 17, paragraphe 1, de l'Arrêté royal du 12 mars 1976 permet désormais d'établir que, bien que ne figurant pas sur la liste des créances énumérées parmi les valeurs réglementaires, les créances sur réassureurs sont susceptibles d'être acceptées sur proposition des cédantes dans la mesure où elles font l'objet d'une reconnaissance de dette du réassureur, garantie par le nantissement de valeurs déterminées ${ }^{51}$. Les autorités de contrôle belges ont fixé toutefois un plafond à la valeur d'affection de l'ensemble de ces créances : elle ne peut s'élever, par gestion distincte, à plus de la moitié de la quote-part des réassureurs dans les provisions techniques, ni à plus de $30 \%$ du total des provisions brutes $\mathbf{5 2}$.

A part les restrictions dans le choix des placements que la pratique du dépôt des réassureurs impose à ces derniers et aux entreprises mixtes traitant à la fois des affaires directes et des opérations de réassurance pure, il convient aussi de relever les conséquences diverses de la localisation de la quote-part de la réassurance aux provisions techniques, partie dans le pays de la compagnie cédante, partie dans les autres pays de la CE.

Ainsi, pour l'entreprise pratiquant à la fois des affaires directes et la réassurance, la provision technique de réassurance pour des affaires traitées en Italie, par exemple, peut être couverte par des placements en Allemagne ; elle bénéficie ainsi d'une protection relative contre l'érosion monétaire et de gains de change éventuels sur le DM. Cette possibilité n'existant pas pour les affaires traitées en Belgique, les entreprises mixtes spécialisées dans ce marché subissent ainsi un préjudice. Par corollaire, les entreprises traitant des affaires directes sur le marché belge ne peuvent bénéficier de tous les avantages d'une réassurance pouvant effectuer des placements à l'échelle communautaire.

\subsubsection{Financements autres que ceux provenant de l'activité de l'assurance non-vie}

Toute entreprise d'assurance (à l'exclusion des mutuelles) peut en principe compléter ses actifs nets pour atteindre la marge requise en augmentant son capital social. Le recours au marché des capitaux en temps opportun est un des attributs de toute

$50 \mathrm{La}$ loi belge du 9 juillet 1975, article 16, paragraphe 1, alinéa 3, a confirmé cette interprétation restrictive en stipulant : " la part incombant aux réassureurs ne peut être déduite des réserves ou provisions techniques ». Cette même loi impose par le paragraphe 2, alinéa 1, du même article que ces réserves ou provisions soient « représentées à tout moment par des actifs équivalents appartenant en pleine propriété à l'entreprise d'assurances et affectés spécialement à la garantie des obligations (...) afférentes aux contrats souscrits en Belgique... »

51 Rapport du Groupe de Travail constitué par des représentants de l'OCA, de l'UPEA et de réassureurs européens.

52 Communication D.16 de l'Office de Contrôle des Assurances, Bruxelles, 29 mai 1978. 
bonne gestion financière. Il est évident qu'avec ou sans marge réglementaire, les conditions d'accès et de succès sur les places financières sont inégales suivant les entreprises et les marchés nationaux considérés. En imposant une politique de retenue dans la distribution des dividendes, il n'est pas moins évident toutefois que la marge rendra plus difficile aux entreprises les moins prospères les augmentations de capital.

A défaut de pouvoir procéder à ce type d'opération, les entreprises de cette catégorie sont condamnées à la liquidation, à la fusion ou à l'absorption. Cette dernière issue est la plus vraisemblable ${ }^{53}$. Plusieurs compagnies belges d'entre les quelque 300 qui se partagent ce petit marché ont déjà été reprises par des groupes financièrement plus puissants. Dans tous les pays étudiés les concentrations d'entreprises vont être ainsi à l'ordre du jour, si elles ne le sont déjà pour d'autres raisons que l'introduction de la marge réglementaire.

On rappellera qu'il est précisément du ressort des holdings et des konzerns de participer à l'augmentation de capital des sociétés dépendantes. Les groupes multibranches ont ainsi la possibilité d'affecter à la libération d'actions nouvelles de sociétés non-vie tout ou partie des revenus accumulés ou des bénéfices réalisés dans la branche vie ou la réassurance. $\mathrm{La}$ double imposition des profits étant généralement évitée par les législations nationales sur les holdings, ce type d'opération est relativement aisé et avantage incontestablement les sociétés non-vie qui appartiennent à de tels groupes.

Il en est de même des sociétés qui ont des participations croisées, les sociétés sœurs de la branche vie ou de la réassurance pouvant venir soutenir financièrement les entreprises non-vie en quête de garanties financières additionnelles. En France, on cite le cas d'entreprises nationalisées de la branche vie qui ont procédé à cette fin à l'augmentation du capital social des sociétés sœurs non-vie, l'Etat-actionnaire n'ayant pas été disposé à faire de nouveaux apports.

Les appuis financiers entre sociétés d'un même groupe peuvent sous certaines conditions aussi s'effectuer entre branches d'une même entreprise, précisément pour faciliter la constitution de la marge pour les branches dommages par des apports des des branches vie ou réassurance. Ainsi les entreprises mixtes existantes, pratiquant les branches vie et non-vie, ont la possibilité de transférer des bénéfices sous certaines conditions et de financer par ce biais leur marge de solvabilité non-vie. Elles sont aussi autorisées à utiliser la réserve non-zillmérisation (hors impôt) pour constituer la marge non-vie.

On attirera toutefois l'attention sur le fait que, dans les conditions actuelles, la possibilité de financement de la marge par les activités non-dommages n'existe pas dans tous les pays en raison d'exigences en matière de spécialisation. On rappellera que la spécialisation était exigée jusqu'ici dans trois des six pays étudiés, à savoir la R.F. d'Allemagne, la France et les Pays-Bas (en Allemagne, il y a toutefois une exception puisque quelque 5 entreprises dommages pratiquent aussi l'assurance-vie). La directive sur l'assurance-vie 54 introduit par ailleurs la spécialisation pour toutes entreprises

53 Encore qu'en théorie les entreprises petites et moyennes aient intérêt à fusionner pour minimiser la marge calculée au taux de $18 \%$ des primes et maximiser celle à $16 \%$.

54 Adoptée par le Conseil le 5 mars 1979 et publiée au J.O.C.E. du 13 mars 1979 (Réf. L 63). 
nouvelles sur l'ensemble du territoire de la $\mathrm{CE}$ tout en maintenant les multibranches existantes pour les pays qui le souhaitent.

$\mathrm{Au}$ Royaume-Uni, les transferts au bénéfice de la branche non-vie pouvaient jusqu'à récemment s'effectuer, après alimentation des réserves mathématiques des opérations vie, au travers du compte de pertes et profits global soumis à l'approbation de l'Assemblée générale.

En Italie, le transfert de bénéfices non distribués est toujours possible dans des conditions similaires. Le transfert de réserves déjà affectées à la branche vie est par contre plus délicat en raison de l'étanchéité de la comptabilité entre la branche vie et les branches non-vie.

Selon d'aucuns, le financement de la marge de solvabilité non-vie par la branche vie selon les différentes formules esquissées ici ne devrait toutefois constituer qu'une disparité passagère entre des entreprises concurrentes qui exercent des activités plus ou moins étendues. L'adoption de la directive vie, instituant aussi une marge de solvabilité pour cette branche, devrait en effet avoir pour conséquence de réduire, sinon d'empêcher, les transferts d'une branche à l'autre. L'assurance vie devra à son tour faire état d'un niveau de fonds propres suffisant, et ce à partir de 1981 55. Par ailleurs, de nouvelles sociétés vie / non-vie ne pourront plus être créées. Une disparité entre les sociétés mixtes existantes et les sociétés non-vie simples subsistera néanmoins du fait de la plus grande facilité à financer la marge de solvabilité des branches vie.

Les entreprises mixtes existantes, pratiquant de surcroît la réassurance, sont en meilleure position pour conserver les avantages d'une profitabilité plus élevée. On rappellera toutefois que ces entreprises qui ne traitent pas les affaires de réassurance par des sociétés sœurs doivent aussi constituer la marge sur leurs affaires de réassurance, le montant des primes acceptées en réassurance étant ajouté aux primes émises dans les affaires directes.

Quant aux entreprises non-vie appartenant à des groupes pratiquant la réassurance au travers de sociétés distinctes, elles resteront au bénéfice de transferts possibles de la part de ces dernières aussi longtemps que les compagnies de réassurance échapperont à la marge et à une réglementation rigoureuse. La question du contrôle financier des entreprises de réassurance est fort controversée. La disparité entre les entreprises nonvie appartenant à ces groupes et les autres pourrait bien avoir ainsi un caractère durable.

On relèvera toutefois que les compagnies de réassurance établies au Royaume-Uni doivent présenter des garanties financières minimales. Les groupes qui y sont établis ne semblent toutefois pas s'estimer discriminés, les exigences étant bien en deçà de leur puissance financière. Ils restent ainsi en mesure de financer la marge des sociétés non-vie le cas échéant.

D'une façon générale, les entreprises non-vie liées organiquement à des entités pratiquant la branche vie et la réassurance disposent d'un atout additionnel pour faire face aux exigences de solvabilité. Les réglementations nationales existantes ne créent pas de disparités majeures qui s'y ajouteraient.

5530 mois à compter du 5 mars 1979. 


\subsection{Différences de conditions économiques générales}

Beaucoup de facteurs extérieurs affectent la capacité bénéficiaire de l'entreprise d'assurance et, par conséquent, l'alimentation de la marge. On a déjà considéré les interventions gouvernementales en matière de tarification des primes, de taxes sur polices émises et d'orientation des placements. D'autres aspects spécifiques des conditions du financement ont été aussi évoqués.

$\mathrm{Au}$ plan des conditions générales, on considérera le problème et les différences nationales quant à la rémunération du capital. On s'attachera ensuite aux conséquences des taux d'inflation. On ne refermera le dossier des aspects économiques généraux qu'après avoir donné un bref aperçu de l'incidence des taux de change et de la fiscalité.

\subsubsection{Rémunération des placements}

L'obligation pour l'entreprise d'assurance d'augmenter ses bénéfices en conséquence de l'introduction de la marge intervient à une époque où à la fois les soldes techniques des opérations d'assurances 56 et la rémunération du capital tendent à fléchir.

On se bornera ici à citer quelques résultats issus de nombreux relevés statistiques effectués par les commissions préparatoires du $\mathrm{X}^{\mathrm{e}}$ Congrès de la Fédération Européenne des Associations d'Analystes Financiers (FEAAF), tenu à Bruxelles en octobre 1978. Ces résultats traduisent bien les tendances et les différences entre pays.

A titre de premier indicateur, la rentabilité des fonds propres des sociétés privées, dûment corrigée des incidences de l'inflation, fait ressortir la différence de situation entre l'Italie et la Belgique, d'une part, et la R.F. d'Allemagne, d'autre part.

Tableau 4: Rentabilité des fonds propres des sociétés privées 57 (en \%)

$\begin{array}{lrrrrrr}\text { Pays } & 1966 & 1968 & 1970 & 1972 & 1974 & 1975 \\ \text { Allemagne fédérale } & 16,4 & 17,6 & 16,7 & 13,2 & 9,4 & 9,4 \\ \text { France } & 4,0 & 4,3 & 4,6 & 4,5 & 4,0 & 3,0 \\ \text { Italie } & 8,6 & 8,7 & 6,4 & 7,3 & 3,2 & 2,0 \\ \text { Pays-Bas } & 3,3 & 7,1 & 6,3 & 5,4 & 4,6 & 2,9 \\ \text { Belgique } & 5,0 & 4,0 & 4,5 & 5,3 & 4,3 & 1,7 \\ \text { Suisse } & - & - & 9,3 & 6,7 & 4,5 & 2,8\end{array}$

Source : FEAAF, cité par PECLARD, M. : « La crise du capital risque » dans le Mois Economique et Financier, Société de Banque Suisse, 1979/3.

56 Sur cette importante question, voir, par exemple: LEGRAND, G. : «Réflexions sur la marge de solvabilité et son application dans le marché français », dans l'Argus, 15 septembre 1978.

57 Calculée sur la base des bénéfices nets publiés, après déduction du surcroît d'amortissement, et des fonds propres inflatés. 
Du point de vue tant du maintien de la substance de la marge que de son alimentation, le critère le plus important est le rendement global en performance financière intégrée comprenant :

- le revenu en intérêts et dividendes ;

- la variation du principal ou montant investi ;

- les gains ou pertes réalisés lors de la vente d'actifs.

Au cours des quinze dernières années (1961-76), la performance financière intégrée, en termes réels, a été souvent négative, les revenus cumulés et la variation du capital investi n'ayant pas compensé l'érosion monétaire.

\section{Tableau 5 : Performance intégrée moyenne (ou "return») en termes réels entre 1961 et 1976}

Actions

Fonds d'Etat

Pays

Allemagne fédérale en \% du capital investi

France 2,2 3,5

Italie

$$
-0,2
$$

Pays-Bas

$$
-7,7
$$

Belgique

$-0,9$

$-2,0$

Suisse

$-0,8$

1,6

$$
-0,7
$$

Source : loc. cit.

Sur la base de ces chiffres, il est évident que l'Italie et, dans une certaine mesure, les Pays-Bas ont offert des conditions de placements particulièrement désavantageuses par rapport à des pays telle par exemple la R.F. d'Allemagne ou même la France. Les entreprises d'assurance opérant dans le premier groupe de pays et y investissant leurs fonds propres sont ainsi défavorisées par rapport au second pour alimenter la marge et maintenir la substance réelle de celle-ci au cours des années.

\subsubsection{Conséquences des taux d'inflation}

Cette situation sur le plan de la rémunération des capitaux est d'autant plus préoccupante que ce sont souvent les entreprises opérant dans les mêmes pays qui se trouvent dans l'obligation de renforcer l'alimentation de leur marge du fait de l'inflation.

En référence à ce qui a été mentionné à propos du calcul de la marge sur la base des primes (voir section 2.1.2.), il convient d'apprécier ici le problème issu du fait qu'il existe des pays à inflation forte et des pays à inflation faible.

Reprenons un exemple déjà discuté dans les milieux professionels de l'assurance ${ }^{58}$. Supposons que l'industrie de l'assurance progresse à l'avenir à un taux annuel de $5 \%$ en termes réels, soit une progression vraisemblablement plus forte que l'éco-

58 Voir PLESCOFF, G., op. cit. 
nomie en général. Admettons par ailleurs par simplification que la marge se calcule sur la base des primes seulement et au taux de $16 \%$. Cela signifie qu'il faut trouver $16 \%$ des $5 \%$ de l'augmentation d'encaissement, soit $0,8 \%$ après impôt correspondant à un profit de $1,6 \%$ avant impôt par rapport aux primes encaissées pour doter simplement le supplément de marge requis. C'est difficile à supporter, car dans peu d'Etats membres on obtient des marges de profit qui dépassent en moyenne $2 \%-2,5 \%$ des primes.

Dans les pays où l'inflation est forte, l'accroissement annuel moyen peut facilement atteindre $15 \%$ à prix courants (pour la même expansion de $5 \%$ en termes réels retenue ci-dessus). La marge requise est alors de $16 \%$ de $15 \%$, soit $2,4 \%$ après impôt ou 4,8\% avant impôt. Cela paraît excéder nettement la capacité bénéficiaire de l'entreprise moyenne.

Même si la progression des affaires en termes réels était stoppée dans les pays à inflation forte, l'entreprise devrait accroître la valeur nominale de ses actifs nets en couverture de la marge, et ce dans la proportion de $16 \%$ de $10 \%$ de l'encaissement total, soit 1,6\% après impôt ou 3,2 \% avant impôt par rapport aux primes émises.

Les chiffres associés à ces trois cas de figure - croissance de $5 \%$ sans inflation / avec inflation et croissance $0 \%$ avec inflation - ont le mérite d'attirer l'attention, et sur les exigences de l'expansion, et sur celles de l'inflation.

Pour la compagnie qui n'a pas de capacité excédentaire, il est évident que, pour chaque encaissement additionnel de fr. 100.-, 16.- après impôt ou 32.- avant impôt doivent être trouvés pour augmenter sa part de marché. La réassurance permet de réduire ces montants au maximum de moitié si les sinistres nets atteignent $50 \%$ des dommages payés, ce qui demeure néanmoins considérable. L'entreprise d'assurance est ainsi incitée à obtenir une meilleur performance en revenu et capital de ses placements et/ou d'avoir recours à l'augmentation de son capital social. A défaut, et si les conditions de concurrence le permettent, elle peut aussi essayer de reporter sur le preneur d'assurance l'augmentation de marge impliquée par l'accroissement de ses affaires. En reprenant le premier cas de figure d'une expansion de $5 \%$ sans inflation, on a :

- Primes encaissées durant l'année $\mathrm{t}-1$ 2000

Accroissement de $5 \%$ en l'année $\mathrm{t}$ 100.-

- Marge existante en $\mathrm{t}-1(16 \%)$ 320.Marge requise en $\mathrm{t}(16 \%$ de 2 100.-)

- Bénéfice avant impôt pour augmenter la marge de 16.soit :

Augmentation des primes pour alimenter la marge

$(32: 2100) \times 100=$

En intégrant l'inflation, on obtient le résultat suivant :

(Primes encaissées en l'année $\mathrm{t}-1$

- Primes ajustées à l'inflation de $10 \%$ en $\mathbf{t}$ 
- Marge existante en $\mathrm{t}-1(16 \%)$

soit :

Augmentation des primes pour alimenter la marge

(en sus de l'inflation) : $(99,20: 2310) \times 100=$

Augmentation des primes par rapport à l'année précédente

Ces calculs simplifiés ne constituent que des ordres de grandeur, car les augmentations de primes pour financer la marge additionnelle requièrent également une alimentation de cette dernière.

Par ailleurs, le second calcul fait clairement apparaître que la valeur des actifs en représentation de la marge est supposée ne pas avoir augmenté en valeur nominale, ce qui signifie qu'en raison de l'inflation ils se sont dépréciés. D'où la hausse des primes nettement plus élevée que dans le premier calcul, en référence toutefois à cette hypothèse extrême.

En période de croissance $0 \%$ et d'inflation, il est évident que la marge fait problème dans la mesure où la valeur des actifs nets n'augmente pas au même rythme que la hausse des prix. Similairement, si les charges et les dommages augmentent plus rapidement que les primes du fait de l'inflation ou des distorsions des taux de change, le revenu des primes est dès lors insuffisant comme source unique d'alimentation de la marge. M. Harvey attribue en partie à cette évolution les augmentations significatives de capital et les réorganisations qui ont eu lieu en Grande-Bretagne au cours de la période $1974-76^{59}$.

D’une manière générale, vu son importance, la gestion des placements mériterait une analyse quantitative beaucoup plus approfondie pour juger des problèmes de l'incidence de l'inflation sur le financement de la marge déjà constituée. Les quelques considérations faites ici montrent qu'on ne peut dissocier le taux d'inflation des performances globales de la gestion financière de l'entreprise en termes nominaux. A cela s'ajoute la prise en compte de l'allocation des résultats de cette gestion. Il est évident que si le rendement sur les actifs placés en couverture des engagements techniques est déjà déduit du coût des risques assurés - ainsi que cela se pratique en Italie dans la tarification de l'assurance responsabilité automobile - cette ressource financière ne peut être affectée à la revalorisation de la marge dans les pays à inflation forte.

En résumé, les entreprises opérant dans des pays à inflation forte sont défavorisées dans la mesure où :

(i) la gestion financière ne permet pas une revalorisation suffisante des actifs en couverture de la marge correspondant au volume d'affaires existant (en raison de taux d'intérêts inférieurs à l'inflation, de plus-values décevantes sur valeurs réelles, de moins-values sur titres à revenus fixes, etc.) ;

59 HARVEY, M. : \& Solvency Margins - A Question of Balance », dans The Review, 30 novembre 1979. 
(ii) tout ou partie du « return » sur les actifs en couverture des provisions techniques doit être affecté à combler des pertes sur les opérations techniques (en raison notamment d'une augmentation des sinistres plus rapide que la hausse possible des primes) ;

(iii) la tarification des primes (du fait de l'intervention des pouvoirs publics ou d'une concurrence exacerbée) ne permet pas de procéder aux hausses de prime requises pour l'alimentation de la marge supplémentaire qu'implique la progression des affaires.

On relève parfois que les assureurs ayant leur siège dans des pays tiers sont favorisés dans de telles circonstances puisqu'ils n'ont à constituer une marge que pour les affaires traitées sur le territoire de la $\mathrm{CE}$. Toutefois, si ces mêmes assureurs opèrent par le biais d'une filiale communautaire ils sont mis sur pied d'égalité avec toute autre entreprise nationale ayant un même champ d'activité. Si la filiale ou la succursale traite les mêmes volumes d'affaires dans un seul et même pays, le montant de la marge est identique. Il n'y a donc pas de traitement de faveur dans ce cas, contrairement à ce qu'on a pu avancer.

Par contre, il convient de relever les avantages - par rapport à une entreprise cantonnée au territoire national - des entreprises transnationales et qui peuvent, le cas échéant, atténuer les effets négatifs rencontrés dans un pays à inflation forte en optimisant leur gestion financière sur un plan international.

\subsubsection{Incidence des taux de change}

A une époque qui connaît de fortes fluctuations des taux de change, les monnaies dans lesquelles sont libellées les actifs en couverture de la marge ne sont pas indifférentes pour le maintien de la substance de cette dernière. La question pourrait être toutefois ramenée à celle des pays à inflations différentes s'il y avait une évolution parallèle entre dépréciation monétaire et baisse du taux de change. Les quelques indices des taux de change effectifs en termes réels du Tableau 6 montrent néanmoins que cela n'a guère été le cas dans les pays étudiés au cours de ces dernières années.

\section{Tableau 6: Taux de change effectifs en termes réels*} (mars $1973=100$ )

$\begin{array}{lrrrrr}\text { Pays } & 1975 & 1976 & 1977 & 1978 & 1979 \\ \text { R.F. d'Allemagne } & 100,5 & 101,2 & 102,5 & 103,3 & 104,1 \\ \text { Belgique } & 98,0 & 97,9 & 99,7 & 99,6 & 97,1 \\ \text { France } & 102,5 & 100,0 & 96,1 & 96,7 & 98,9 \\ \text { Italie } & 97,8 & 92,6 & 95,5 & 93,8 & 93,4 \\ \text { Pays-Bas } & 100,0 & 101,8 & 103,8 & 103,6 & 100,3 \\ \text { Royaume-Uni } & 104,4 & 96,6 & 101,5 & 106,3 & 118,4 \\ \text { Suisse } & 104,4 & 110,8 & 105,2 & 121,7 & 115,2 \\ \text { Etats-Unis } & 98,6 & 100,1 & 99,8 & 95,2 & 95,2\end{array}$

* Taux de change nominal ajusté par les différences d'inflation mesurées par l'indice des prix de gros des produits non alimentaires.

Source: Morgan Guaranty Trust Company of New York: "World Financial Markets», January 1980. 
Il est évident que les groupes transnationaux opérant dans des pays à inflation forte ont pu atténuer les effets de celle-ci sur la gestion financière en opérant des placements dans des pays comme l'Allemagne ou le Royaume-Uni, et a fortiori la Suisse si ils y sont parvenus au travers d'interdictions prises à l'égard des non-résidents. Il n'est pas moins manifeste que les groupes allemands ou britanniques qui ont pu rapatrier les bénéfices obtenus sur les marchés des autres pays étudiés ont joui d'un avantage pour revaloriser par la simple appréciation du taux de change la part de marge nécessaire à la poursuite de leurs activités dans ces autres pays.

Les entreprises mixtes pratiquant des affaires directes non-vie et la réassurance sur un plan international ont pu également faire des bénéfices de change non négligeables sur leurs traités de réassurance, payant le cas échéant leur part de sinistres en monnaie dépréciée par rapport à celle choisie pour les actifs placés en couverture des provisions techniques (pour autant bien sûr qu'elle n'ait pas été soumise à l'obligation de dépôt auprès de la cédante ${ }^{60}$ ).

Il est important d'indiquer que les avantages offerts par les fluctuations de taux de change ont pu aussi se retourner contre les transnationales de l'assurance lorsque leurs anticipations ont été déjouées.

On relèvera par ailleurs que, sous l'angle des taux de change, les entreprises de pays tiers comme la Suisse auraient été désavantagées par l'obligation qu'il leur est faite désormais de constituer une marge de solvabilité partie en monnaie du pays d'exercice, partie en monnaie des autres Etats membres de la $\mathrm{CE}{ }^{61}$. Bien que le taux de change du dollar se soit déprécié plus fortement que celui des autres monnaies européennes, des assureurs américains se sont exprimés négativement sur les risques monétaires accrus découlant de l'introduction de la marge de solvabilité pour les pays tiers ${ }^{62}$.

\subsubsection{Aspects fiscaux}

Les quelques calculs présentés à la section 6.3.2. ont mis en évidence l'incidence fiscale sur l'alimentation de la marge. Par ailleurs, la gestion financière dont on a relevé l'importance pour le maintien de la substance de la marge recouvre aussi des aspects fiscaux. Or, qu'il s'agisse de l'imposition du revenu d'exploitation ou de l'impact de la fiscalité sur la gestion financière, les conditions diffèrent de pays à pays.

Nous ne prétendrons pas traiter ici à fond des disparités d'origine fiscale, aussi importantes soient-elles. Il y a deux raisons à cela : d'une part, le droit fiscal comparé est affaires d'experts ; d'autre part, le Comité Européen des Assurances a constitué un sous-groupe de travail pour en traiter, et ce en relation avec l'introduction de la marge.

\subsubsection{Imposition du revenu d'exploitation}

Les entreprises d'assurance, comme toute autre société, sont astreintes à l'imposition sur les bénéfices. Si dans la plupart des pays étudiés, le taux se situe aux alentours

\footnotetext{
60 Voir supra, p. 50 et ss.

61 Voir supra, p. 20 et 28.

62 MANTON, E.A.G. : "Solvency Requirements », dans International Insurance Monitor,
} janvier 1977. 
de $50 \%$, les quelques pourcentages de différence ne sont pas indifférents si on se réfère aux difficultés précédemment évoquées pour alimenter la marge correspondant à une progression normale des affaires et pour protéger les fonds propres accumulés contre l'érosion monétaire ou les aléas des taux de change. Par ailleurs, les taux en R.F. d'Allemagne et en Italie sont nettement plus favorables, ainsi que le montrent les taux d'imposition des bénéfices dans les pays étudiés (1979):

$\begin{array}{lll}\text { - R.F. d'Allemagne : } & 36 \% \\ \text { - Belgique } & : & 48 \%^{*} \\ \text { - France } & : & 50 \% \\ \text { - Italie } & : & 40 \%{ }^{* *} \\ \text { - Pays-Bas } & : & 48 \% \\ \text { - Royaume-Uni } & : & 52 \%\end{array}$

* taux réduit à $33 \%$ pour un bénéfice imposable inférieure à fr. b. 1 million, à $40 \%$ pour un bénéfice entre fr. b. 1,7 et 3 millions, et majoré de $10 \%$ pour les bénéfices dépassant la moyenne des exercices de 1972 à 1974. D'autres dispositions portent à $56.8 \%$ l'impôt pour les entreprises dont le bénéfice est supérieur à fr. b. 100 millions et à une croissance de plus de $6 \%$ par an.

** $25 \%$ sur les bénéfices de toute provenance, plus $15 \%$ sur les bénéfices réalisés en Italie.

Contrairement aux remarques faites à plusieurs reprises au sujet de l'Italie, ce pays se signale sous l'angle fiscal par une position nettement plus avantageuse, notamment par rapport au Royaume-Uni.

Ce bref aperçu ne donne toutefois qu'une indication approximative. Les déductions et suspensions fiscales d'éléments du revenu d'exploitation varient de pays à pays.

\subsubsection{Taxes se répercutant sur les résultats de la gestion des placements}

Cette dernière remarque vaut en particulier pour les moins-values comptables sur actifs, selon qu'elles sont déductibles ou non du revenu d'exploitation.

D'une façon plus spécifique, le traitement fiscal des valeurs réelles (actions et biens immobiliers) mériterait une attention plus particulière. Ainsi en France, les gains provenant de la vente de valeurs réelles deux ans après leur acquisition sont imposables au taux de $15 \%$ au lieu de $50 \%$ (à condition toutefois que ces gains soient réinvestis dans l'entreprise) ${ }^{63}$. En Belgique, la moitié du bénéfice réalisé sur des actifs acquis avant 1950 est exemptée d'impôts sous certaines conditions; les gains réalisés sur des immeubles et autres éléments figurant au moins 5 ans dans le patrimoine sont taxés à la moitié du taux normal. Au Royaume-Uni, une distinction est faite entre les valeurs réelles détenues à titre de placement et celles constituant des immobilisations (exemple :

$63 \mathrm{Ce}$ taux est de $25 \%$ pour les terrains à bâtir. Le réinvestissement dans l'entreprise s'effectue de la façon suivante: les gains nets réalisés sont portés au crédit d'un compte spécial figurant au passif du bilan sous le titre « réserve spéciale de plus-values à long terme »; ce compte ne peut être utilisé que pour augmenter le capital. 
bâtiments abritant les bureaux de l'entreprise). Dans ce dernier cas, l'impốt sur les bénéfices est réduit à $30 \%$.

Par ailleurs, aussi longtemps qu'il n'y a pas réalisation, les plus-values sur immeubles ne sont en principe pas taxables. Elles sont tout au plus traitées en suspension d'impôt. Lors de réévaluations de bilans, ces plus-values ont été parfois taxées suivant les périodes et les pays qui appliquent cette pratique (Belgique, France, Italie). En Italie, on fait état d'une imposition de $15 \%$ sur les plus-values durables qui seraient affectées indirectement à des distributions de profits.

Les quelques sources de disparité ici relevées ne constituent toutefois que des approximations. Vu l'importance des immeubles comme source de plus-values et, par conséquent, comme élément de protection contre l'érosion monétaire de l'actif net, il conviendrait de procéder à une analyse comparative, entre pays, beaucoup plus approfondie de traitement fiscal des actifs immobiliers.

\subsubsection{Traitement fiscal des profits destinés à alimenter la marge}

Dans le cadre des régimes fiscaux actuels, la part des profits affectée à l'alimentation de la marge est taxable au même titre que n'importe quel autre profit.

Les milieux professionnels de l'assurance ont parfois invoqué le caractère obligatoire de la marge pour suggérer une détaxe. D'aucuns ont avancé qu'étant établie en faveur de l'intérêt général, elle devrait être considérée au même titre que les provisions techniques ${ }^{64}$. Conscients toutefois qu'en cas de liquidation de l'entreprise, la marge de solvabilité, ou ce qui en resterait, serait répartie entre les actionnaires, d'autres ont proposé qu'à ce moment-là seulement une taxation au titre des plus-values réalisées intervienne ${ }^{65}$.

On tend aujourd'hui à une plus grande rigueur de jugement mêlée d'un réalisme certain. Ainsi lors de l'Assemblée générale du Comité Européen des Assurances de 1978, M. Martin a attiré l'attention sur le fait que la marge ne peut être regardée comme un engagement proprement dit de l'entreprise vis-à-vis des assurés ; elle constitue plutôt un bien propre de l'entreprise. Ce point de vue n'exclut toutefois pas que sa constitution soit effectuée en suspension d'impôt. Pour sa part, M. Plescoff 66 a proposé lors de la même assemblée que la dotation de la marge soit scindée en deux parties, dont l'une - correspondant à la compensation de l'inflation - soit exonérée de l'impôt. Les considérations que nous avons faites à la section 6.3.2. sur la revalorisation des actifs en couverture de la marge en cas d'inflation montrent cependant que des critères précis devraient être établis pour procéder à ce partage de la dotation à la marge. L'étude quantitative proposée sur la contribution des résultats de la gestion financière à la protection de la marge permettrait sans doute de dégager des critères qui soient acceptables par les autorités fiscales.

64 LEGRAND, G., loc. cit., 15 septembre 1978 : « l'alimentation de la marge avant calcul de l'impôt, déjà prévue dans certains pays, mériterait une étude poussée ».

65 BARBIER, J., loc. cit., 12 janvier 1978.

66 PLESCOFF, G., loc. cit. 


\section{Evaluation comparée des disparités et conclusions}

\subsection{Problèmes de l'évaluation de l'importance des disparités}

Dans les sections précédentes, on a identifié un certain nombre de disparités à leur source et, dans la mesure du possible, on s'est efforcé d'en apprécier la portée. L'approche analytique suivie a eu pour conséquence qu'aucune d'entre elles n'a été écartée en raison, par exemple, de son caractère passager ou de son importance éventuellement mineure.

Pour s'exprimer sur l'importance de telle ou telle disparité, il convient :

(i) d'avoir une vue d'ensemble des disparités étudiées ;

(ii) de préciser les points de vue auxquels on se place pour porter un jugement de valeur.

La vue d'ensemble est donnée par un premier tableau récapitulatif présenté à la section suivante.

La question des points de vue adoptés se situe :

(i) au niveau de chaque disparité jugée pour elle-même ;

(ii) au niveau de chaque disparité appréciée dans un essai de synthèse, la comparant alors à toutes les autres disparités pour ses effets économiques.

Au niveau du jugement analytique, on s'est placé d'abord du point de vue de l'entreprise existante, en référence à sa nationalité et à son marché principal (présumé correspondre au pays de sa nationalité); pour corriger cette appréciation par trop restrictive, on a considéré ensuite les points de vue de l'entreprise multibranches ou appartenant à un groupe national, voire transnational, et celui de la petite et moyenne entreprise. On a retenu par ailleurs le principe de ne se prononcer - positivement ou négativement - sur une disparité que dans les cas où l'étude apportait une information suffisante. Les avantages et inconvénients mineurs ou passagers ont été qualifiés comme tels. Les situations qui méritent d'être suivies en raison d'une évolution rapide ou d'une information risquant d'être rapidement dépassée ont été aussi signalées.

Au niveau du jugement comparatif, nous avons repris comme points de vue les trois principales catégories de disparités considérées par l'étude selon qu'il s'agit de différences entre entreprises :

- pour la justification de la marge sur la base des actifs existants ;

- pour l'alimentation de la marge en référence à des conditions particulières à l'économie de l'assurance ;

- quant à l'influence des conditions économiques générales au niveau national sur le financement de l'entreprise et le maintien de la substance de la marge.

On retrouvera ces points de vue dans le second tableau de la section suivante (p. 68) qui tente de déboucher sur un jugement à la fois analytique et global des disparités récapitulées dans le premier tableau (pp. 64-67). 


\subsection{Essai de comparaison et d'appréciation}

\subsubsection{Tableau récapitulatif des disparités (pp. 64-67)}

Ce premier tableau, établi sur la base des principes énoncés à la section précédente, donne une dénomination succincte des disparités considérées. Comme il est difficile de caractériser ces disparités en quelques mots, des références au corps du rapport sont données au lecteur qui, dans le doute, est invité à se reporter aux sections et pages citées.

Les effets de ces disparités sont formulés en termes d'avantages ou de désavantages pour l'entreprise par rapport à des concurrents placés dans d'autres conditions pour justifier et alimenter leurs marges (en raison principalement d'une localisation différente de leur siège ou de leurs marchés principaux). Un découpage géographique a ainsi été retenu pour ce premier tableau récapitulatif.

Toutefois, pour certaines des disparités considérées, l'étude ayant fait apparaître des avantages ou des désavantages pour l'entreprise selon sa taille, l'appartenance à un groupe, la non-spécialisation, etc., on les a aussi pris en compte dans ce tableau récapitulatif en en faisant mention en caractères italiques au travers des colonnes du découpage géographique.

\subsubsection{Tableau évaluant les principales disparités identifiées (p. 68)}

En référence aux principes retenus pour l'évaluation des disparités (voir section 7.1.), on a établi un second tableau résumant le premier en distinguant avantages/inconvénients significatifs et mineurs.

Par ailleurs, on a tenté d'établir une balance des avantages et désavantages selon les points de vue :

(1) de la justification,

(2) de l'alimentation de la marge, et

(3) des conditions économiques générales,

et ce en se référant aux caractéristiques géographiques et non géographiques de l'entreprise (ces dernières ne comprenant qu'une seule distinction entre petites et moyennes entreprises et entreprises multibranches ou appartenant à des groupes). On a par ailleurs simplifié l'évaluation en considérant qu'au plan des Etats membres, les entreprises nationales dépendaient étroitement des conditions du pays du siège. Les entreprises des pays tiers ont été considérées quant à leurs avantages/désavantages pour opérer sur le marché communautaire de l'assurance sans distinction de pays membre.

Enfin, la dernière ligne de ce second tableau donne le résultat d'un jugement global. La balance des avantages/inconvénients nets (doubles signes positifs ou négatifs) a été distinguée des avantages/inconvénients simplement significatifs ${ }^{67}$ de chacune des disparités pour bien faire ressortir la situation des entreprises considérées pour surmonter les difficultés résultant de l'introduction de la marge communautaire.

67 Ceux qui nous ont paru peu significatifs figurent entre parenthèses. 
Tableau 7. - RECAPITULATIF DES DISPARITES ENTRE ENTREPRISES D'ASSURANCE NON-VIE

\begin{tabular}{|c|c|c|}
\hline DENOMINATION ET REFERENCE DES DISPARITES & R. F. D'ALLEMAGNE & BELGIQUE \\
\hline $\begin{array}{l}\text { 1. Obligation de constituer la marge aussi sur la part de prime } \\
\text { (variable) qui ne peut être affectée à la couverture des ris- } \\
\text { ques assurés (s. } 2.12, \text { p. 14). }\end{array}$ & \multicolumn{2}{|c|}{ 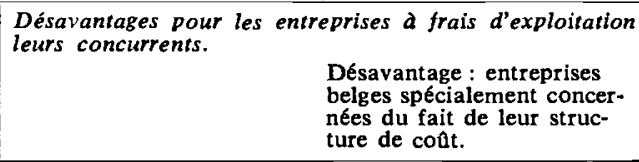 } \\
\hline $\begin{array}{l}\text { 2. Conséquence maximaliste du coefficient réducteur pour ces- } \\
\text { sion en réassurance, calculé sur une base annuelle (fluc- } \\
\text { tuant selon la part des sinistres à charge des réassureurs) } \\
\text { (s. } 2.22 \text {, p. 17). }\end{array}$ & \multicolumn{2}{|c|}{$\begin{array}{l}\text { Désavantages pour les entreprises (petites et moyennes) } \\
\text { de marge que l'année suivant l'exercice où les réassu }\end{array}$} \\
\hline $\begin{array}{l}\text { 3. Maintien de la pratique du dépôt et du cautionnement de la } \\
\text { part des succursales communautaires dans l'impossibilité de } \\
\text { produire le certificat de solvabilité globale de leur siège cen- } \\
\text { tral (s. 3.312, p. 26) ou pour d'autres raisons (s. } 3.312, \text { p. 27) } \\
\text { PASSAGERES. }\end{array}$ & & $\begin{array}{l}\text { Cas des succursales d'entre- } \\
\text { prises italiennes operant en } \\
\text { Belgique. }\end{array}$ \\
\hline \multicolumn{3}{|l|}{$\begin{array}{l}\text { 4. Maintien d'un contrôle financier antérieur impliquant des } \\
\text { obligations supplémentaires à celles de la marge communau- } \\
\text { taire (s. } 3.321, \text { p. } 28 \text { ). }\end{array}$} \\
\hline $\begin{array}{l}\text { 5. Localisation des actifs en couverture de la marge sur le ter- } \\
\text { ritoire de la CE pour les succursales des entreprises de pays } \\
\text { tiers (s. } 3.321, \text { p. 29). }\end{array}$ & \multicolumn{2}{|c|}{$\begin{array}{l}\text { Inconvénient pour toutes les entreprises des pays tiers } \\
\text { naires des pays d monnaie forte (cas des entreprises }\end{array}$} \\
\hline \multicolumn{3}{|l|}{$\begin{array}{l}\text { 6. Non-admissibilité de certains actifs en couverture de la } \\
\text { marge ou de provisions techniques (s. } 4.21, \text { p. } 34-35) \text {. }\end{array}$} \\
\hline $\begin{array}{l}\text { 7. Différences dans la valeur nette de réalisation des immeu- } \\
\text { bles (s. } 4.221 \text {, p. } 35-36) \text {. }\end{array}$ & $\begin{array}{l}\text { Désavantage : montant infé- } \\
\text { rieur a la valeur du marché } \\
\text { et admissible seulement si } \\
\text { la couverture de la marge } \\
\text { est insuffisante dans cas } \\
\text { particulier et à titre excep- } \\
\text { tionnel (réf. } 6.07 .1978 \text { ). }\end{array}$ & \\
\hline $\begin{array}{l}\text { 8. Différences dans l'estimation de filiales non cotées (s. } 4.222 \text {, } \\
\text { p. } 37-38 \text { ). }\end{array}$ & $\begin{array}{l}\text { Désavantage : circulaire du } \\
6.07 .1978\end{array}$ & $\begin{array}{l}\text { Désavantage : } \\
\text { circulaire D.8. }\end{array}$ \\
\hline $\begin{array}{l}\text { 9. Atténuation des déductions pour moins-values sur actifs } \\
(\text { s. } 4.23, \text { p. } 38-40) \text {. }\end{array}$ & $\begin{array}{l}\text { Désavantage : pas de com- } \\
\text { pensation entre plus-value } \\
\text { et moins-value. }\end{array}$ & $\begin{array}{l}\text { Désavantage : pas de com- } \\
\text { pensation entre plus-values } \\
\text { et moins-values. }\end{array}$ \\
\hline $\begin{array}{l}\text { 10. Prise en compte de plus-values cachées sur actifs (s. } 4.24 \text {, } \\
\text { p. } 40-41) \text {. }\end{array}$ & $\begin{array}{l}\text { Les plus-values cachées ne } \\
\text { cas des formalités doivent } \\
\text { Désavantage : seulement } \\
\text { dans cas particulier et a } \\
\text { titre exceptionnel } \\
\text { (réf. } 6.07 .1978 \text { ) }\end{array}$ & $\begin{array}{l}\text { sont prises en compte que si } \\
\text { être entreprises par lassu }\end{array}$ \\
\hline $\begin{array}{l}\text { 11. Surestimation réglementaire des provisions sur primes non } \\
\text { reconnue comme telle par les autorités de surveillance } \\
(\text { s. } 5.22, \text { p. } 42-43) \text {. }\end{array}$ & & $\begin{array}{l}\text { Avantage : fiscal } \\
\text { (jusqu'a } 50 \%)\end{array}$ \\
\hline
\end{tabular}


(résuitant de ou renforcées par l'introduction de la marge de solvabilité de la CE)

\begin{tabular}{c|c|c|c|}
\hline FRANCE & ITALIE & PAYS-BAS & ROYAUME-UNI \\
\hline etlou marges bénéficiaires élevés et dont les risques assurés ne sont pas a priori plus mauvais aue ceux de
\end{tabular}

et/ou marges bénéficiaires élevés et dont les risques assurés ne sont pas a priori plus mauvais que ceux de

liées par des traités non-proportionnels et qui, de ce fait, ne peuvent béneficier d'une réduction substantielle reurs ont été mis fortement à contribution par le règlement de sinistres exceptionnels.

\begin{tabular}{|c|c|}
\hline $\begin{array}{l}\text { Cas de succursales d'entre- } \\
\text { prises italiennes opérant en } \\
\text { France. }\end{array}$ & $\begin{array}{l}\text { Désavantage : s'applique } \\
\text { aux entreprises italiennes } \\
\text { opérant en Belgique et en } \\
\text { France par des succursales }\end{array}$ \\
\hline
\end{tabular}

Désavantage : s'applique aux entreprises des pays tiers opérant au RoyaumeUni au travers de succursales.

opérant sur le territoire de la Communauté Européenne, mais plus spécialement pour celles d'entre elles origisuisses operant au travers de succursales).

\author{
Situation à suivre en raison \\ de nouvelles règles de pla- \\ cement obligeant des entre- \\ prises à se dessaisir \\ d'immeubles.
}

Inconvenient mineur en pratique : s'applique seulement aux entreprises saines ou aux petites entreprises qui ne peuvent fractionner certains actifs (exemple : immeuble du siège).
Avantage : seulement au prix d'achat si participations non cotées en représentation des provisions techniques mais valeur d'utilité si en représentation des fonds propres.
Avantages : moins-values sur actions ne sont prises en compte que si le cours est inférieur à $75 \%$ du prix d'achat; prise en compte de la valeur du remboursement sur obligations.
Avantage : même en incluant actifs incorporels de valeur certaine. Avantage :
l'actif net.

Avantage : moins-value sur

obligations n'est pas prise

en compte si la valeur au

remboursement est supé-

rieure au prix d'achat.

l'estimation réglementaire des actifs a pour conséquence une insuffisance de couverture de la marge (auquel reur pour s'en prévaloir).

Avantage : correctifs au bilan sont effectués sur simple déclaration.

Avantage : s'applique seulement si provisions nécessaires sont inférieures à $36 \%$.
Situation à suivre: les

$5-10 \%$ de plus-values sur les provisions en question sont en cours de règlement. 
Tableau 7. (suite) - RECAPITULATIF DES DISPARITES ENTRE ENTREPRISES D'ASSURANCE NON-VIE

\begin{tabular}{|c|c|c|}
\hline DENOMINATION ET REFERENCES DES DISPARITES & R.F. D'ALLEMAGNE & BELGIQUE \\
\hline $\begin{array}{l}\text { 12. «Schwankungsrückstellungen » provisions de ré́quilibrage } \\
\text { (p. 44). }\end{array}$ & \multicolumn{2}{|l|}{$\begin{array}{l}\text { Désavantage : obligation } \\
\text { généralisée s'ajoutant aux } \\
\text { exigences de la marge; } \\
\text { affaire à suivre. }\end{array}$} \\
\hline \multicolumn{3}{|l|}{$\begin{array}{l}\text { 13. Tarification des primes tendant à comprimer la marge béné- } \\
\text { ficiaire de l'entreprise (s. } 6.11, \text { p. } 45-47) \text {. }\end{array}$} \\
\hline $\begin{array}{l}\text { 14. Différence en matière de taxes sur polices émises (s. } 6.12, \\
\text { p. } 47 \text { et Annexe 1). }\end{array}$ & Situation moyenne. & Situation moyenne \\
\hline \multicolumn{3}{|l|}{$\begin{array}{l}\text { 15. Incidence sur le rendement financier des règles un matière } \\
\text { de placement des avoirs en représentation des provisions } \\
\text { techniques (s. } 6.211, \text { p. } 47-49 \text { ). }\end{array}$} \\
\hline \multicolumn{3}{|l|}{$\begin{array}{l}\text { 16. Incidence sur la conservation de la substance de la marge } \\
\text { de restrictions en matière de placements à l'étranger dans } \\
\text { les pays à monnaie faible (s. } 6.212 \text {, p. } 49 \text { ). }\end{array}$} \\
\hline $\begin{array}{l}\text { 17. Conséquences de pratiques nationales en matière de dépôts } \\
\text { des réassureurs (s. } 6.22, \text { p. } 50-51) \text { pour le financement de la } \\
\text { marge. }\end{array}$ & & $\begin{array}{l}\text { Avantage pour l'assureur } \\
\text { belge : les cessions en réas- } \\
\text { surance ne diminuent qu'en } \\
\text { partie (p. 63) le volume des } \\
\text { placements correspondant } \\
\text { aux provisions calculées au } \\
\text { brut. } \\
\text { Désavantage pour l'assureur } \\
\text { tiers: les affaires traitées } \\
\text { tent pas de couvrir la quote } \\
\text { actifs libelles en une autre } \\
\text { et le franc français respecti }\end{array}$ \\
\hline $\begin{array}{l}\text { 18. Incidence de sources de financement autres que celles cons- } \\
\text { tituées par les affaires non-vie }(s .6 .23, \text { p. } 52-53) \text {. }\end{array}$ & \multicolumn{2}{|c|}{$\begin{array}{l}\text { Avantage pour (1) les entreprises les plus prospères } \\
\text { multibranches capables dêtre soutenues financierement } \\
\text { - spécialisation excluant } \\
\text { pratiquement (3). }\end{array}$} \\
\hline \multirow[t]{2}{*}{$\begin{array}{l}\text { 19. Incidence de la rémunération et de l'appréciation des pla- } \\
\text { cements (s. } 6.31, \text { p. } 55) \text {. }\end{array}$} & $\begin{array}{l}\text { Avantage : rémunération } \\
\text { des fonds propres et } \\
\text { «return » sur capital investi } \\
\text { supérieurs à la moyenne. }\end{array}$ & $\begin{array}{l}\text { Désavantage : rémunération } \\
\text { des fonds propres en ter- } \\
\text { mes réels inférieurs à la } \\
\text { moyenne. }\end{array}$ \\
\hline & Avantage des entreprises tr & ransnationales pouvant opti \\
\hline $\begin{array}{l}\text { 20. Incidence de l'inflation et des taux de change (s. } 6.32 \text { et } \\
6.33 \text {, pp. 55-59). }\end{array}$ & $\begin{array}{l}\text { Avantage : inflation faible } \\
\text { couplée a « return » sur ca- } \\
\text { pital investi au-dessus de la } \\
\text { moyenne et à appréciation } \\
\text { du DM sauf récemment. }\end{array}$ & \\
\hline $\begin{array}{l}\text { 21. Indice de l'imposition des bénéfices d'exploitation et gains } \\
\text { sur les actifs en valeur réelle (s. } 6.34, \mathrm{pp} .60-61) \text {. }\end{array}$ & $\begin{array}{l}\text { Avantage : taux d'imposi- } \\
\text { tion des bénéfices inférieur } \\
\text { à la moyenne. }\end{array}$ & $\begin{array}{l}\text { Impôt sur superbénéfices } \\
\text { mais taux spécial sur réali- } \\
\text { sation d'actifs. }\end{array}$ \\
\hline
\end{tabular}


(résultant de ou renforcées par l'introduction de la marge de solvabilité de la CE)

\begin{tabular}{|c|c|c|c|}
\hline FRANCE & ITALIE & PAYS-BAS & ROYAUME-UNI \\
\hline \multicolumn{4}{|c|}{$\begin{array}{r}\text { Voir détail par pays sur le tableau de la page } 46 . \\
\text { Avantage : pas de tarifica- } \\
\text { tion, report possible de } \\
\text { l'alimentation de la marge } \\
\text { sur taux de prime. }\end{array}$} \\
\hline \multirow[t]{3}{*}{$\begin{array}{l}\text { Désavantage : niveau de } \\
\text { taxation le plus élevé. }\end{array}$} & $\begin{array}{l}\quad \text { Voir la situation dan } \\
\text { Désavantage : niveau de } \\
\text { taxation comparables à la } \\
\text { France. }\end{array}$ & $\begin{array}{l}\text { s chaque pays d lannexe } 1 . \\
\text { Avantage : faible niveau } \\
\text { de taxation. }\end{array}$ & $\begin{array}{l}\text { Avantage : pratiquement } \\
\text { pas de taxe sur l'émission } \\
\text { des primes. }\end{array}$ \\
\hline & $\begin{array}{l}\text { Situation à suivre : de nou- } \\
\text { velles dispositions pour- } \\
\text { raient avoir une influence } \\
\text { négative. }\end{array}$ & $\begin{array}{l}\text { Avantages résultant de } \\
\text { moindres contraintes. }\end{array}$ & $\begin{array}{l}\text { Avantages résultant de } \\
\text { moindres contraintes, en- } \\
\text { core que la tendance soit à } \\
\text { l'introduction de règles } \\
\text { nouvelles. }\end{array}$ \\
\hline & $\begin{array}{l}\text { Désavantage : obligation } \\
\text { de rapatrier } 95 \% \text { des excé- } \\
\text { dents d'actifs a l'étranger. }\end{array}$ & $\begin{array}{l}\text { Désavantage : la liberté de } \\
\text { placement à l'étranger est } \\
\text { assortie d'une obligation de } \\
\text { dépôt en lires qui annihile } \\
\text { les avantages d'avoirs à } \\
\text { monnaie forte. }\end{array}$ & \\
\hline
\end{tabular}

-réassureur des autres pays sur ces marchés ne permet-

-part en réassurance par ces monnaie que le franc belge vement.

pour faire appel au marché des capitaux et pour celles appartenant (2) à des groupes ou (3) à des soctétés par les bénéfices sur affaires non-vie.

- spécialisation excluant pratiquement (3). spécialisation excluant
pratiquement (3).
Désavantage : rémunération Désavantage : «return» des fonds propres en termes réels et «return » sur capital investi (immeubles non compris) inférieurs à la moyenne. sur capital investi inférieur

Comparaison non à la moyenne. disponible.

miser leur gestion financière en fonction des avantages et inconvéntents des différents marchés financiers.

$\begin{array}{lll}\text { Désavantage : inflation } & \text { Désavantage : inflation } & \text { Avantage récent: inflation } \\ \text { forte, mais situation } & \text { forte couplé a rémunéra- } & \text { inférieure à la moyenne } \\ \text { moyenne pour « return } & \text { tion et appréciation du } & \text { couplée à appréciation de } \\ \text { sur capital investi. } & \text { capital problématique. } & \text { la livre sterling. }\end{array}$


Tableau 8: Essai d'évaluation des disparités entre entreprises d'assurance résultant de l'introduction de la marge de solvabilité de la CE

\begin{tabular}{|c|c|c|c|c|c|c|c|c|c|c|}
\hline \multirow{2}{*}{ 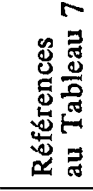 } & \multicolumn{6}{|c|}{$\begin{array}{l}\text { Entreprises de droit national } \\
\text { opérant principalement en : }\end{array}$} & \multirow{2}{*}{$\begin{array}{c}\text { Entreprises } \\
\text { des pays } \\
\text { tiers }\end{array}$} & \multirow[t]{2}{*}{ PME } & \multirow{2}{*}{$\begin{array}{l}\text { Multi- } \\
\text { branches/ } \\
\text { Groupes }\end{array}$} & \multirow{2}{*}{ 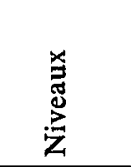 } \\
\hline & D & B & $\mathbf{F}$ & I & $\mathbf{N}$ & UK & & & & \\
\hline 1 & & - & & & & & & - & & \\
\hline 2 & & & & & & & & - & + & \\
\hline 3 & & & & $(-)$ & & & & & & \\
\hline 4 & & & & & & & $(-)$ & & & \\
\hline 5 & & & & & & & - & & & \\
\hline 6 & & & & $!$ & & & & $(-)$ & & \\
\hline 7 & $(-)$ & & & & & $(-)$ & & & & \\
\hline 8 & $(-)$ & $(-)$ & + & + & $(+)$ & + & & & $(t)$ & \\
\hline 9 & $(-)$ & - & + & + & & & & & & કี ڤ્ \\
\hline 10 & - & & & & & & & & & 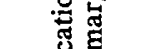 \\
\hline 11 & & $(+)$ & $(+)$ & $!$ & & $(+)$ & & & & 莺 \\
\hline 12 & - & & & & & & & & & $\Xi$ \\
\hline 13 & & & + & & & + & & & & \\
\hline 14 & & & - & - & + & + & & & & \\
\hline 15 & & & & $!$ & + & + & & & & .ొْ \\
\hline 16 & & & - & - & & & & & & 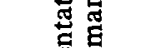 \\
\hline 17 & & + & & & & & & & - & 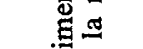 \\
\hline 18 & & $(+)$ & & $(+)$ & & $(+)$ & & & + & $\ddot{z} \approx$ \\
\hline 19 & + & - & & $(-)$ & - & & & & + & \\
\hline 20 & + & & - & - & & + & & & & 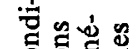 \\
\hline 21 & ++ & & + & + & & & & & & $0.0 \%$ \\
\hline $1-12$ & - & - & ++ & + & $(+)$ & $(+)$ & - & - & + & - Justification \\
\hline $13-18$ & 0 & + & - & - & + & + & & & 0 & - Alimentation \\
\hline $19-21$ & $+t$ & - & 0 & $(-)$ & - & + & & & + & - Conditions \\
\hline$\Sigma$ & + & -- & $(+)$ & $(+)$ & 0 & $+t$ & -- & -- & $+t$ & - Jugement \\
\hline
\end{tabular}

Légende : $(+)$ : avantage mineur

$+\quad$ : avantage significatif

++ : avantage net

$(-)$ : inconvénient mineur

- : inconvénient significatif

- - : inconvénient net

! : situation à suivre
D : R.F. d'Allemagne

B : Belgique

F : France

I : Italie

$\mathbf{N}$ : Pays-Bas

UK : Royaume-Uni

PME : Petites et moyennes entreprises 


\subsection{Conclusions: Appréciation des disparités entre entreprises résultant de l'introduction de la marge de solvabilité}

Pour faire état de leur marge de solvabilité, les entreprises communautaires se trouvent techniquement dans des situations différentes suivant le pays du siège du fait du maintien des contrôles nationaux. Dans l'ensemble, la portée économique des différences de traitement est cependant faible, encore que l'on relève un certain désavantage pour les entreprises allemandes et belges et un certain avantage pour les entreprises françaises et italiennes. La raison majeure de l'effet peu significatif des nombreuses disparités constatées en cours d'étude réside qu'en cas de besoin, tous les Etats membres admettent les réserves cachées en représentation de la marge, encore que la position de la R.F. d'Allemagne soit très conservatrice. Les entreprises belges sont pour leur part surtout désavantagées par le mode de calcul de la marge, prélevée aussi sur la part - élevée en Belgique - de la prime qui ne correspond pas à des risques assurés. Les entreprises françaises bénéficient essentiellement d'un traitement avantageux pour les moins-values et l'estimation des filiales.

Plus évidents à ce niveau de la justification de la marge sont certains désavantages touchant les entreprises petites et moyennes. A part la structure des coûts qui pèse souvent défavorablement sur la relation entre marge exigible et risques assurés des entreprises petites et moyennes, le recours à la réassurance est pris en compte de telle façon que la réduction de marge qui y est associée ne peut être pratiquement inférieure au taux des années où les réassureurs interviennent peu dans le règlement des sinistres. Les grandes entreprises qui sont soumises à de moins fortes fluctuations méconnaissent en général l'incidence du calcul du coefficient réducteur pour la réassurance. Ces aspects particuliers mis à part, il est fondé de considérer qu'en dernière analyse les entreprises petites et moyennes bénéficient d'un avantage net au niveau de la justification de la marge en raison du taux à peine supérieur à celui des entreprises plus grandes. La diversité des placements de ces dernières qui permet d'atténuer les variations de fortune en couverture de leurs fonds propres ou de leurs engagements est un élément parmi d'autres qu'il importe d'avoir à l'esprit pour se garder de conclure, même si cela est vrai au plan actuariel, que les grandes entreprises sont considérablement prétéritées puisqu'elles ne bénéficient pas d'un taux de marge décroissant en fonction de leur volume d'affaires.

Pour l'alimentation de la marge, les conditions propres au secteur de l'assurance dans chacun des pays étudiés sont une source beaucoup plus évidente de disparités entre entreprises que les réglementations et pratiques nationales en matière de contrôle financier. Si l'on compare les effets des contraintes imposées à la gestion des placements de l'assurance non-vie dans les différents pays étudiés, le Royaume-Uni et les Pays-Bas paraissent offrir nettement des avantages à la formation d'excédents d'actifs. Les conditions sont par contre beaucoup moins favorables en France et en Italie, la R.F. d'Allemagne et la Belgique se situant à un niveau intermédiaire (la position de la Belgique se rapprochant toutefois de celle des Pays-Bas). D'une façon générale, les entreprises multibranches ou appartenant à des groupes nationaux ou internationaux sont également favorisées pour compenser les effets restrictifs découlant des réglementations en matière d'assurance-dommages. 
La formation du surplus d'exercice dépend cependant également des conditions économiques générales propres à chaque pays. De ce point de vue, la R.F. d'Allemagne et le Royaume-Uni offrent le plus d'avantages, la Belgique et les Pays-Bas en offrant le moins.

Si d'une part l'on intègre les points de vue (1) des exigences en matière de contrôle de solvabilité, (2) des conditions de la formation d'excédents d'actifs qui sont spécifiques à l'assurance et (3) des conditions économiques générales qui, en dernier ressort, commandent la croissance et le maintien de la substance des fonds propres (donc de la marge) et si, d'autre part, on fait abstraction de la situation technique et financière actuelle des différentes entreprises opérant sur le territoire de la $\mathrm{CE}$, les conditions les plus favorables pour faire face aux exigences réglementaires nouvelles en matière de solvabilité se trouvent réunies en R.F. d'Allemagne, suivi par le Royaume-Uni. Les conditions les plus critiques paraissent, par contre, être rassemblées en Belgique. La balance des avantages et désavantages offerts aux trois niveaux considérés par la France et l'Italie est plus délicate à établir; la position de ces pays se situe autour de la moyenne et se distancie difficilement de celle des Pays-Bas.

Les entreprises des pays tiers opérant sur le territoire de la CE voient leur position plutôt affaiblie par la nouvelle réglementation, encore qu'elles puissent, suivant le pays considéré (exemple : la Suisse), compenser les inconvénients qui en résultent par des conditions d'opération et surtout des conditions économiques générales dans l'ensemble favorables.

Plus importantes que les différences résultant du pays du siège et du pays d'exercice paraissent néanmoins en dernière analyse les incidences de la croissance de l'entreprise suivant son champ d'activité et son appartenance ou non à des groupes nationaux ou internationaux. Pour s'adapter aux exigences financières qu'implique la marge de solvabilité communautaire et poursuivre leur expansion, les compagnies multibranches et liées à des groupes sont mieux placées que les monobranches et les entreprises, souvent petites et moyennes, leur étant assimilées, qui avaient pu accroître rapidement leur part de marché. Sans autre considération, les entreprises les plus dynamiques sont les plus affectées, surtout si elles s'appuyaient déjà dans le passé fortement sur la réassurance ou avaient épuisé leur capacité de faire appel au marché financier pour augmenter leurs fonds propres. On relèvera toutefois qu'un développement sain en assurance ne peut être que progressif et qu'il ne convient pas, par conséquent, de dramatiser les conséquences du frein à la croissance que constitue la marge communautaire.

Sur le plan économique, on peut en inférer que la protection de l'assuré (que la marge de solvabilité est censée renforcer) pourrait bien ainsi s'accompagner d'un affaiblissement de l'agressivité des compagnies les plus dynamiques et d'une certaine concentration des entreprises d'assurance au sein de la CE. La concentration des entreprises est compatible avec la protection de l'assuré aussi longtemps que l'élimination des entreprises à coûts élevés n'a pas pour conséquence de faciliter les ententes cartellaires. De situations de dumping qui existaient encore récemment sur certains marchés à des conditions où quelques entreprises seulement pourraient imposer leurs tarifs, il existe un large champ à parcourir. Actuellement, à l'instar de ce que l'on observe pour les autres secteurs de l'économie, une concentration de l'assurance en Europe occidentale, accompagnée d'une plus grande efficience, paraît correspondre à 
une tendance souhaitable. Cette conséquence économique de la marge de solvabilité ne devrait donc pas être combattue.

L'existence de conditions différentes entre des pays membres dans l'exercice de l'assurance-dommages n'est pas non plus nécessairement une mauvaise chose. Dans le cadre de la liberté d'établissement désormais étendue au sein de la $\mathrm{CE}$ à l'exercice de l'activité d'assurance, il est du ressort des gouvernements nationaux d'apprécier l'intérêt de retenir sur leur territoire les sièges principaux des compagnies transnationales et de créer à cet effet les conditions jugées appropriées. L'industrie de l'assurance est une option de stratégie nationale de développement au même titre que l'industrie automobile ou toute autre industrie industrialisante. Il appartient bien sûr aux industries nationales s'estimant défavorisées sur le plan communautaire et international de plaider leur dossier tant auprès des pouvoirs publics que de l'opinion.

Si les concentrations d'entreprises et l'aménagement des conditions de l'exercice de l'assurance dans certains pays membres peuvent être considérés, pour l'assuré et l'assureur, comme des retombées économiques positives de l'introduction d'une marge de solvabilité réglementaire pour l'ensemble de la $\mathrm{CE}$, il ne conviendra pas moins d'éviter que cette dernière ait pour conséquence de freiner systématiquement le développement des entreprises de taille modeste à forte croissance. Les difficultés que les plus dynamiques d'entre elles pourraient rencontrer pour se maintenir et se développer constitueraient à terme une atteinte à l'alimentation optimale du marché. Avec ou sans aménagements en matière de contrôle de solvabilité (par exemple : pour remédier aux conséquences de la fluctuation de la quote-part des réassureurs aux sinistres) ou en matière de fiscalité, la compréhension et la perspicacité des autorités de surveillance resteront, comme par le passé, les meilleurs garants d'un développement équilibré de la branche sur le plan national ; sur le plan européen, la coordination amorcée entre ces autorités de surveillance a montré qu'elle pouvait éviter les conséquences négatives des disparités les plus évidentes, même si l'harmonisation de principe (par exemple en matière de plus-values latentes) doit encore se traduire dans la pratique par une attitude également compréhensive et dénuée de tout ostracisme.

\section{ANNEXE I}

à la Section 6.12

TAXES ET REDEVANCES SUR PRIMES

- R.F. d'Allemagne

- Belgique

- France

- Italie

- Pays-Bas

- Royaume-Uni 


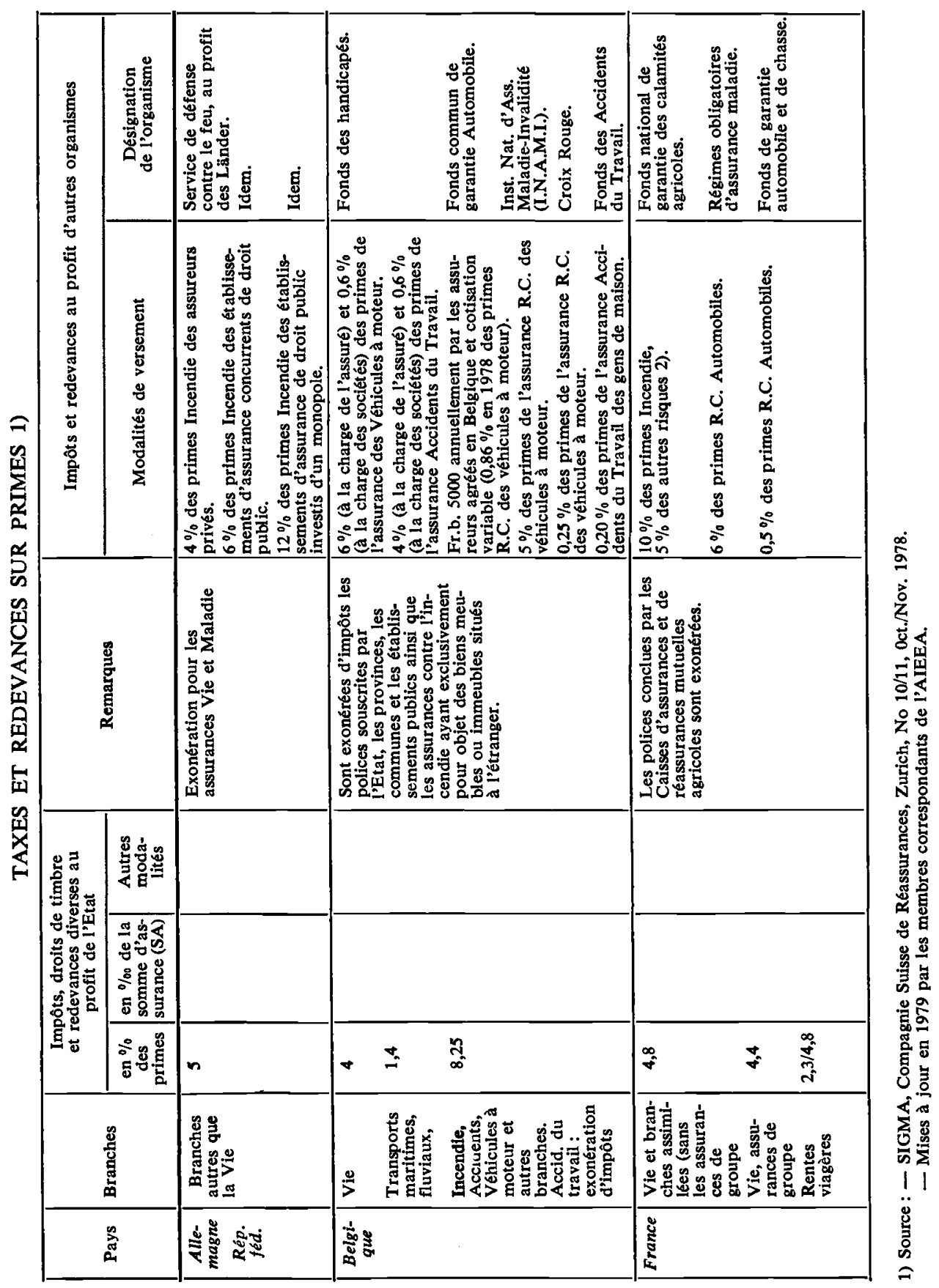




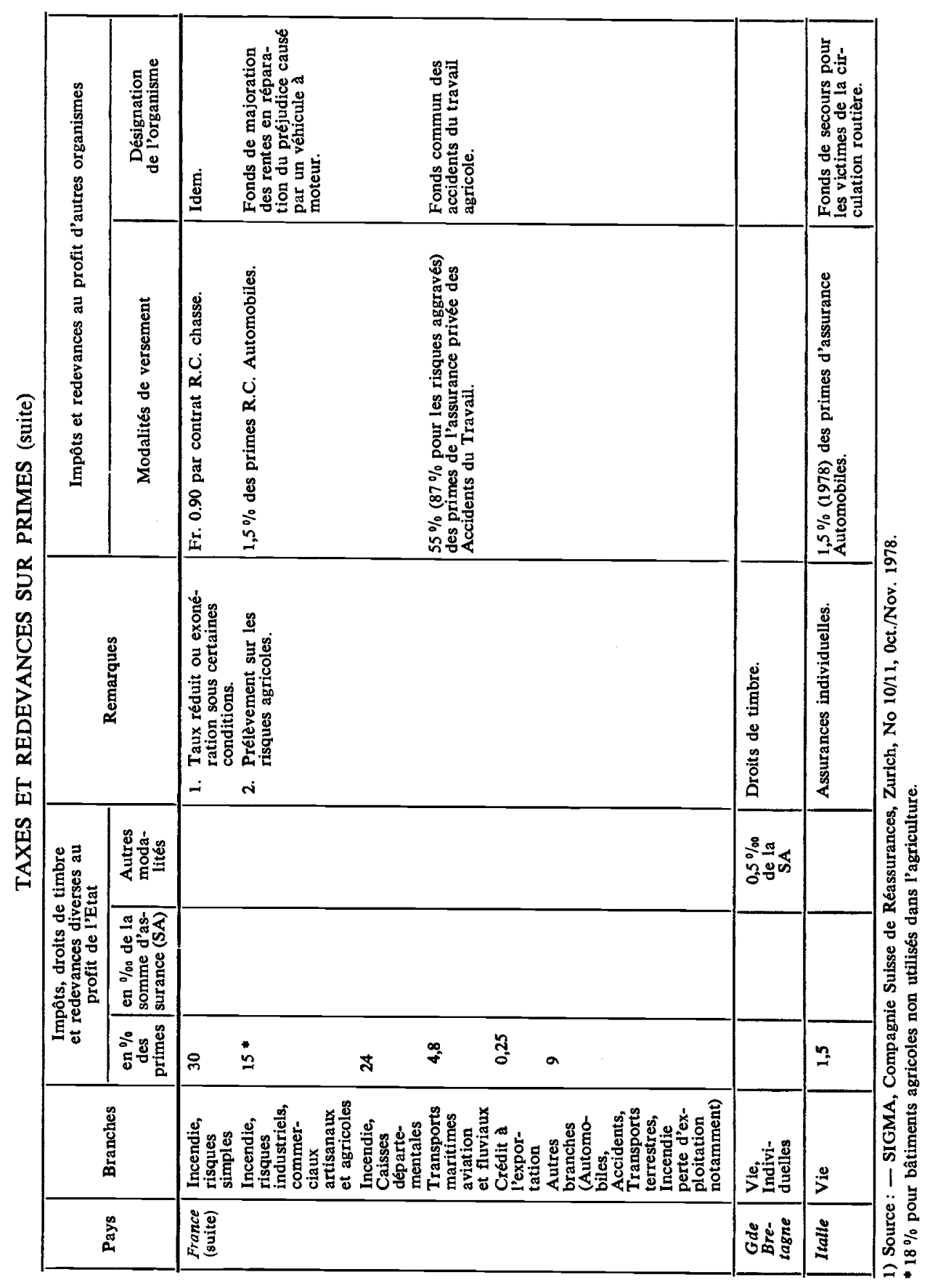




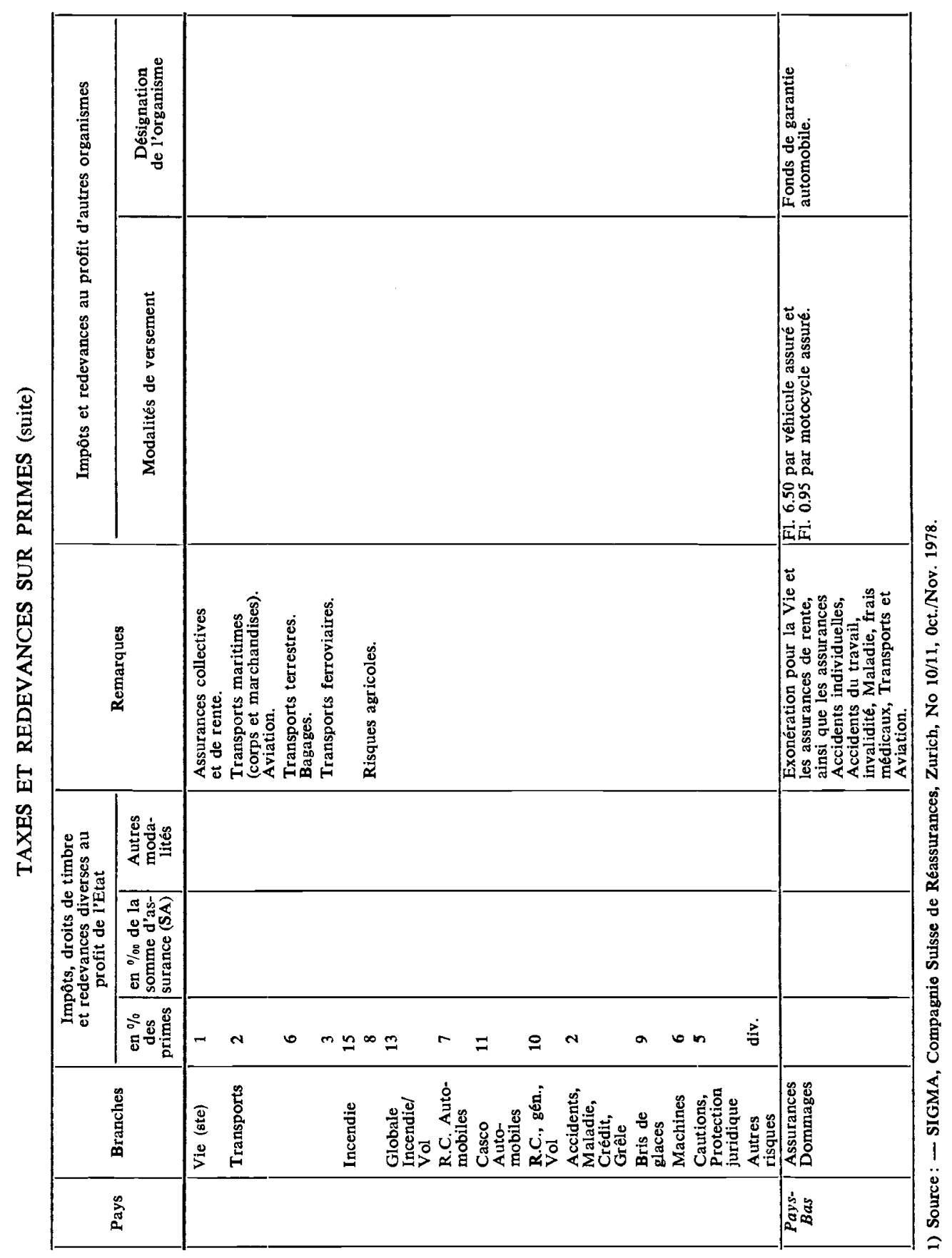

74 


\section{ANNEXE ||}

\section{A. REFERENCES CITEES}

BARBIER, J. : «Aspects économiques de la marge de solvabilité », dans le Petit Moniteur des Assurances, Bruxelles, 12 janvier 1978.

BECCHIO, L., et al. : «La nuova legge sulle assicurazioni private contro $i$ danni $»$ in « Capire l'assicurazione, una pubblicazione della Società Assicurazione Industriale », No. 4-5, octobre 1978.

BLANKART, Franz: "Das Versicherungsabkommen Schweiz/EWG aus Integrationspolitischer Sicht 》, Assemblée générale de l'Association suisse des compagnies d'assurance, Winterthur, 17 mai 1977.

BRAESS, P. : « Betriebswirtschaftliche Aspekte der Solvabilitätsvorschriften 》, dans VW 1969.

Communication D.16 de l'Office de Contrôle des Assurances, Bruxelles, 29 mai 1978.

DEPARTMENT OF TRADE : «Insurance Business Account Report 1977 », London, 1978.

FARNY, D. : «Versicherungsbilanzen », Francfort s/Main, 1975.

GMEINER, P. : «The EEC Interest of the Swiss Insurance Industry », dans International Insurance Monitor, janvier 1975.

HARVEY, Michael : "When is a $16 \%$ Solvency Margin not a $16 \%$ Solvency Margin?» dans Reinsurance, February 1978.

HARVEY, M. : « Solvency Margins - A question of Balance », dans The Review, 30 novembre 1979.

HATCH, M. : " Assemblée générale du Comité Européen des Assurances 》, Paris, 1978.

KONRATH, N. : "Solvabilitätsregeln auf dem Prüfstand, dans VW 1979.

LEGRAND, G. : "Réflexions sur la marge de solvabilité et son application dans le marché français », dans l'Argus, Paris, 15 septembre 1978.

MANTON, E. A.G.: "Solvency Requirements», dans International Insurance Monitor, janvier 1977.

PICCARD, M., et BESSON, A. : « Les Assurances terrestres », Tome II, Paris, 1977.

PLESCOFF, Georges : « Allocution à l'occasion du 25e anniversaire du Comité Européen des Assurances », octobre 1978.

Rapport du Groupe de Travail constitué par des représentants de l'OCA, de l'UPEA et de réassureurs européens.

SCHMIDT, Reimar : "L'importance de la puissance financière des entreprises d'assurance en ce qui concerne la concurrence, compte tenu plus particulièrement du marché européen $\gg$, dans Compte Rendu du Rendez-vous de Monte-Carlo, septembre 1978.

ZIMOLO, A.: «L'armonizzazione del settore assicurativo nelle directive della communita economica europea », dans Practica, mai 1978.

\section{B. AUTRES REFERENCES BIBLIOGRAPHIQUES}

BEARD, R.E. : Some Thoughts on Solvency of Insurance Companies, in : Quarterly Letter from the Algemeene Reinsurance Companies, publ. by Algemeene Herverzekering, Amsterdam, Jubilee Number, Juli 1964, Bd 1.

BERTSCHINGER, P. B. : Has this company solid foundations?, in : The Review, Vol. 106, 1975.

BERTSCHINGER, P. B. : Kriterien der Bonität von Nicht-Lebens- und RückversicherungsGesellschaften, in : Zeitschrift für Versicherungswesen, 29, Jg., 1978.

BESSON, A. : La nouvelle marge de sécurité imposée en France aux sociétés d'assurancedommage, in: Grundprobleme des Versicherungsrechts, Festgabe für Hans Möller, Karlsruhe 1972. 
BEUGEL, H. H. : Selbstbehaltsfindung beim Erstversicherer, in : Zeitschrift für Versicherungswesen, 29. Jg., 1978.

BRAESS, P. : Betriebswirtschaftliche Aspekte der «Solvabilitäts 》 vorschriften, in : Ausblick und Rückblick, Erich R. Prölss zum 60. Geburtstag, München 1967.

CAMPAGNE, C.: Enige aspekten met betrekking tot het solvabiliteitsvraagstuk in het schadenverzekeringsbedrijf, in : Het Verzekerings-Archief (1959).

CARSON, E. H. : Insurance company solvency, in : Best's Insurance News, Property/Liability Editions.

CARSON, E. H.: La solvabilité des compagnies d'assurances aux Etats-Unis, in : L'Argus, Jg. 1975.

FARNY, D. : Die * Solvabilität * der Schadenversicherungsunternehmen, in : der Arbeitgeber, 28. Jg., 1976.

FREY, E. : Zwei Probleme der Rechtsangleichung aus dem Niederlassungsrecht der Versicherungswirtschaft in der Europäischen Wirtschaftsgemeinschaft, in : Probleme des Europäischen Rechts, Festschrift für Walter Hallstein, Frankfurt, 1966.

GROSSMAN, M. : Solvabilitätsspanne und finanzielle Lage der Versicherungs-Gesellschaften, in : Schweizerische Versicherungs-Zeitschrift, 46. Jg., 1978.

HAMMOND, J.D., SCHILLING, N. : Some relationships of portfolio theory to the regulation of insurer solidity, in : Journal of Risk and Insurance, Vol. 40., 1978.

HESBERG, D.: Anmerkungen zur Ausstattung der deutschen Schaden-Versicherungsunternehmen mit Sicherheitskapital nach der Novellierung des Versicherungsaufsichtsgesetzes durch das Erste Durchführungsgesetz/EWG zum VAG, in : Zeitschrift für die gesamte Versicherungswissenschaft, 65. Band, 1976.

JOHNSON, M. B. : Solvency testing programme for property and liability insurers, in: The Interpreter, Vol. 32, 1974, Nr. 12.

LEGRAND, G. : Solvency margins are an absolute necessity, in : The Review, Vol. 180, 1978, No. 4523.

MAEIJER, J. M. N. : Het ontweerp-tweede E.E.G.-Richtlijn inzake de harmonisatie van het vennotschapsrecht en de Verzekeringsmaatschappijen, in: Het Verzekerings-Archief, Jg. 158, 1971, Nr. 1.

MARCHAL, M. : Réflexions sur la marge de solvabilité, in : L'Argus International, Jg. 1978, Nr. 7.

MORI, B., de : Possibilité d'établir des bases techniques acceptables pour le calcul d'une marge minimum de solvabilité des entreprises contre les dommages, in: The ASTIN Bulletin, Vol. III (1965).

MORI, B., de : La solvabilità delle imprese di assicurazione contro i danni, in : Assicurazione, H. 2, März/April 1966.

MUDRACK, O.: Die neue Europäische Rechnungseinheit (ERE) - Auswirkungen auf die Solvabilitätsanforderungen in der Schadensversicherung, in : Veröffentlichungen des Bundesaufsichtsamtes für das Versicherungswesen, 1976.

NOLLA, P.: Solvabilitätsmargen des Versicherungsunternehmen in der Europäischen Wirtschaftsgemeinschaft, in : Zeitschrift für Versicherungswesen, 28. Jg., 1977.

NOLLA, P. : Solvabilitätsspanne für Versicherungsunternehmen, in : Zeitschrift für Versicherungswesen, 23. Jg., 1972.

PENTKÄINEN, T.: On the solvency of Insurance Companies, in: The ASTIN Bulletin, Vol. IV (1966/67).

PILOT, J.: Marge de solvabilité et réassurance, in : L'Argus International, Jg. 1978, Nr. 7.

PINCHES, G. E., TRIESCHMANN, J.S. : The efficiency of alternative models for solvency surveillance in the insurance industry, in : Journal of Risk and Insurance, Vol. 41, 1974. 
SIMONET, G.: Le mécanisme de la marge et les conséquences possibles pour l'entreprise et le marché, in : L'Argus International, Jg. 1978. Nr. 7.

STEWART, C. M.: The Assessment of Solvency, in : ASTIN Bulletin, Vol. VI, Part 2, Dezember 1971.

THORNTON, J.H., MEADOR, J. W. : Comments on the validity of the NAIC early warning system for predicting failures among property and liability insurance companies, in: CPCU-Annals, Vol. 30, 1977.

ZELTEN, R.A.: Solvency surveillance: the problem and a solution, in: Journal of Risk and Insurance, Vol. 39, 1972.

Enquête sur le contrôle de la marge de solvabilité des sociétés non-vie, in : L'Argus International, Jg. 1978, Nr. 7.

Using the Solvency Tests, in: Best's Insurance News, Property/Liability Editions, Vol. 73, 1972/73, No. 8.

(Solvenztest der National Association of Insurance Commissioners) Vgl. auch Journal of Commerce, 6./7.11.1972. 